\title{
ipen
}

INSTITUTO DE PESQUISAS ENERGÉTICAS E NUCLEARES

Autarquia associada à Universidade de São Paulo

\section{DESENVOLVIMENTO DE DOSÍMETROS COM DIODOS DE Si \\ RESISTENTES À RADIAÇÃO PARA DOSIMETRIA DE ALTAS DOSES}

\section{FÁBIO DE CAMARGO}

Tese apresentada como parte dos requisitos para obtenção do Grau de Doutor em Ciências na Área de Tecnologia Nuclear - Aplicações.

Orientadora:

Profa. Dra. Carmen Cecília Bueno Tobias

São Paulo

2009 
Dedico este trabalho à minha noiva e companheira Paula, à minha família, em especial aos meus pais e sogros, aos meus amigos e a Deus. 


\section{AGRADECIMENTOS}

Em nossa jornada existem muitas pessoas que contribuem de modo direto ou indireto, ajudando-nos na construção do nosso ínfimo conhecimento, a todas deixo o meu mais singelo, eterno e cordial agradecimento. Entretanto, existem aquelas, que de modo peculiar, merecem ser destacadas e agradecidas em especial.

À Profa. Dra. Carmen Cecília Bueno Tobias (IPEN-CNEN/SP e PUC/SP) pela confiança depositada e por fazer parte da minha história, orientando-me com sabedoria e inteligência em cada momento do desenvolvimento desta tese, sem medir esforços, sempre com carinho, amizade, compreensão e paciência. Não existem palavras que consigam traduzir minha imensa gratidão.

À Profa. Dra. Josemary Angélica Correia Gonçalves (IPEN-CNEN/SP e PUC/SP) que com seu jeito meigo, sempre me direcionou, proferindo palavras de sabedoria ao longo de minha trajetória acadêmica que contribuíram muito nas discussões e melhorias deste trabalho.

Ao Prof. Dr. Marcello Damy de Souza Santos (IPEN-CNEN/SP) pelo fato de me ensinar na prática os significados das palavras humildade e educação. Com ele tive a oportunidade de descobrir que um grande mestre jamais precisa impor-se pelas suas conquistas, pois o reconhecimento aflora naturalmente.

Ao PhD. Jaakko Härkönen e a toda sua equipe do Instituto de Física de Helsinki (HIP) por ter me cedido os diodos empregados neste estudo e pela valiosa colaboração.

À Profa. Dra. Helen Jamil Khoury por disponibilizar seu laboratório na Universidade Federal de Pernambuco, me ensinando técnicas de dosimetria com semicondutores, que foram as bases para o desenvolvimento desta tese.

Ao PhD. Alessio Mangiarotti do Laboratório de Instrumentação e Física Experimental de Partículas (LIP) da Universidade de Coimbra pelo desenvolvimento de uma macro para análise das fotocorrentes e pelo incentivo durante todo o trabalho.

Ao Eng. Jair S. do Nascimento da Semikron Elektronik GmbH pelas valiosas discussões e pelo projeto e construção do sistema de caracterização IV e CV dos dispositivos semicondutores. 
Ao Laboratório de Microeletrônica da Escola Politécnica da Universidade de São Paulo (LME/POLI-USP), em nome do Prof. Dr. José Kleber da Cunha Pinto e do Tec. Jair Pereira de Souza, pela confecção das bases de cerâmicas banhadas a ouro e montagem das amostras, imprescindível ao desenvolvimento deste trabalho.

À Divisão de Empacotamento Eletrônico do Centro de Tecnologia da Informação Renato Archer (DEE/CTI), em nome do seu coordenador MSc. Márcio Tarozzo Biasoli e da Tec. Marinalva Muniz Rocha, pela confecção das microsoldas dos diodos na base de cerâmica, fundamentais para a realização desta pesquisa.

Ao Conselho Nacional de Desenvolvimento Científico e Tecnológico (CNPq) pela concessão de bolsa nos primeiros meses deste doutorado.

À Fundação de Amparo à Pesquisa do Estado de São Paulo (FAPESP) por acreditar em meu potencial e me permitir integrar o seu quadro de bolsistas de doutorado, me dando todo o suporte financeiro (processo $n=05 / 00258-1$ ).

Ao Centro de Tecnologia das Radiações (CTR) do Instituto de Pesquisas Energéticas e Nucleares (IPEN-CNEN/SP), em nome do seu gerente, Dr. Wilson Aparecido Parejo Calvo e dos chefes de Divisão, Dra. Margarida Mizue Hamada (Pesquisa e Desenvolvimento) e Dr. Leonardo Gondim de Andrade e Silva (Serviços), por ter me acolhido, desde minha iniciação científica até o presente, dando o suporte necessário para a realização desta pesquisa, sem exceções.

Aos engenheiros Elizabeth S. R. Somessari, Carlos Gaia da Silveira, Samir Luiz Somessari e ao Tec. Hélio Antônio Paes, funcionários do Laboratório de Fontes Intensas de Radiação (LAFIR) do CTR, pela atenção, amizade e presteza que sempre dispensaram e fundamentalmente pelas incansáveis irradiações dos diodos.

Aos Funcionários do CTR, em nome do Tec. Cláudio Botelho, pela ajuda e inestimável colaboração.

Aos Funcionários da Oficina Mecânica do IPEN, em nome do Tec. José Carlos Sabino, que não mediram esforços na confecção das sondas de medidas e me ensinaram muito sobre mecânica de precisão.

Aos meus Colegas de Grupo de Pesquisa, em nome de Kelly C. S. Pascoalino e Italo Soares Santos, pelas palavras de incentivo, companheirismo e principalmente pela ajuda nos experimentos. 
"Há três métodos para ganhar sabedoria: primeiro, por reflexão, que é o mais nobre; segundo, por imitação, que é o mais fácil; e terceiro, por experiência, que é o mais amargo." "Conte-me e eu esqueço. Mostre-me e eu apenas me lembro. Envolva-me e eu compreendo."

\section{Confúcio}

"Jamais considere seus estudos como uma obrigação, mas como uma oportunidade invejável (...) para aprender a conhecer a influência libertadora da beleza do reino do espírito, para seu próprio prazer pessoal e para proveito da comunidade à qual seu futuro trabalho pertencer" "Faça as coisas o mais simples possível, mas não de maneira simplória." "Quem nunca errou, jamais também experimentou algo de novo." 


\title{
DESENVOLVIMENTO DE DOSÍMETROS COM DIODOS DE Si RESISTENTES À RADIAÇÃO PARA DOSIMETRIA DE ALTAS DOSES
}

\author{
Fábio de Camargo
}

\section{RESUMO}

Neste trabalho são apresentados os resultados obtidos com diodos resistentes a danos de radiação dos tipos fusão zonal padrão (FZ), fusão zonal com difusão de oxigênio (DOFZ) e Czochralski magnético (MCz) em dosimetria de processamento por radiação gama. Estes dispositivos de junção $\mathrm{p}^{+}-n-n^{+}$foram manufaturados por Okmetic Oyj. (Vantaa, Finland) e processados no Centro de Microeletrônica da Universidade de Tecnologia de Helsinki no âmbito da colaboração RD50 do CERN.

As sondas dosimétricas, baseadas nos dispositivos $F Z$, DOFZ and $M C Z$, foram projetadas para operar sem tensão de polarização no modo de corrente direta como dosímetros on-line de radiação. As irradiações foram realizadas no Centro de Tecnologia das Radiações (CTR) no IPEN-CNEN/SP usando a fonte de ${ }^{60} \mathrm{Co}$ (Gammacell 220 - Nordion) com a taxa de dose de aproximadamente 2,4 kGy/h.

A resposta em corrente de cada diodo foi medida em função do tempo de exposição em intervalos de dose desde 5 kGy até 50 kGy atingindo a dose total absorvida $275 \mathrm{kGy}$. Os resultados obtidos demonstraram um significante decréscimo da fotocorrente gerada em todos os dispositivos para doses totais absorvidas superiores a aproximadamente $25 \mathrm{kGy}$. Para reduzir este efeito, as amostras foram pré-irradiadas com raios gama do ${ }^{60} \mathrm{Co}$ a uma dose de $700 \mathrm{kGy}$, para saturar a produção de armadilhas no volume sensível do diodo. Depois da pré-irradiação, apesar de serem menos sensíveis, todos os dispositivos apresentaram sinais de corrente estáveis mesmo para a dose total absorvida de $275 \mathrm{kGy}$. A fim de monitorar possíveis efeitos de danos de radiação 
produzidos nos diodos, as correntes de fuga e capacitância destes dispositivos foram medidas em função da dose total absorvida.

As curvas de calibração dos dosímetros mostraram respostas quadráticas com coeficientes de correlação maiores do que 0,9999 para doses totais absorvidas de até 275 kGy. A comparação entre as respostas dosimétricas dos diodos estudados evidenciou que o melhor resultado foi obtido com o $M C z$ que exibiu maiores sensibilidade $\mathrm{e}$ estabilidade do que os dispositivos FZ e DOFZ. No entanto, é importante notar que todos os diodos pré-irradiados podem ser utilizados como dosímetros em aplicações de processamento por radiação gama. 


\title{
DEVELOPMENT OF DOSIMETERS WITH RAD-HARD SILICON DIODES FOR HIGH DOSE DOSIMETRY
}

\author{
Fábio de Camargo
}

\begin{abstract}
In this work we report on results obtained with rad-hard Standard Float Zone (FZ), Diffusion Oxygenated Float Zone (DOFZ) and Magnetic Czochralski (MCz) silicon diodes in gamma radiation processing dosimetry. These $p^{+}-n-n^{+}$junction devices were manufactured by Okmetic Oyj. (Vantaa, Finland) and processed by the Microelectronics Center of Helsinki University of Technology in the framework of the CERN RD50 Collaboration.

The dosimetric probes, based on $\mathrm{FZ}, \mathrm{DOFZ}$ and $\mathrm{MCZ}$ devices, were designed to operate without bias voltage in the direct current mode as on-line radiation dosimeter. The irradiations were performed in the Radiation Technology Center (CTR) at IPENCNEN/SP using a ${ }^{60}$ Co source (Gammacell 220 - Nordion) with a dose rate around of $2.4 \mathrm{kGy} / \mathrm{h}$.

The current response of each diode was measured as a function of the exposure time in steps from 5 kGy up to $50 \mathrm{kGy}$ to achieve a total absorbed dose of $275 \mathrm{kGy}$. The results obtained showed a significant decrease in the photocurrent generated in all devices for total absorbed doses higher than approximately $25 \mathrm{kGy}$. To reduce this effect, the samples were pre-irradiated with ${ }^{60} \mathrm{Co}$ gamma rays at $700 \mathrm{kGy}$ in order to saturate the trap production in the diode's sensitive volume. After pre-irradiation, despite of being less sensitive, all devices exhibited more stable photocurrent signals, even for total absorbed doses of $275 \mathrm{kGy}$. To monitor possible gamma radiation damage effects produced on the diodes, their dynamic leakage current and capacitance were measured as a function of the absorbed dose.
\end{abstract}


The calibration curves of the dosimeters showed quadratic responses with correlation coefficient higher than 0.9999 for total absorbed dose up to $275 \mathrm{kGy}$. The comparison among the dosimetric response of the diodes studied evidenced that the best result was achieved with the $M C z$ which exhibited higher sensitivity and stability than the FZ and DOFZ devices. However, it is important to note that all pre-irradiated diodes can be used as gamma dosimeters in radiation processing applications. 


\section{SUMÁRIO}

Página

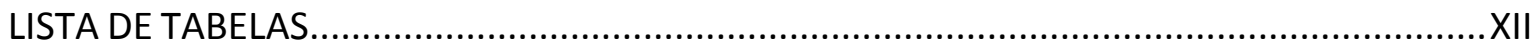

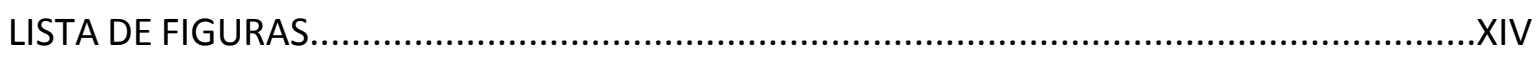

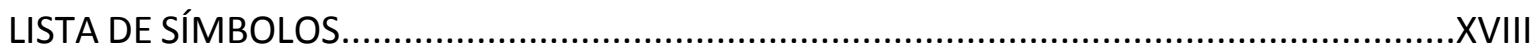

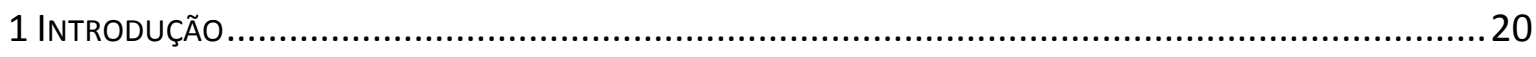

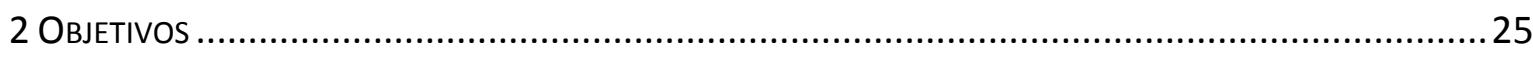

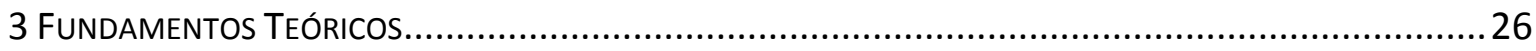

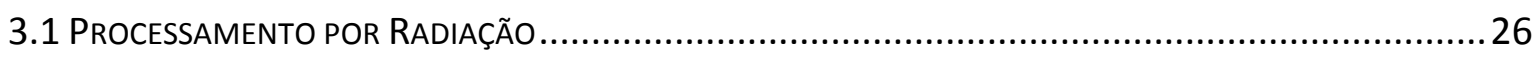

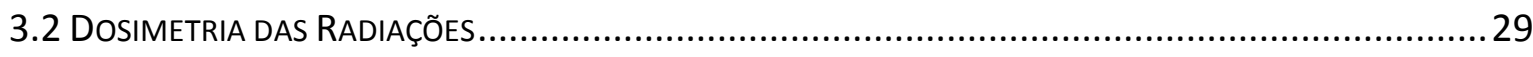

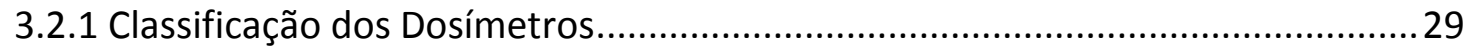

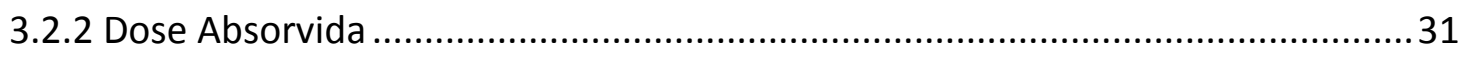

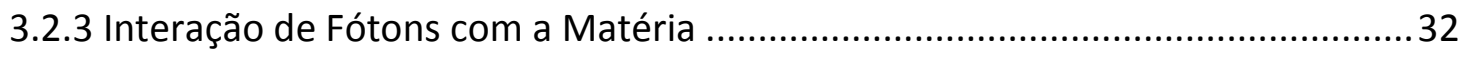

3.2.4 Atenuação da Radiação Eletromagnética............................................................36

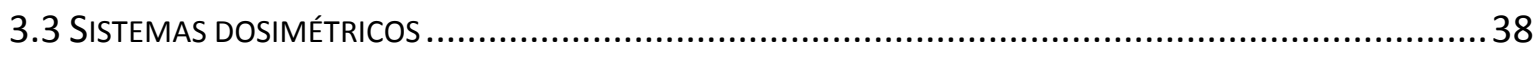

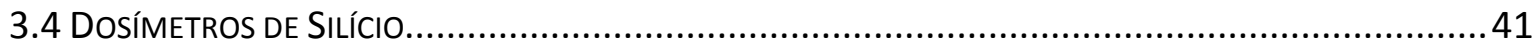

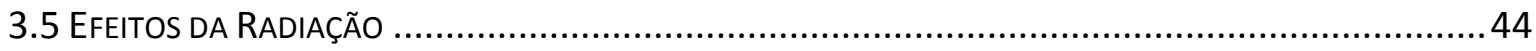

3.5.1 Mecanismos dos danos de radiação.............................................................. 45

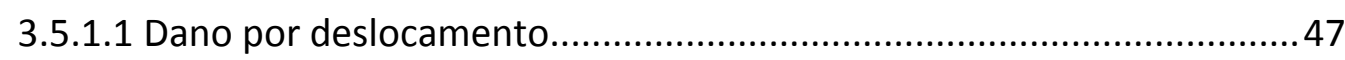

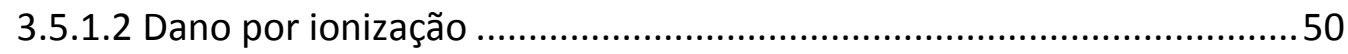

3.5.2 Danos de radiação em diodos .................................................................... 51

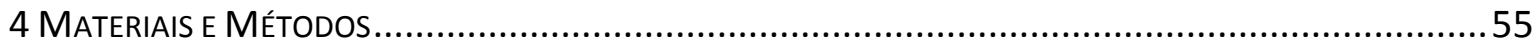

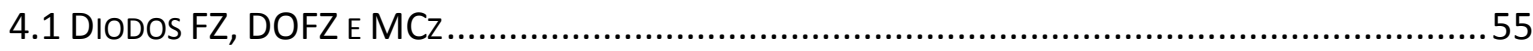

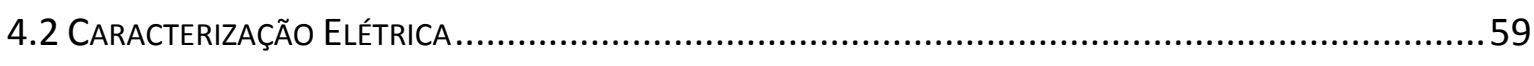

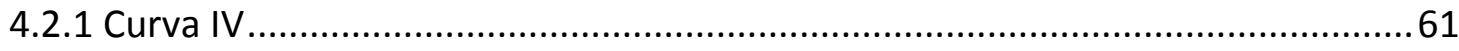

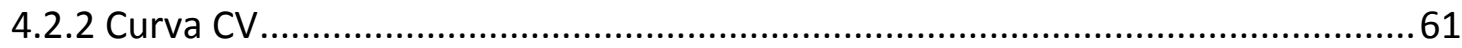

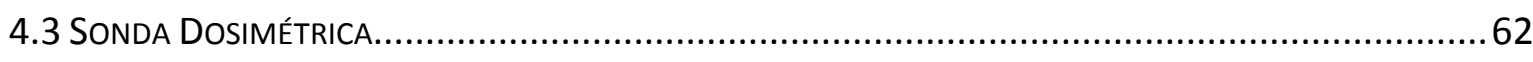

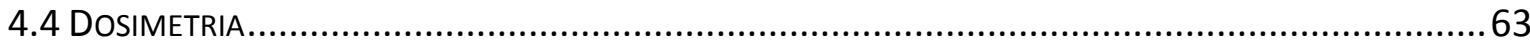




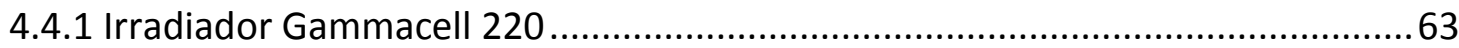

4.4.2 Irradiador Panorâmico ........................................................................................64

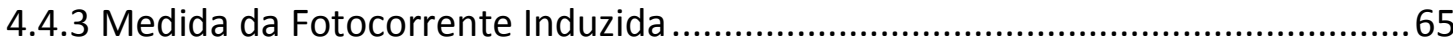

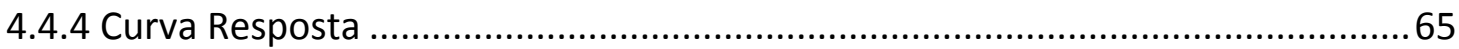

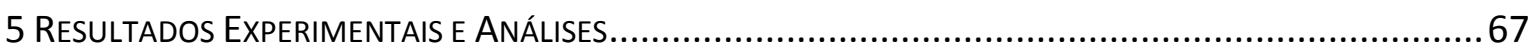

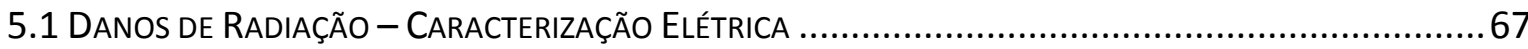

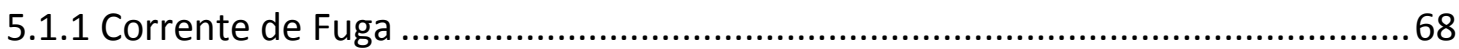

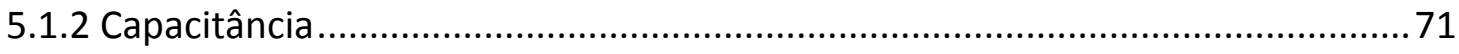

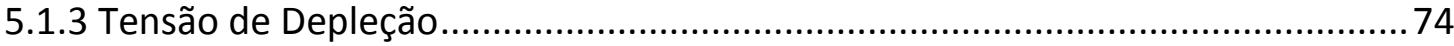

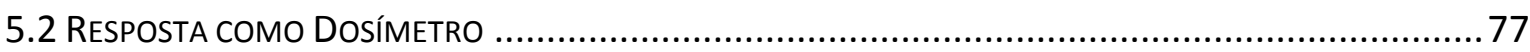

5.2.1 Fotocorrente $\times$ Tempo de Exposição ………...................................................... 77

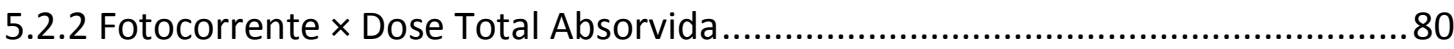

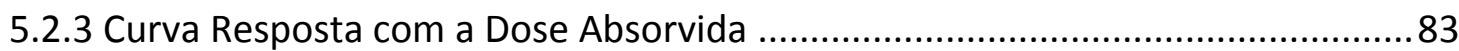

5.2.4 Curva Resposta com a Dose Total Absorvida ................................................... 86

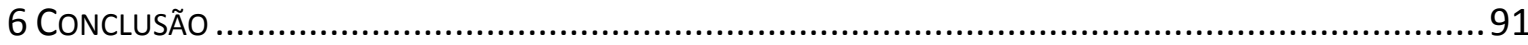

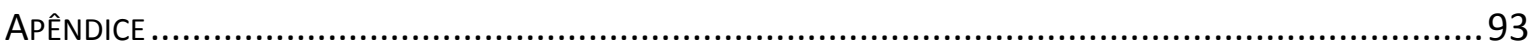

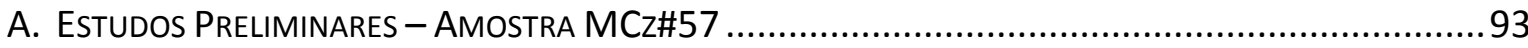

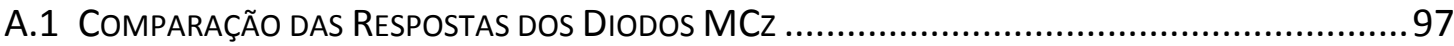

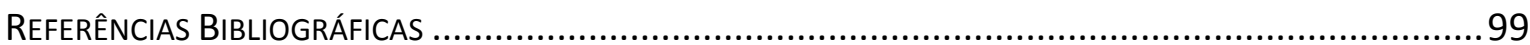




\section{LISTA DE TABELAS}

Página

Tabela 3.1.1 - Principais aplicações da radiação ionizante e seus respectivos intervalos de dose [44] 28

Tabela 3.5.1 - Comparação simples do dano por deslocamento para próton, nêutron e elétron todos com energia de $1 \mathrm{MeV}$.

Tabela 3.5.2 - Defeitos pontuais gerados pela irradiação gama com ${ }^{60} \mathrm{Co}$ identificados pelos métodos TSC (Thermally Stimulated Currents) e DLTS (Deep Level Transient Spectroscopy), com as respectivas seções de choque de captura $\left(\sigma_{\mathrm{n}}\right.$ e $\left.\sigma_{\mathrm{p}}\right)$, em diferentes detectores fabricados por processos de fusão zonal (STFZ) e fusão zonal com difusão de oxigênio (DOFZ), compilados por I. Pintilie [80]. 54

Tabela 4.1.1 - Características dos diodos 56

Tabela 4.4.1 - Taxas de dose para as diferentes distâncias do irradiador Panorâmico de

${ }^{60}$ Co, calibradas e certificadas pelo IDAS-IAEA em 01/11/2004. 64

Tabela 5.1 - Condições de pré-irradiação e taxas de doses empregadas no estudo das amostras

Tabela 5.1.1 - Valores médios das tensões de depleção $\left(V_{d}\right)$ e concentrações efetivas $\left(N_{e f}\right)$ para os diodos FZ, DOFZ e MCZ.

Tabela 5.2.1 - Fotocorrentes médias $\left(\overline{I_{F}}\right)$ e sensibilidade $(S)$ dos diodos FZ\#75, DOFZ\#6 e MCz\#69 pré-irradiados 77

Tabela 5.2.2 - Parâmetros dos ajustes lineares realizados nas fotocorrentes em função da dose total absorvida nas amostras pré-irradiadas

Tabela 5.2.3 - Parâmetros dos ajustes quadráticos realizados nas curvas resposta em função da dose absorvida nas amostras pré-irradiadas. 86

Tabela 5.2.4 - Parâmetros dos ajustes quadráticos realizados nas curvas resposta em função da dose total absorvida nas amostras pré-irradiadas. 89 
Tabela A.1 - Fatores de correção empregados na correção das fotocorrentes médias do diodo MCz\#57. 95 


\section{LISTA DE FIGURAS}

Página

Figura 3.1.1 - Digrama esquemático típico de um irradiador gama de grande porte [44].27

Figura 3.1.2 - Diagrama esquemático de um acelerador de elétrons industrial [45]. 27

Figura 3.2.1 - Exemplo da cadeia de rastreabilidade nacional para o calorímetro padrão primário aplicada a um fonte de ${ }^{60} \mathrm{Co}$, determinando a dose absorvida na água [46] 31

Figura 3.2.2 - Representação do efeito fotoelétrico [52]. 33

Figura 3.2.3 - Representação do efeito Compton [52]. 34

Figura 3.2.4 - Representação do efeito produção de pares [52]. 35

Figura 3.2.5 - Importância relativa dos diferentes processos de interação dos fótons em função do número atômico do material e energia do fóton incidente [52].

Figura 3.2.6 - Coeficiente de atenuação total linear (curva azul) da radiação eletromagnética em função da energia do fóton incidente para o silício, particularizando a contribuição dos efeitos: fotoelétrico (curva vermelha), Compton (curva preta) e produção de pares (curva verde) [55].

Figura 3.2.7 - Principais processos de interação da radiação eletromagnética com a matéria [52]

Figura 3.3.1 - Sistemas dosimétricos empregados em diversos intervalos de dose absorvida [50].

Figura 3.4.1 - Esquema da junção $p-n$ de um diodo do tipo $\mathrm{p}^{+} / \mathrm{n} / \mathrm{n}^{+}$, com as respectivas espessuras [69]

Figura 3.5.1 - Dano por deslocamento em função da energia de nêutrons, prótons, píons e elétrons calculados em relação a nêutrons de $1 \mathrm{MeV}$. Estes dados foram compilados por A. Vasilescu e G. Lindstroem [73], baseado nos dados de Griffin et al. [74], Konobeyev [75], Huhtinen and Aarnio [76] e Summers et al. [77] 48 
Figura 3.5.2 - Distribuição inicial de vacâncias produzidas no silício por prótons de 10 $\mathrm{MeV}$ (esquerda), prótons de $24 \mathrm{GeV} / \mathrm{c}$ (centro) e nêutrons de $1 \mathrm{MeV}$ (direita). Os gráficos foram feitos à profundidade $(z)$ de $1 \mu \mathrm{m}$ no plano cartesiano xy e correspondem à fluência de $10^{14}$ partículas $/ \mathrm{cm}^{2}[79] \ldots \ldots . . .49$

Figura 3.5.3 - Esquema das lacunas armadilhadas no óxido 50

Figura 3.5.4 - Curvas IV (a) e CV (b) dos diodos antes e depois da irradiação gama [12]. .51 Figura 3.5.5 - Tensão de depleção e corrente de fuga para a tensão de depleção em função da dose para diodos do tipo STFZ e DOFZ [18] 52

Figura 4.1.1 - (a) Layout dos diodos especiais. (b) Estrutura dos 17 anéis de guarda e pad's de contato dos eletrodos de sinais. Fotografias obtidas no LME/Poli-USP. 56

Figura 4.1.2 - Posicionamento dos diodos na lâmina de silício. 57

Figura 4.1.3 - (a) Lâmina de alumina com camada de ouro, (b) fotolito com layout e (c) base para montagem dos diodos. 58

Figura 4.1.4 - Diodos montados na base de alumina. 58

Figura 4.2.1 - Esquema do circuito empregado nas caracterizações elétricas dos diodos.59

Figura 4.2.2 - Medidor IV-CV, utilizado na caracterização elétrica das amostras 60

Figura 4.2.3 - Instrumentos utilizados na caracterização elétrica dos diodos. 60

Figura 4.3.1 - Fotografias da sonda dosimétrica 62

Figura 4.4.1 - Fotografias (a) do irradiador Gammacell 220 - Nordion e (b) do cilindro de isopor com a sonda dosimétrica e o termopar do tipo $\mathrm{K}$. 63

Figura 4.4.2 - Fotografia do irradiador Panorâmico do Laboratório de Fontes Intensas de Radiação do CTR 64

Figura 4.4.3 - Desenho esquemático do sistema de medidas (a) e fotografia dos equipamentos empregados na obtenção das fotocorrentes (b). 65

Figura 5.1.1 - Curvas IV dos diodos originais: DOFZ\#2 e MCZ\#56. 69

Figura 5.1.2 - Curvas IV dos diodos pré-irradiados: FZ\#75, DOFZ\#6 e MCz\#69...................70

Figura 5.1.3 - Curvas CV dos diodos originais: DOFZ\#2 e MCz\#56. .................................72

Figura 5.1.4 - Curvas CV dos diodos pré-irradiados: FZ\#75, DOFZ\#6 e MCz\#69. 73

Figura 5.1.5 - Tensão de depleção e concentração efetiva vs. dose total absorvida para cada tipo de diodo. .75 
Figura 5.1.6 - Valores teóricos de capacitância $\left(C_{d}\right)$ e zona de depleção $(d)$ dos diodos crescidos pela tecnologia de fusão zonal (FZ ou DOFZ) e Czochralski magnético (MCz). 76

Figura 5.2.1 - Fotocorrentes dos diodos originais FZ\#54, DOFZ\#2 e MC\#56 para diferentes doses. 78

Figura 5.2.2 - Fotocorrentes dos diodos pré-irradiados FZ\#75, DOFZ\#12 e MC\#69, para diferentes doses.

Figura 5.2.3 - Fotocorrentes em função da dose total absorvida para os diodos originais FZ\#54, DOFZ\#2 e MCZ\#56. 80

Figura 5.2.4 - Fotocorrentes em função da dose total absorvida para os diodos FZ\#75, DOFZ\#6 e MCz\#69 pré-irradiados.

Figura 5.2.5 - Fotocorrentes normalizadas em função da dose total absorvida para os diodos originais.

Figura 5.2.6 - Fotocorrentes normalizadas em função da dose total absorvida para os diodos pré-irradiados. 83

Figura 5.2.7 - Curvas resposta com a dose para os diodos FZ, DOFZ e MCz (originais e préirradiados).

Figura 5.2.8 - Comparação das curvas resposta com a dose para as amostras FZ, DOFZ e $\mathrm{MCz}$

Figura 5.2.9 - Curvas resposta em função da dose total absorvida para os dispositivos FZ, DOFZ e MCZ.

Figura 5.2.10 - Curvas resposta em função da dose total absorvida para os diodos originais FZ, DOFZ e MCZ. 88

Figura 5.2.11 - Curvas resposta em função da dose total absorvida dos diodos FZ, DOFZ e MCz pré-irradiados

Figura A.1 - Fotocorrentes médias em função da taxa de dose para o diodo MCz\#57 (sensibilidade). As incertezas representadas na fotocorrente são menores do que os pontos experimentais e são a composição das incertezas do tipo A e B. 94

Figura A.2 - Fotocorrentes médias do diodo MCz\#57 em função da dose total absorvida. 
Figura A.3 - Comparação das fotocorrentes normalizadas em função da dose total absorvida para os diodos MCz \#56 e \#57 ...................................................99 


\section{LISTA DE SÍMBOLOS}

\begin{tabular}{|c|c|c|}
\hline Símbolo & Significado & Unidade \\
\hline$A$ & Área da junção do diodo & $\mathrm{cm}^{2}$ \\
\hline$c$ & Velocidade da luz & $\mathrm{m} / \mathrm{s}$ \\
\hline$C_{d}$ & Capacitância do diodo & $\mathrm{pF}$ \\
\hline$D$ & Dose absorvida & Gy, kGy \\
\hline$\dot{D}$ & Taxa de dose absorvida & Gy/s, kGy/h \\
\hline$D_{n}, D_{p}$ & Coeficientes de difusão dos elétrons e lacunas & $\mathrm{cm}^{2} / \mathrm{s}$ \\
\hline$E$ & Energia do fóton & $\mathrm{J}, \mathrm{eV}$ \\
\hline$\varepsilon_{S i}$ & Permissividade elétrica do silício & $\mathrm{F} / \mathrm{m}$ \\
\hline$E_{d}$ & Energia depositada no meio & $\mathrm{J}, \mathrm{eV}$ \\
\hline$E_{g}$ & Energia da banda proibida do silício & $\mathrm{J}, \mathrm{eV}$ \\
\hline$E_{\text {par }}$ & Energia para geração de um par elétron-lacuna & $\mathrm{J}, \mathrm{eV}$ \\
\hline$\Phi$ & Taxa de fótons & $s^{-1}$ \\
\hline$f$ & Freqüência & $\mathrm{Hz}$ \\
\hline$\Gamma$ & Fator de correção da fotocorrente & $\mu \mathrm{A}$ \\
\hline$g$ & Taxa de geração de pares elétron-lacuna & $\mathrm{cm}^{-3} \cdot \mathrm{s}^{-1}$ \\
\hline$G$ & Ganho do amplificador Operacional & 1 \\
\hline$I$ & Intensidade da radiação transmitida & 1 \\
\hline Io & Intensidade da radiação incidente & 1 \\
\hline$I_{F}$ & Fotocorrente & $\mu \mathrm{A}, \mathrm{nA}$ \\
\hline Ifuga & Corrente de fuga do diodo & $\mu \mathrm{A}, \mathrm{nA}$ \\
\hline$k$ & Constante de Boltzmann & $\mathrm{J} / \mathrm{K}, \mathrm{eV} / \mathrm{K}$ \\
\hline$L_{a}$ & Comprimento de absorção da radiação & $\mathrm{cm}, \mu \mathrm{m}$ \\
\hline$L_{n}, L_{p}$ & Comprimentos de difusão dos elétrons e lacunas & $\mathrm{cm}, \mu \mathrm{m}$ \\
\hline$m$ & Massa & $\mathrm{kg}$ \\
\hline$m_{0}$ & Massa de repouso do elétron & $\mathrm{kg}$ \\
\hline$\mu$ & Coeficiente de absorção linear & $\mathrm{cm}^{-1}$ \\
\hline$\mu_{n}, \mu_{p}$ & Mobilidade dos elétrons e lacunas & $\mathrm{cm}^{2} / \mathrm{V} \cdot \mathrm{s}$ \\
\hline$N_{a}$ & Concentração de aceitadores na junção & $\mathrm{cm}^{-3}$ \\
\hline$N_{d}$ & Concentração de doadores na junção & $\mathrm{cm}^{-3}$ \\
\hline$N_{e f}$ & Concentração efetiva de portadores na junção & $\mathrm{cm}^{-3}$ \\
\hline$O_{i}$ & Concentração de oxigênio & $\mathrm{cm}^{-3}$ \\
\hline$\rho$ & Resistividade & $\Omega \cdot \mathrm{cm}$ \\
\hline$q$ & Carga elementar do elétron & C \\
\hline$R_{d}$ & Resistência do diodo & $\Omega$ \\
\hline$R_{r}$ & Resistência de realimentação do amplificador & $\Omega$ \\
\hline$S$ & Sensibilidade do diodo & $\mathrm{C} / \mathrm{Gy}$ \\
\hline$\sigma_{n}, \sigma_{p}$ & Secção de choque de captura & $\mathrm{cm}^{2}$ \\
\hline
\end{tabular}




\begin{tabular}{clc}
\hline Símbolo & \multicolumn{1}{c}{ Significado } & Unidade \\
\hline$t$ & Tempo & $\mathrm{s}, \mathrm{h}$ \\
$T$ & Espessura total do diodo & $\mu \mathrm{m}$ \\
$T_{K}$ & Temperatura & ${ }^{\circ} \mathrm{C}, \mathrm{K}$ \\
$T_{n}$ & Espessura da região n do diodo & $\mu \mathrm{m}$ \\
$\tau_{n,} \tau_{p}$ & Tempos de vida média dos elétrons e lacunas & $\mathrm{s}$ \\
$T_{p}$ & Espessura da região ${ }^{+}$do diodo & $\mu \mathrm{m}$ \\
$T_{r e f}$ & Temperatura de referência & ${ }^{\circ} \mathrm{C}, \mathrm{K}$ \\
$V$ & Tensão de polarização reversa do diodo & $\mathrm{V}$ \\
$V_{A C}$ & Componente da tensão alternada amplificada & $\mathrm{V}$ \\
$V_{d}$ & Tensão de depleção do diodo & $\mathrm{V}$ \\
$V_{D C}$ & Componente da tensão contínua amplificada & $\mathrm{V}$ \\
$V_{i n}$ & Tensão de entrada no amplificador operacional & $\mathrm{V}$ \\
$X$ & Espessura do meio & $\mathrm{cm}, \mu \mathrm{m}$ \\
$X_{C}$ & Reatância capacitiva do circuito amplificador & $\Omega$ \\
$Z_{a m p}$ & Impedância do amplificador & $\Omega$ \\
\hline
\end{tabular}




\section{INTRODUÇÃo}

O uso de detectores de Si com grande rapidez de resposta, excelente resolução espacial e elevada relação sinal-ruído em grande parte das experiências relacionadas à Física de Altas Energias (FAE) [1-5] tem motivado o desenvolvimento dos métodos de purificação deste semicondutor e produção de dispositivos com estruturas complexas (microstrip trapezoidal, detectores anulares, etc.) que permitem medidas de trajetórias de partículas [6-9].

No entanto, como na maioria destas aplicações os detectores estão sujeitos a uma elevada dose (da ordem de dezenas de kGy [10]) torna-se imperativo o aumento da tolerância do semicondutor aos danos de radiação, que se traduzem experimentalmente em uma deterioração das condições operacionais do detector, nomeadamente, no acréscimo da corrente de fuga, na inversão do tipo inicial de semicondutor (de $\mathrm{n}$ para $\mathrm{p}$ e vice-versa), no aumento da tensão de depleção total do dispositivo e na redução da eficiência de coleta de carga nos eletrodos do detector [11-14]. Estes efeitos, cujas intensidades crescem com a fluência de radiação e são maiores para íons pesados, estão relacionados com a alteração da estrutura do cristal mediante a criação de níveis de energia dentro da banda proibida. Esses níveis atuam como centros de armadilhas para as cargas geradas pela radiação incidente, resultando na coleta parcial de cargas e conseqüente diminuição da amplitude do sinal gerado no detector.

Pesquisas neste domínio, prioritariamente conduzidas pelas colaborações RD48 (ROSE) e RD50 do CERN [15-17], têm demonstrado que os principais danos de radiação ocorrem no volume da pastilha de silício e que, paradoxalmente, são maiores nos semicondutores de resistividade elevada e, portanto, mais puros. Nestes casos, a pequena concentração efetiva de dopantes (cerca de $10^{12} \mathrm{~cm}^{-3}$ ), responsável pela determinação do tipo inicial do semicondutor, pode ser facilmente excedida pela 
concentração de defeitos produzidos pela radiação incidente, alterando as características elétricas do cristal [18].

Para conciliar as exigências das aplicações em FAE no tocante à rapidez de resposta do detector e resistência aos danos de radiação, surgiram linhas de pesquisa independentes destinadas ao aperfeiçoamento dos métodos de crescimento dos cristais com a introdução controlada de impurezas que não alterem significativamente a resistividade do semicondutor. Resultados obtidos pela colaboração RD48 mostraram que a inserção de oxigênio com concentração superior a $10^{17} \mathrm{~cm}^{-3}$ em cristais de Si de elevada pureza produzidos pelo método de fusão zonal promove um aumento significativo da sua tolerância aos danos de radiação $[7,19,20]$. O mesmo comportamento tem sido observado em cristais obtidos pelo método de Czochralski que naturalmente contém mais oxigênio do que os crescidos por fusão zonal padrão [9].

Uma outra proposta para a redução do dano de radiação em detectores de silício baseia-se no desenvolvimento de novas técnicas de fabricação destes dispositivos com estruturas complexas constituídas por múltiplos anéis de guarda [21]. Os anéis permitem uma variação gradual do potencial elétrico entre o eletrodo coletor de cargas e a borda do dispositivo, evitando que ocorra a ruptura do semicondutor, mesmo para tensões de polarização maiores do que a de depleção total. Além disto, nesta configuração reduz-se a contribuição da corrente superficial no ruído eletrônico, o que viabiliza o emprego do dispositivo mesmo após a manifestação dos danos de radiação.

A recuperação das condições operacionais de diodos de Si dotados de múltiplos anéis de guarda quando submetidos a uma intensa exposição de partículas pesadas e radiação eletromagnética tem sido estudada no âmbito da colaboração RD39 do CERN da qual faz parte o Laboratório de Instrumentação e Física Experimental de Partículas (LIP) de Portugal. O resultado mais importante obtido até o presente nesse campo refere-se à descoberta do efeito Lazarus [11,22-24] que indica a recuperação de desempenho dos dispositivos quando operados em temperaturas da ordem de $130 \mathrm{~K}$. A explicação deste fenômeno reside no aumento do tempo de vida dos níveis criados pela radiação incidente tornando-os eletricamente inativos, com a conseqüente melhora da eficiência de coleta de cargas e redução da corrente de fuga destes dispositivos.

A colaboração mantida com o LIP, aliada à experiência do grupo de Desenvolvimento de Novos Tipos de Detectores de Radiação do IPEN-CNEN/SP no estudo 
das condições de resposta de diodos comerciais de Si para detecção de partículas carregadas e raios-X [25-27], conduziu este grupo ao estudo das características espectrométricas de diodos de Si com múltiplos anéis de guarda (MGR) e resistentes à radiação produzidos para o CERN [28-32].

Uma análise das características dos diodos MGR quanto à densidade de corrente de fuga, tensão de depleção total, capacitância e robustez evidenciou que as suas possibilidades de uso não se esgotavam na espectrometria de radiações ou nos sistemas de medidas de trajetórias de partículas nas experiências realizadas no CERN. Outra aplicação importante que poderia resultar do desenvolvimento tecnológico associado a este diodo, principalmente no tocante aos danos de radiação, é o da medida de doses em campos intensos de radiação eletromagnética necessária em aplicações associadas à área industrial.

Até o presente, apesar das inúmeras vantagens do uso de diodos convencionais como dosímetros, como por exemplo, baixo custo, facilidade de operação, insensibilidade a perturbações magnéticas e mecânicas e da pequena tensão operacional, o seu emprego restringe-se à dosimetria de baixas doses devido fundamentalmente a sua grande sensibilidade à radiação [33-35].

Os sistemas dosimétricos que permitem medidas de doses em campos de intensa radiação como o encontrado em grandes aceleradores de partículas, reatores nucleares e plantas industriais são constituídos basicamente por transistores de efeito de campo resistentes à radiação (sigla em inglês RadFET), microcalorímetros, detectores gama auto polarizados (do inglês Self Powered Gamma Detectors - SPGD) e câmaras de ionização.

Os RadFETs são pequenos sensores de taxas de dose cujo princípio de operação reside na alteração de suas propriedades elétricas como conseqüência da incidência de radiação. Neste caso, as cargas são retidas no gatilho do transistor e na interface $\mathrm{Si} / \mathrm{SiO}_{2}$ causando alterações na tensão limiar do dispositivo (tensão necessária para manter um valor específico de corrente). Nos RadFETs o parâmetro dosimétrico (medida de tensão) está relacionado com a taxa de dose e quando se atinge uma dose total de 10 kGy ocorre a saturação do dispositivo, limitando o seu emprego em campos intensos de radiação. Para ser reutilizado, esses dispositivos devem ser submetidos a altas temperaturas ou expostos à luz ultravioleta, tornando impossível o seu uso contínuo [36-38]. 
Nos microcalorímetros são obtidas medidas absolutas de doses absorvidas de radiação e, quando operados no modo adiabático, a taxa de deposição de energia na amostra é proporcional à taxa de elevação da temperatura. Teoricamente, os microcalorímetros podem medir taxas de doses de $0-18 \mathrm{kGy} / \mathrm{h}$, mas a complexidade de construção e operação não incentivam a sua produção comercial. Além disso, outras limitações importantes para o emprego de microcalorímetros em campos intensos de radiação são a pequena resolução temporal (cada medida é realizada em torno de 10 minutos) e a alteração local do campo de irradiação devido às suas dimensões (volume em torno de centenas de $\mathrm{cm}^{3}$ ) [39].

Os SPGDs consistem basicamente de dois eletrodos concêntricos separados por uma camada isolante na qual uma irradiação externa de raios gama induz uma corrente de elétrons com intensidade proporcional à taxa de dose. No entanto, uma das maiores desvantagens deste tipo de sensor é a baixíssima corrente gerada (apenas para exemplificar, para uma taxa de dose de raios gama do ${ }^{60} \mathrm{Co}$ de $1 \mathrm{kGy} / \mathrm{h}$, a corrente típica de saída é de apenas 20 pA), o que exige o emprego de medidores de corrente extremamente sofisticados [40].

As câmaras de ionização operando em regime de corrente são as mais freqüentemente utilizadas em medidas de taxas de dose desde $10^{-5}$ até $10^{5} \mathrm{~Gy} / \mathrm{h}$ [41]. Nestas aplicações, as câmaras têm geometria cilíndrica, são preenchidas com gases inertes em pressão atmosférica ou superior, e os eletrodos polarizados de tal forma a criar um campo elétrico muito intenso nas vizinhanças do eletrodo central. O sinal elétrico é fornecido pela ionização produzida no gás devida a radiação incidente, cujos deslocamentos de elétrons e íons positivos em direção aos eletrodos geram uma corrente com uma intensidade proporcional à taxa de dose. As câmaras de ionização disponíveis comercialmente para taxas de dose de $10^{5} \mathrm{~Gy} / \mathrm{h}$ são relativamente caras e robustas o que reduz também a possibilidade de sua utilização em medidas de taxas de doses bem localizadas e com mínima interferência no campo de radiação.

A fim de explorar as potencialidades de diodos especiais crescidos pelas tecnologias de fusão zonal enriquecido com oxigênio e Czochralski magnético, bem como participar dos esforços exigidos no desenvolvimento de instrumentação nuclear destinada à dosimetria de radiações gama emitidas por fontes intensas de ${ }^{60} \mathrm{Co}$ disponíveis no Irradiador de Grande Porte, recentemente construído no CTR do IPEN [42], 
decidiu-se desenvolver um sistema para medidas de dose baseado no uso destes diodos. Nesta aplicação, até mesmo a pequena área útil $\left(\cong 25 \mathrm{~mm}^{2}\right.$ ) destes dispositivos representa uma vantagem, uma vez que tornará possível a realização de medidas instantâneas de dose sem que ocorram significativas alterações no campo de radiação presente nas proximidades do irradiador devido às fontes de ${ }^{60} \mathrm{Co}$. No entanto, como em algumas aplicações do irradiador serão obtidas doses tão elevadas quanto 1 MGy (irradiação de gemas, por exemplo) torna-se necessário um estudo prévio dos possíveis danos de radiação sofridos por estes dispositivos, priorizando aqueles que resultem em mudanças de suas propriedades elétricas e estruturais e que comprometam a sua resposta em dosimetria de radiação gama.

Vale a pena ressaltar que até o presente não existem sistemas comerciais que permitam medidas instantâneas de doses da ordem de dezenas de kGy, e, portanto, a possibilidade de desenvolvimento de um dosímetro baseado em diodos de $\mathrm{Si}$ com elevada resistência a danos de radiação representa uma contribuição inédita para a instrumentação nuclear nesta área. 


\section{OBJETIVOS}

O presente projeto visa o desenvolvimento de um sistema dosimétrico com diodos de Si resistentes a danos de radiação para medidas instantâneas de elevadas doses provenientes de fontes gama.

Em função da elevada dose a que esses dispositivos serão submetidos, também se faz necessário um estudo dos possíveis danos provocados pela radiação eletromagnética nos diodos de $\mathrm{Si}$, priorizando aqueles que resultem em mudanças nas correntes de fuga, bem como em alterações na tensão de depleção total. 


\section{FUNDAMENTOS TEÓRICOS}

Neste item da tese serão apresentados de maneira sucinta os conceitos fundamentais que servirão de base para análise e discussão dos resultados apresentados.

\subsection{Processamento POR RADIAÇão}

Há muito tempo sabe-se que a radiação ionizante pode induzir efeitos com potencial aplicação industrial. Entretanto, esta realidade tornou-se possível após a década de 50 com o advento das fontes de radiação em escala industrial (radioisótopos e máquinas), criando uma nova área denominada de processamento por radiação. A partir de então, esta área tem crescido continuamente e contribui de forma significativa em vários setores industriais como, por exemplo, os setores de polímeros e médico.

Nas aplicações de processamento por radiação são empregados dois tipos de fontes, os irradiadores gama de grande porte (Figura 3.1.1) e os aceleradores industriais de elétrons (Figura 3.1.2). Em ambos, as doses empregadas podem ser classificadas em três intervalos [43]:

- Baixa dose: 10 Gy a 3 kGy (1 krad a 300 krad);

- Média dose: 1 kGy a 10 kGy (100 krad a 1 Mrad);

- Alta dose: 5 kGy a 100 kGy ( 500 krad a 10 Mrad).

Uma das principais vantagens da radiação ionizante como ferramenta industrial é a capacidade de obter efeitos químicos, físicos e biológicos, reprodutíveis para uma determinada dose absorvida. Portanto, a dosimetria do processo é essencial para o sucesso comercial da área de processamento por radiação, tornando-se um desafio realizá-la, pois neste tipo de aplicação as doses envolvidas são freqüentemente altas, com 
grande intervalo de taxas de dose em um ambiente de condições extremas (alta umidade e temperatura).

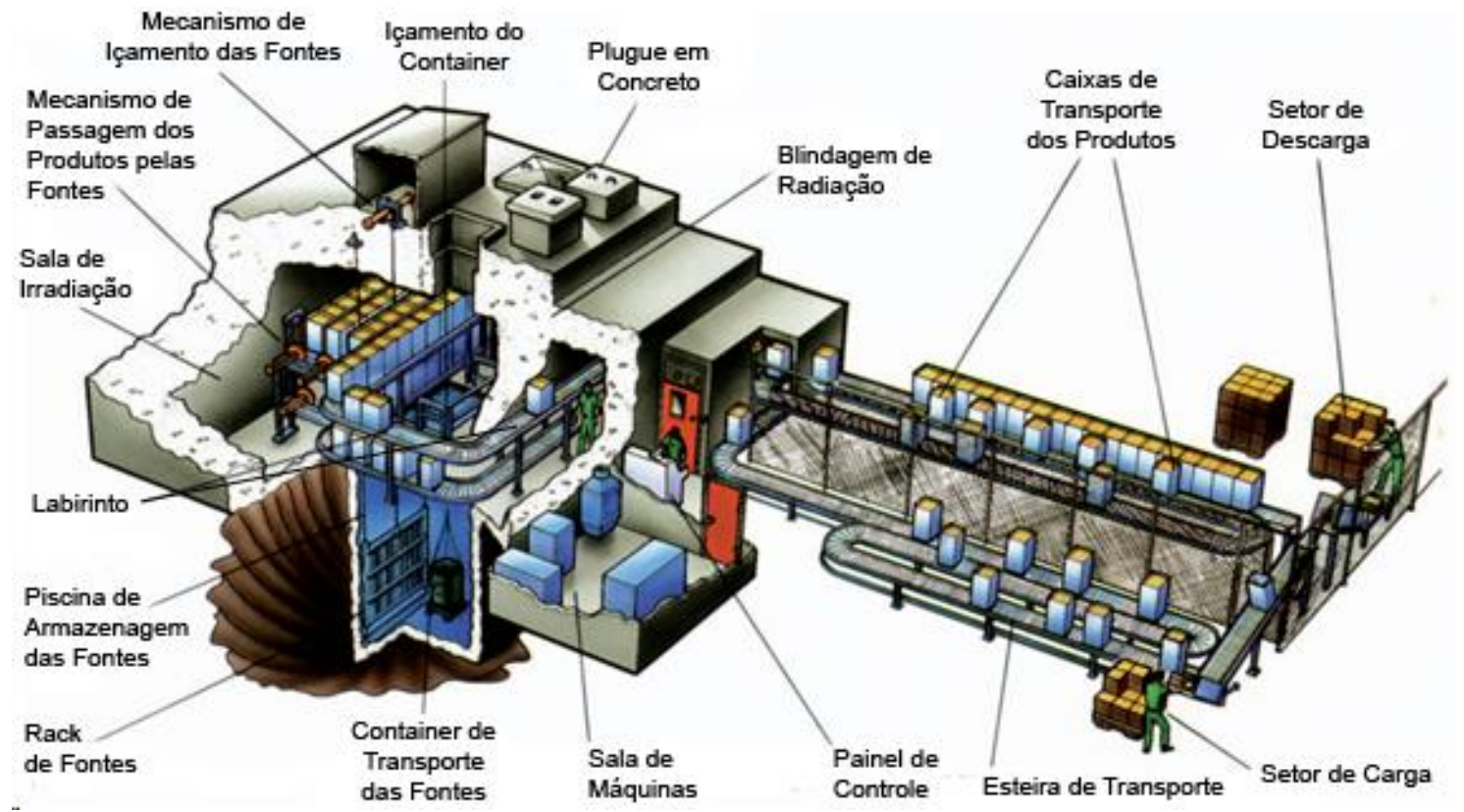

Figura 3.1.1 - Digrama esquemático típico de um irradiador gama de grande porte [44].

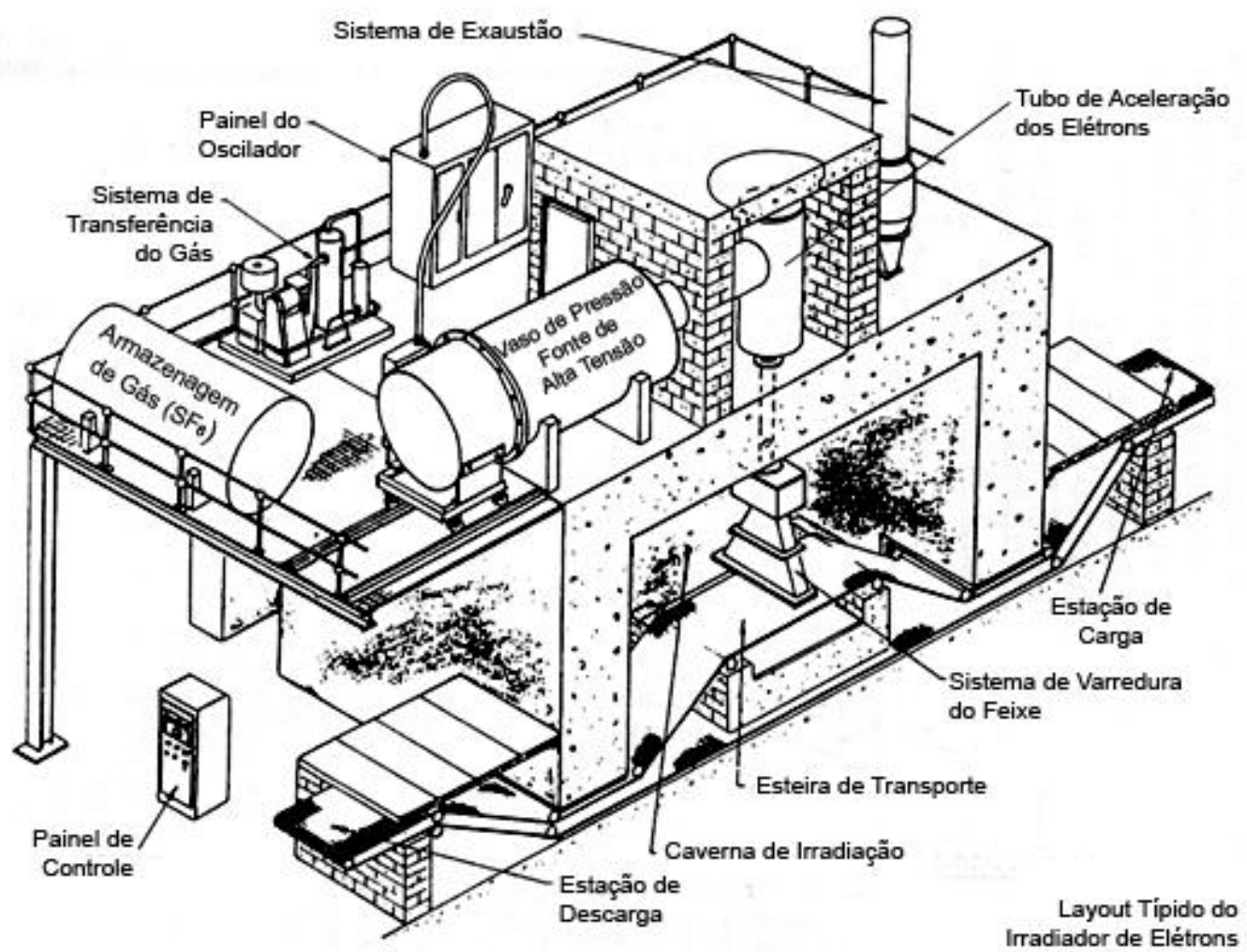

Figura 3.1.2 - Diagrama esquemático de um acelerador de elétrons industrial [45]. 
Atualmente, as principais aplicações industriais de processamento por radiação são a esterilização de insumos médicos, o tratamento de alimentos e a modificação de polímeros. Não menos importante, mas em escala bem menor, têm-se outras aplicações como a modificação das propriedades de semicondutores, os tratamentos de esgoto, efluentes e gases de combustão. A Tabela 3.1.1 apresenta as principais áreas de aplicações da radiação ionizante e seus respectivos intervalos de dose.

Como exemplos dos processamentos por radiação, no intervalo de baixas doses, têm-se as aplicações de inibição de brotamento de batatas e cebolas, desinfestação de grãos e aumento do tempo de prateleira de vários alimentos. Já as doses denominadas médias são empregadas em pasteurização de alimentos e desinfecção de esgotos sólidos e líquidos. Por outro lado, as doses altas são utilizadas na esterilização de produtos em geral (alimentos e insumos médicos), bem como, na cura de vários plásticos.

Tabela 3.1.1 - Principais aplicações da radiação ionizante e seus respectivos intervalos de dose [44].

\begin{tabular}{lc}
\hline \multicolumn{1}{c}{ Aplicação } & Intervalo de Dose \\
\hline Médica - diagnóstico & $10-100 \mathrm{mGy}$ \\
Médica - terapia & $1-10 \mathrm{~Gy}$ \\
Industrial - alimento e agricultura & $0,1-10 \mathrm{kGy}$ ou mais \\
Industrial - esterilização & $10-30 \mathrm{kGy}$ \\
Industrial - modificação de materiais & $50-100 \mathrm{kGy}$ ou mais \\
\hline
\end{tabular}

É importante salientar que em todos esses processos a dosimetria tem papel fundamental tanto na caracterização dos equipamentos que realizam o processamento por radiação, como no estabelecimento das doses dos processos e no monitoramento de rotina. Na caracterização dos equipamentos de radiação os parâmetros envolvidos são a dose fornecida e sua distribuição espacial dentro do irradiador, enquanto que para se estabelecer um processo com radiação é necessário medir as doses absorvidas (mínima e máxima) aceitáveis e a distribuição destas no produto para que haja os efeitos desejáveis. Por esta razão durante o processamento por radiação os dosímetros são empregados no monitoramento da irradiação para verificar se as doses desejadas estão sendo fornecidas aos produtos. 
Como este trabalho tem por objetivo a dosimetria gama de elevadas doses, somente os aspectos relevantes para este tipo de dosimetria serão apresentados a seguir.

\subsection{DOSIMETRIA DAS RADIAÇõES}

Em processos por radiação a medida precisa da quantidade de energia que a radiação deposita no meio é muito importante para a caracterização dos efeitos que esta produz, por isso, a dosimetria das radiações é uma componente essencial no processo. Os instrumentos que são empregados na determinação de dose são denominados de dosímetros.

Os dosímetros são materiais que apresentam qualquer tipo de alteração de suas características físicas ou químicas com a dose absorvida. Existem dosímetros químicos, físicos e eletrônicos. As técnicas freqüentemente empregadas na detecção das alterações dessas propriedades são: a espectrofotometria, a ressonância paramagnética eletrônica, a termoluminescência, a calorimetria, a luminescência, a medida das cargas geradas pela radiação entre outras mais.

A dosimetria em âmbito industrial apresenta algumas condições de trabalho inerentes ao processo que afetam a resposta da maioria dos sistemas dosimétricos. Por esse motivo, é extremamente complexa a determinação das doses absorvidas por esses materiais com elevada precisão, devido à dificuldade em se reproduzir em laboratórios de calibração as condições dos irradiadores [46].

\subsubsection{ClassificaÇão dos Dosímetros}

Os dosímetros são classificados em hierarquia de acordo com a precisão de suas respostas como: primário, referência ou secundário, transferência e rotina.

Os dosímetros primários são aqueles capazes de realizar a medida absoluta da dose absorvida feita em termos das grandezas básicas do Sistema Internacional - SI (massa, comprimento, tempo, corrente elétrica, etc.) e das constantes físicas fundamentais, sem a necessidade de um campo de radiação calibrado. Geralmente, estes dosímetros são mantidos e operados por laboratórios nacionais primários. Exemplos: calorímetros e câmaras de ionização [46].

Os dosímetros de referência ou secundários são definidos como dosímetros de elevada reprodutibilidade, calibrados pela comparação com os dosímetros primários e 
que possuem a capacidade de servir como padrão de referência para a calibração de outros dosímetros, desde que satisfeitos alguns critérios como: medir a resposta induzida pela radiação com precisão e que esta tenha uma função muito bem definida com a dose absorvida e que os efeitos de temperatura da irradiação ou pós-irradiação sejam muito bem caracterizados, podendo ser aplicados fatores de correção simples. Exemplos: dosímetros sulfato ferroso (Fricke), cérico-ceroso, dicromato e alanina [46,47].

Por outro lado, os dosímetros de transferência são aqueles que muitos laboratórios de calibração enviam às plantas industriais para serem irradiados e, depois, retornam ao laboratório de calibração para a certificação da dose recebida. Este tipo de serviço é utilizado para criar uma rastreabilidade de calibração com os dosímetros de rotina. Exemplo: alanina [46].

Os dosímetros de rotina, por sua vez, são aqueles que não têm um desempenho tão bom quanto os dosímetros de referência, mas apresentam custo baixo e são acessíveis para serem empregados na dosimetria diária nas plantas de irradiação. A resposta deste tipo de dosímetro pode apresentar variações com a temperatura, umidade, taxa de dose desde que existam fatores de correção, que não necessariamente precisam ser aplicados diretamente. Exemplos: polimetilmetacrilato (PMMA), filmes radiocrômicos, termoluminescentes (TLD), transistor de efeito de campo fabricado com a tecnologia Semicondutor de Óxido-Metal (do inglês, Metal Oxide Semiconductor Field Effect Transistor - MOSFET), diodos de silício, câmaras de ionização, entre outros [46].

A Figura 3.2.1. mostra um exemplo da cadeia nacional de rastreabilidade de um calorímetro padrão primário aplicado a ${ }^{60} \mathrm{Co}$, em termos da dose absorvida na água [46]

Também é oportuno classificar os laboratórios de calibração dos dosímetros seguindo uma hierarquia parecida com a dos dosímetros.

Em sendo assim os laboratórios padrão primário são os responsáveis pelo desenvolvimento e manutenção dos dosímetros padrão primário para intercomparações internacionais com outros laboratórios e calibração de instrumentos.

Dentre os laboratórios padrão primário destacam-se [48,49]:

- National Physical Laboratory (NPL) - Inglaterra [50];

- National Institute of Standards and Technology (NIST) - Estados Unidos [51]. 


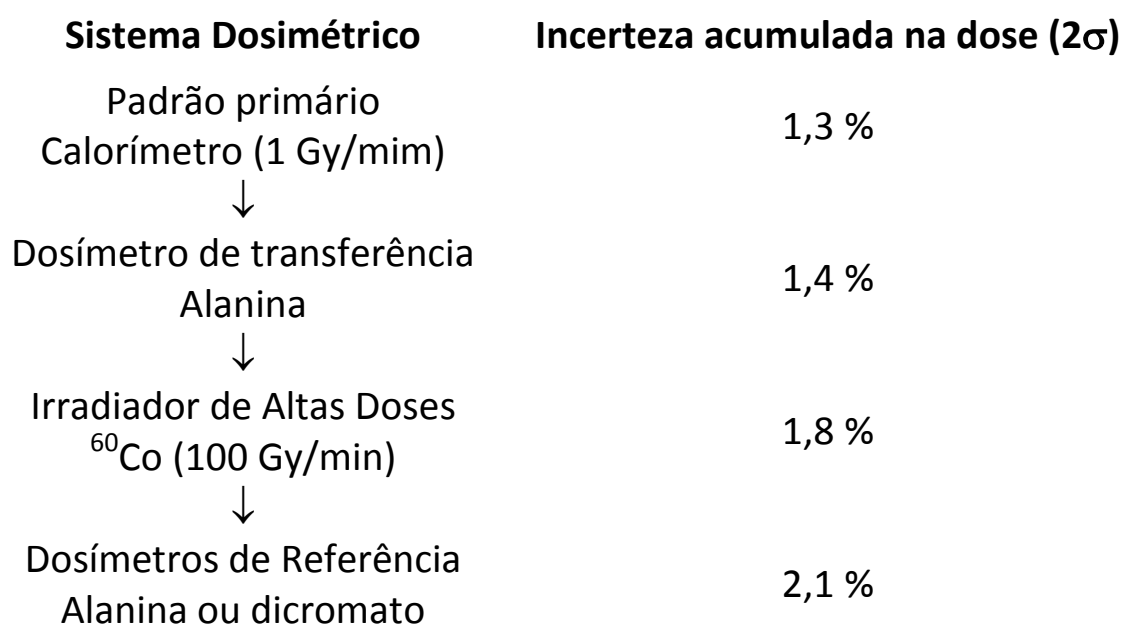

Figura 3.2.1 - Exemplo da cadeia de rastreabilidade nacional para o calorímetro padrão primário aplicada a um fonte de ${ }^{60} \mathrm{Co}$, determinando a dose absorvida na água [46].

Os laboratórios padrão secundário têm por objetivo manter e aplicar padrões secundários para calibração dos instrumentos empregados nas diversas áreas de processamentos por radiação e principalmente à medicina. É importante salientar que o Brasil dispõe de um laboratório padrão secundário, o Instituto de Radioproteção e Dosimetria (IRD), localizado na capital do estado do Rio de Janeiro, parte integrante da Comissão Nacional de Energia Nuclear (CNEN) [48].

\subsubsection{DOSE ABSORVIDA}

A grandeza de interesse fundamental em processos de radiação é a dose absorvida, pois esta quantifica o efeito da irradiação em qualquer meio e para diferentes tipos de partículas. A definição da dose absorvida $(D)$ é [46]:

$$
D=\frac{\overline{E_{d}}}{m}
$$

sendo $\overline{E_{d}}$ a energia média depositada em uma massa $m$ do meio.

Na maioria dos casos de processamento por radiação a dose absorvida será definida na água. A água é empregada como meio devido à facilidade de obtenção de materiais de referência e por possuir capacidade de absorção de energia da radiação próxima de vários materiais, como soluções aquosas, plásticos ou materiais celulósicos 
usados como dosímetros e materiais processados por radiação. Para algumas aplicações, como a irradiação de semicondutores, pode ser necessário determinar a dose absorvida pelo material, no caso o silício.

A unidade de dose absorvida no sistema internacional de unidade (SI) é o Gray e, como para demais grandezas dosimétricas, deve-se informar em que meio está sendo avaliada. Existe uma unidade antiga, porém freqüentemente utilizada que é o rad. A relação entre estas duas grandezas é:

$$
1 \text { Gray }=1 \mathrm{~J} / \mathrm{kg}=10^{2} \mathrm{rad}=10^{4} \mathrm{erg} / \mathrm{g}
$$

Outra grandeza também importante é a taxa de dose absorvida $(\dot{D})$, definida pela variação temporal da dose absorvida em uma determinada massa, ou seja:

$$
\dot{D}=\frac{\Delta D}{\Delta t}
$$

A taxa de dose absorvida é importante em processamento por radiação, pois constitui um dos parâmetros de caracterização dos irradiadores industriais, cuja função consiste em definir o tempo de irradiação necessário para que um produto absorva a dose desejada.

A quantidade de energia depositada na matéria permite a avaliação da dose absorvida sendo uma grandeza de fundamental importância na dosimetria. Portanto, o estudo da interação da radiação eletromagnética com a matéria torna-se imperativo para o entendimento de como ocorre o efeito da deposição de energia no meio, o que será realizado a seguir de maneira resumida.

\subsubsection{INTERAÇÃo DE FótONS COM A MATÉRIA}

Quando a radiação eletromagnética atravessa a matéria ocorrem interações dando origem a elétrons secundários que, por sua vez, depositam sua energia no meio. Os dois principais mecanismos de transferência de energia destes elétrons para os átomos da matéria são a excitação e a ionização.

Na ionização, a energia cedida ao átomo é suficiente para extrair um elétron de qualquer uma de suas camadas, transformando-o em elétron livre, com maior 
probabilidade de ocorrência para os elétrons da camada K. Por outro lado, na excitação, a energia absorvida faz com que o elétron seja transferido da camada mais interior (de menor energia) para outra camada mais distante do núcleo (de maior energia) e, quando ele retorna à camada original, emite a quantidade de energia excedente sob a forma de radiação eletromagnética ou produção de elétrons Auger.

Dos mecanismos descritos, o mais relevante para a detecção da radiação e processamento por radiação é a ionização, devido aos elétrons livres gerados depositarem sua energia no meio, produzindo os efeitos desejados nos materiais e detectores.

Os principais processos de interação da radiação eletromagnética com a matéria são os efeitos: fotoelétrico, Compton e produção de pares. Cada um destes processos apresenta uma probabilidade de ocorrência, que é função da energia do fóton incidente e da natureza do material absorvedor empregado (número atômico).

No efeito fotoelétrico, o fóton incidente transfere toda sua energia para o elétron ligado ao átomo e este é expelido com energia cinética bem definida, dada pela diferença entre a energia absorvida e a energia de ligação do elétron na camada em que foi extraído. Para que o momento total da colisão seja conservado é necessário que o núcleo absorva parte da energia do fóton transformando-a em energia de recuo. A secção de choque para o efeito fotoelétrico diminui à medida que a energia do fóton incidente aumenta, apresentando algumas descontinuidades para as energias dos fótons muito próximas às energias de ligação dos elétrons nas camadas, formando os "joelhos" de absorção. Para exemplificar, o "joelho" de absorção da camada K para o silício é de 1,84 keV [53]. A Figura 3.2.2 representa o efeito fotoelétrico.

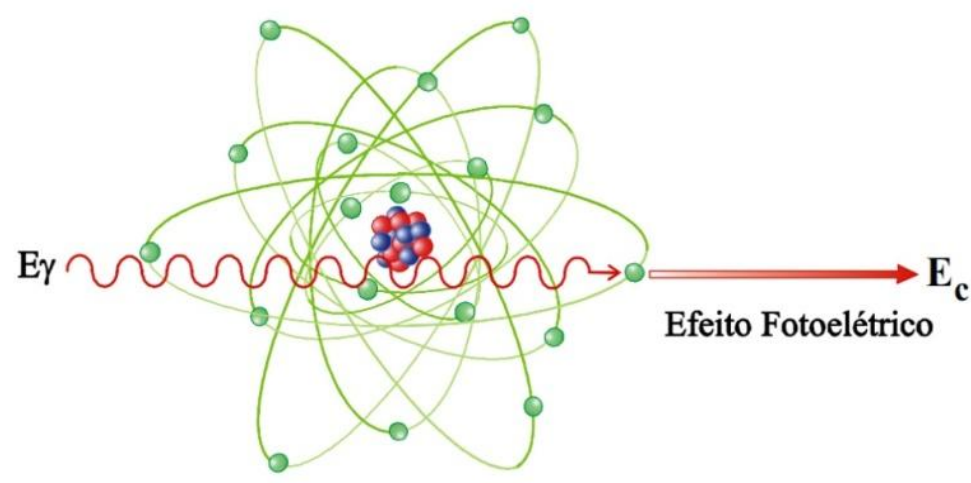

Figura 3.2.2 - Representação do efeito fotoelétrico [52]. 
Como na área de processamento por radiação o isótopo mais empregado é o

${ }^{60} \mathrm{Co}$, que emite raios gama de 1,17 e 1,33 MeV, tem-se majoritariamente a ocorrência de interações por efeito Compton, uma vez que a prevalência deste fenômeno ocorre para energias entre 0,1 e $5 \mathrm{MeV}$. Neste processo, os fótons incidentes que interagem com os elétrons constituintes dos átomos do material, que podem ser livres ou não, sofrem espalhamentos inelásticos, provocando a ejeção dos elétrons com os quais houve a troca parcial de energia. Os elétrons produzidos em decorrência destas interações, denominados elétrons Compton, são emitidos em direções aleatórias com energias variadas. A Figura 3.2.3 apresenta uma ilustração do efeito Compton.

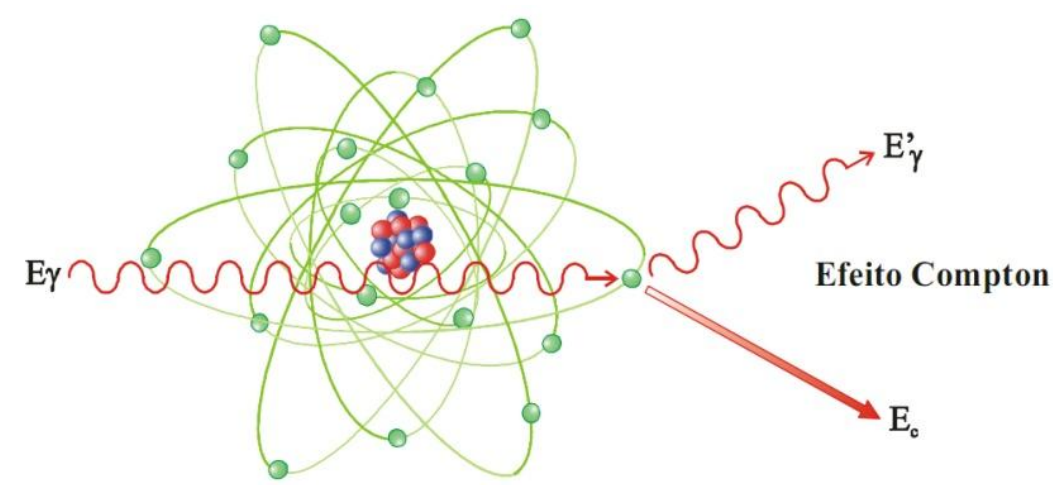

Figura 3.2.3 - Representação do efeito Compton [52].

À medida que se aumenta a energia da radiação eletromagnética, um terceiro tipo de interação torna-se mais importante que os demais, a denominada produção de pares. Neste tipo de interação, cujo limiar de ocorrência é dado pela relação $2 m_{0} c^{2}$, o que corresponde em termos de energia a 1,022 MeV, o fóton interage com o campo coloumbiano do núcleo do átomo ou do elétron criando um par elétron-pósitron. No caso do núcleo, a transferência de energia é pequena, devido a massa deste ser muito maior do que a massa do elétron, enquanto que para a interação com o elétron a transferência de energia é elevada (mesma massa) e como conseqüência o limiar de energia para a produção do par passa ser igual a $4 m_{0} c^{2}=2,044 \mathrm{MeV}$. Se a energia do fóton incidente for maior do que o limiar de energia para ocorrência deste efeito, o excesso de energia aparece sob a forma de energia cinética do próprio par elétron-pósitron gerado.

A interação do pósitron com o meio resulta em uma redução da sua velocidade, favorecendo o processo de aniquilação dele com um elétron, a partir do qual se tem a 
emissão simultânea de dois fótons com energia de 0,511 MeV cada. Estes fótons de aniquilação podem interagir com o meio pelos diferentes efeitos mencionados anteriormente. A Figura 3.2.4 apresenta uma ilustração do processo de produção de pares.

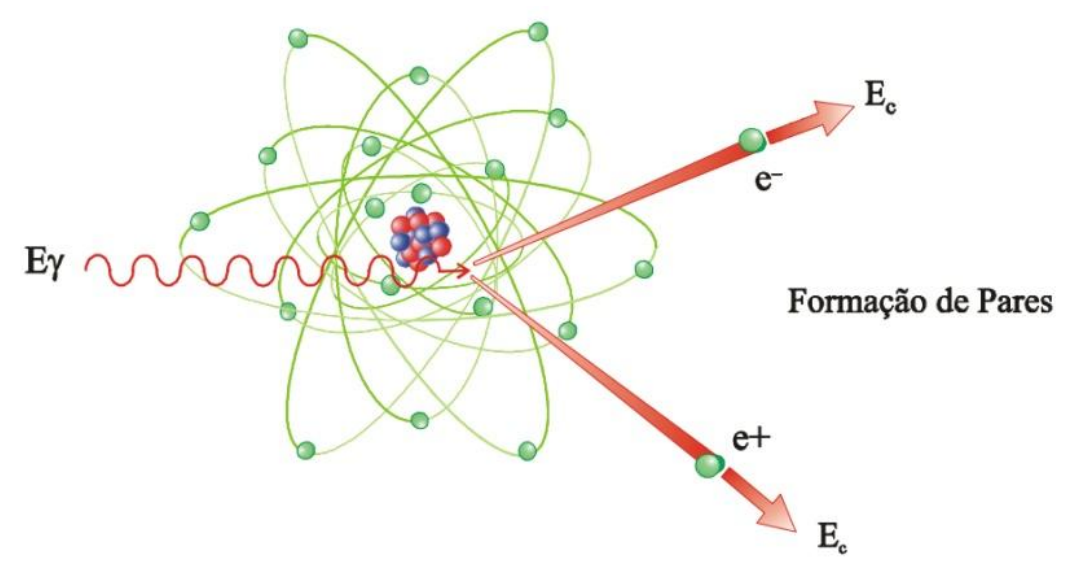

Figura 3.2.4 - Representação do efeito produção de pares [52].

A Figura 3.2.5 mostra a importância relativa desses principais processos de interação da radiação com diferentes materiais absorvedores, mediante a curva dos respectivos números atômicos em função da energia do fóton incidente [52]. A partir desta curva verifica-se que o efeito Compton é o mais importante para o silício $(Z=13)$ quando irradiado pelo ${ }^{60} \mathrm{Co}$. 


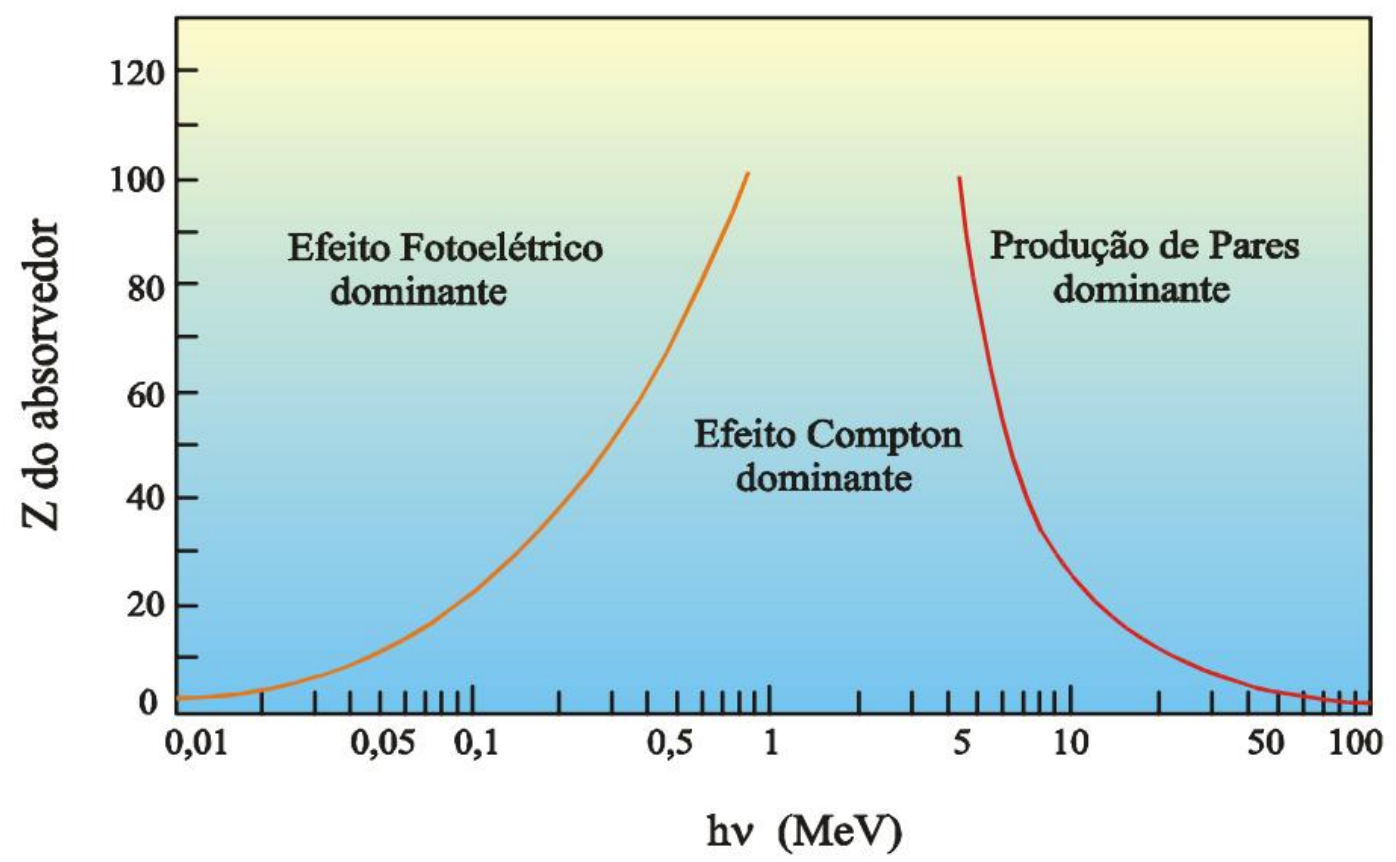

Figura 3.2.5 - Importância relativa dos diferentes processos de interação dos fótons em função do número atômico do material e energia do fóton incidente [52].

\subsubsection{ATENUAÇão da RADiaÇão EletromaGnÉtica}

Nos diferentes processos de interação da radiação eletromagnética com a matéria, os elétrons gerados, assim como os fótons espalhados, interagem com o meio depositando integralmente ou parcialmente a sua energia. Para um dado material absorvedor, quanto maior for a sua espessura maior será a quantidade de energia nele depositada, até o limite de espessura que proporcionará a deposição total da energia.

Dessa forma, quando um feixe de radiação colimado com intensidade inicial $I_{0}$ atravessa um meio qualquer com espessura $x$, este apresentará uma diminuição na sua intensidade inicial dada por:

$$
I=I_{0} \cdot e^{-\mu \cdot x}
$$

onde $I$ é a intensidade do feixe transmitido e $\mu$ o coeficiente total de atenuação linear da radiação eletromagnética, definido como a fração de fótons do feixe incidente absorvida e espalhada nas interações ocorridas por unidade de espessura do meio absorvedor [54].

De acordo com as curvas da Figura 3.2.6, construída a partir da base de dados de referência do National Institute of Standards and Technology (NIST) para o silício, nota-se 
que para energias inferiores a $30 \mathrm{keV}$ tem-se uma predominância do efeito fotoelétrico, ao passo que para energias compreendidas no intervalo de 0,1 a $5 \mathrm{MeV}$ observa-se a ocorrência preferencial do efeito Compton. Contudo, para fótons de energia superior a $10 \mathrm{MeV}$ observa-se que o efeito de produção de pares torna-se dominante [55].

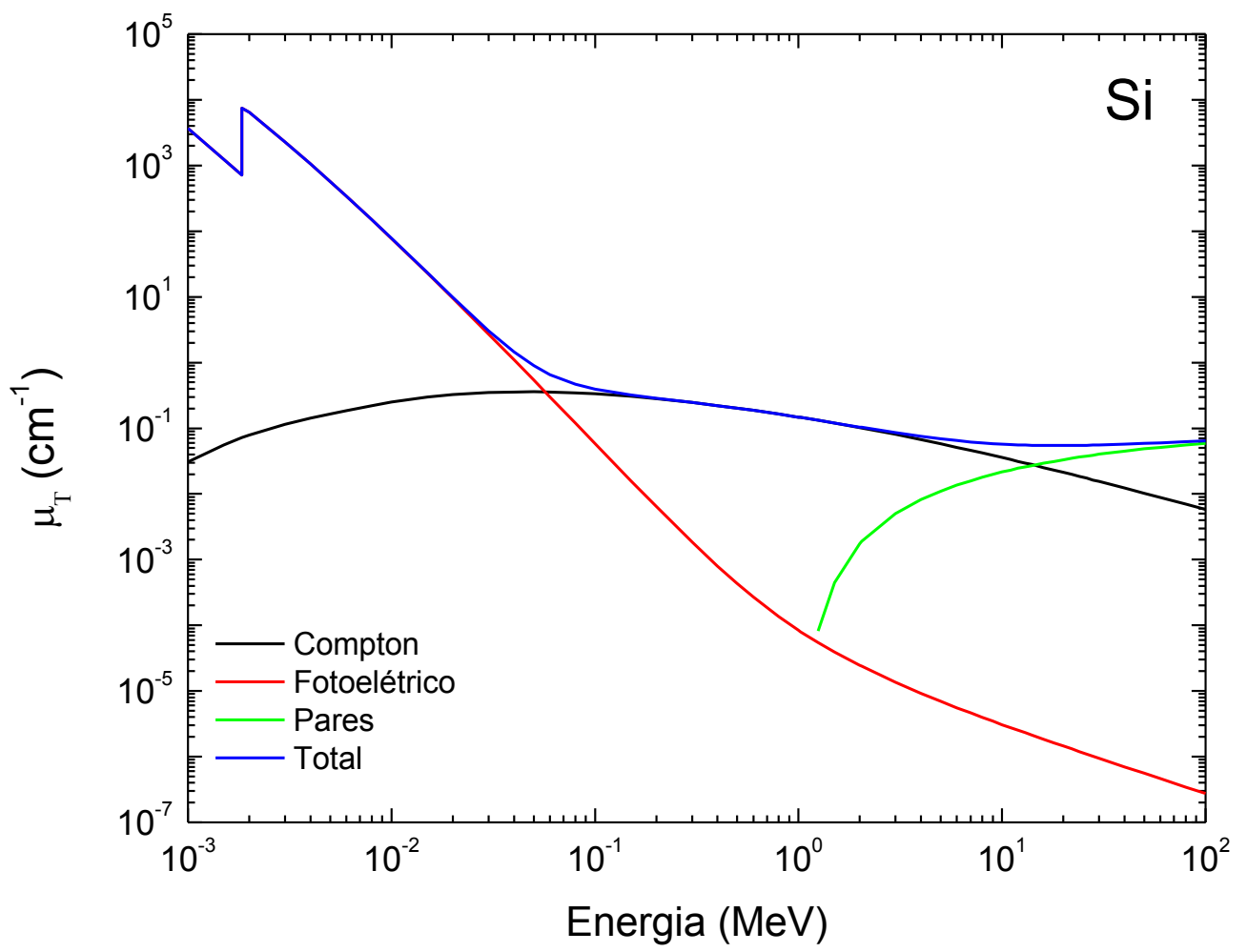

Figura 3.2.6 - Coeficiente de atenuação total linear (curva azul) da radiação eletromagnética em função da energia do fóton incidente para o silício, particularizando a contribuição dos efeitos: fotoelétrico (curva vermelha), Compton (curva preta) e produção de pares (curva verde) [55].

No processo de interação da radiação com o meio, os elétrons gerados e os fótons espalhados interagem com este meio depositando integralmente ou parcialmente a sua energia. A Figura 3.2.7 ilustra a cadeia de processos secundários e terciários que ocorrem entre os fótons incidentes e os elétrons ou fotoelétrons produzidos em função da interação da radiação eletromagnética com o meio. 


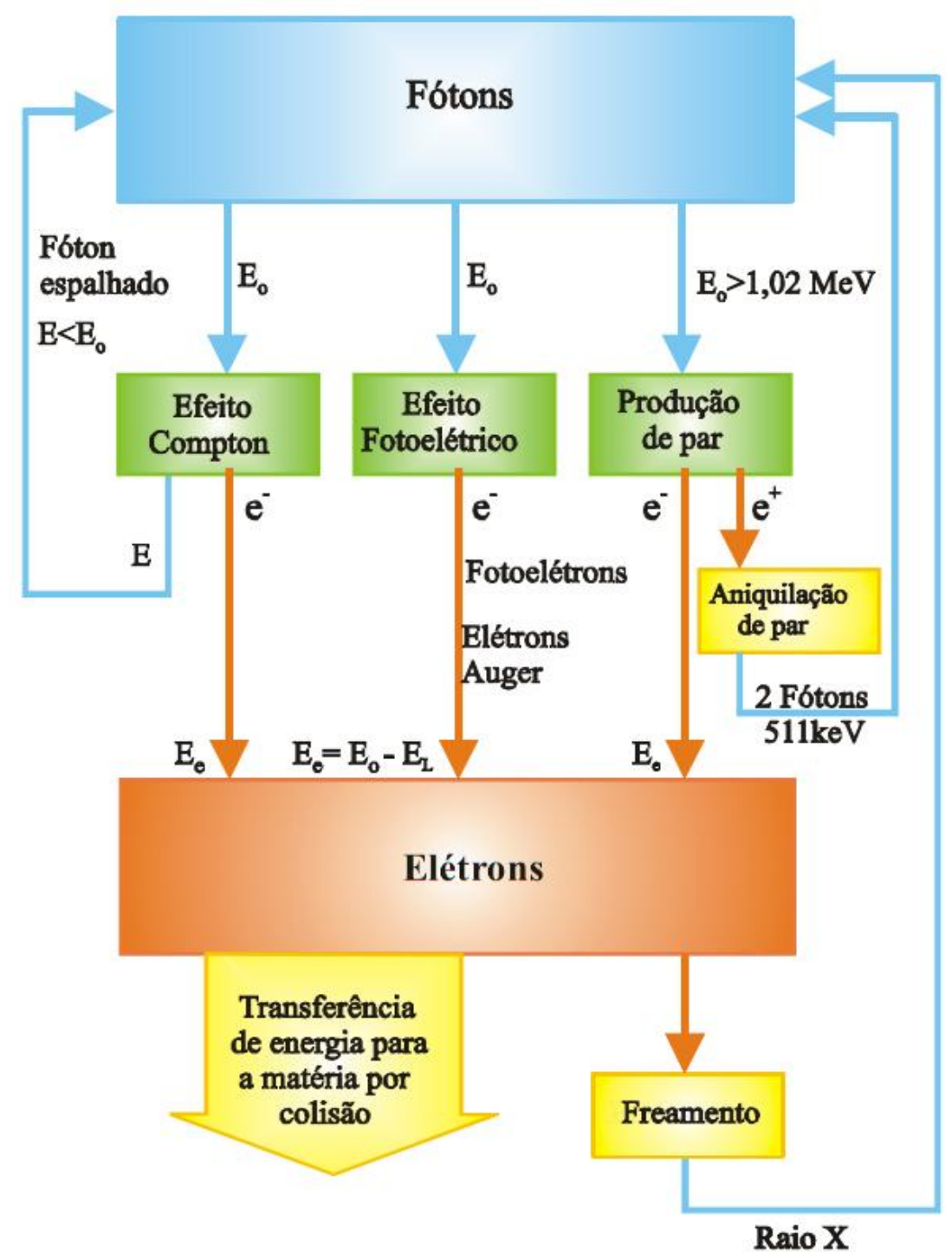

Figura 3.2.7 - Principais processos de interação da radiação eletromagnética com a matéria [52].

\subsection{SISTEMAS DOSIMÉTRICOS}

Existem vários sistemas dosimétricos empregados na área de processamento por radiação, sendo que o princípio de funcionamento básico de todos eles é a alteração de qualquer uma das propriedades mensuráveis do material com a dose absorvida, desde que estas se mantenham estáveis por pelo menos o tempo necessário para realizar a medida e que sejam reprodutíveis. A Figura 3.3.1 apresenta os vários sistemas dosimétricos empregados nos processos de radiação, desde aplicações médicas até industriais, com seus respectivos intervalos de dose absorvida segundo o National Physical Laboratory (NPL) da Inglaterra [50]. 


\section{Intervalo de Dose Absorvida}

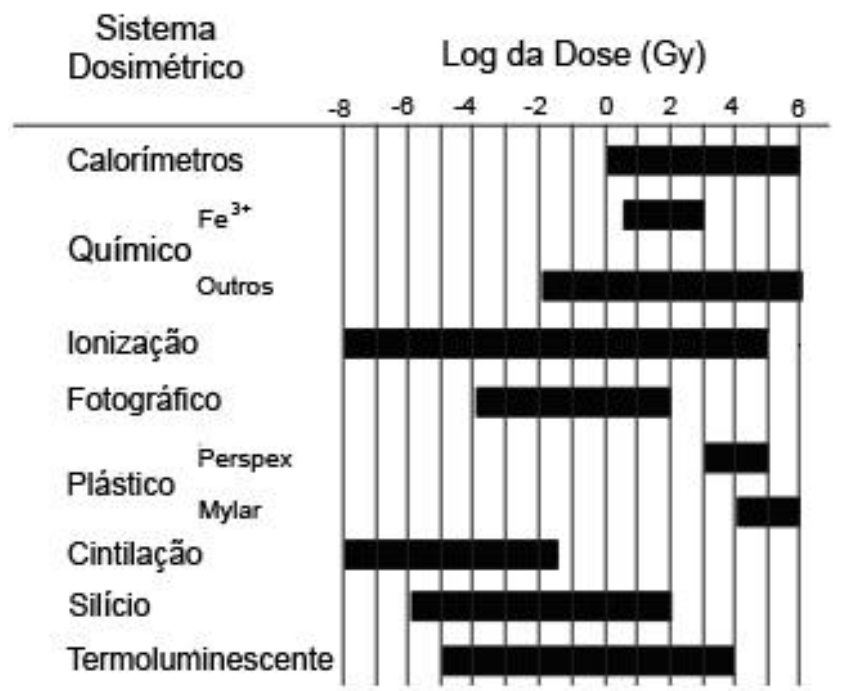

Figura 3.3.1 - Sistemas dosimétricos empregados em diversos intervalos de dose absorvida [50].

Nota-se na Figura 3.3.1 que no intervalo de doses para processamento por radiação industrial, ou seja, doses maiores do que 1 kGy (log da dose > 3), os dosímetros empregados são: calorímetros, câmaras de ionização, TLD’s e dosímetros químicos (gasosos, plásticos e soluções químicas).

O calorímetro é o sistema dosimétrico fundamental para a medida de dose absorvida, pois em princípio sua resposta é relacionada à definição da grandeza. A energia absorvida pelo meio se manifesta na forma de calor e, conseqüentemente, causa um aumento de temperatura do material que está relacionado diretamente à dose absorvida. Geralmente, este tipo de dosímetro é usado como padrão primário para as medidas de dose absorvida por diversos laboratórios nacionais (padrão primário). Apesar dos calorímetros serem dosímetros padrão, eles apresentam as desvantagens de serem equipamentos caros e de difícil construção, devido ao isolamento térmico da região de medida, o que acaba sofrendo interferência da temperatura ambiente, necessitando de correção na resposta.

A câmara de ionização, por sua vez, constitui um tipo de dosímetro amplamente aplicado em dosimetria das radiações em um intervalo de dose muito amplo ( $\mu$ Gy até kGy), podendo ser do tipo padrão primário até de rotina, além de apresentar resposta rápida e precisa. Elas são construídas em diferentes formatos e tamanhos dependendo do tipo de aplicação e são facilmente encontradas comercialmente, o que contribui na disseminação de sua utilização. Por outro lado, ela apresenta algumas desvantagens, 
como a produção de correntes de intensidades muito baixas, da ordem de pA, necessitando, assim, do acoplamento de um sistema eletrônico sofisticado para a aquisição das medidas; custo elevado, além do fato de possuir grandes dimensões para aplicações de altas doses, limitando as medidas de dose bem localizadas.

Nos dosímetros químicos a absorção da radiação ionizante pode favorecer o aparecimento de íons, radicais livres, centros de cores ou moléculas complexas, suficientemente estáveis para serem analisados e medidos com alta reprodutibilidade por meio de métodos analíticos físico-químicos padrão. As técnicas analíticas mais empregadas são a espectrofotometria ótica, a termoluminescência, a fotoluminescência e a espectroscopia de ressonância paramagnética eletrônica (EPR).

O dosímetro Fricke, cujo princípio de funcionamento baseia-se na detecção de radiação por meio da oxidação de uma solução de sulfato de ferro, constitui o dosímetro químico de referência mais utilizado para determinação de doses absorvidas tanto de raios gama oriundos do ${ }^{60} \mathrm{Co}$ quanto de raios-X. Entretanto, tal dispositivo apresenta uma limitação técnica quanto a sua utilização, podendo ser empregado para medidas de dose absorvidas de até 1 kGy [50].

Por outro lado, outros tipos de dosímetros químicos são relatados na literatura $[45,46,56,57]$, com maior destaque para os dosímetros de polimetilmetacrilato (PMMA) que são amplamente empregados na dosimetria rotineira de processos com radiação por apresentarem baixo custo, fácil manuseio e capacidade de medir doses de até 1 MGy $[56,57]$. Contudo, estes dosímetros apresentam desvantagens quanto ao equipamento utilizado para realização das medidas (espectrofotômetro ótico), visto que este apresenta custo elevado e somente permite a realização das medidas após a irradiação, ou seja, em modo off-line.

Com relação aos dosímetros eletrônicos, sabe-se que eles foram amplamente utilizados na área de processamento por radiação até a década de 80 [43,45,46,57-60], sendo posteriormente substituídos, por apresentarem degradação na resposta. Acreditase que o comprometimento destes dispositivos tenha ocorrido devido ao fato dos materiais semicondutores empregados na época não suportarem as doses desses ambientes. É interessante notar que o NPL sequer menciona a aplicabilidade destes dosímetros eletrônicos para doses superiores a 100 Gy, reforçando a idéia de que esses 
equipamentos ainda não são vistos como uma alternativa viável para dosimetria de altas doses.

Contudo esta realidade está sendo alterada com os avanços na tecnologia de produção de dispositivos semicondutores [15-17,61] mais tolerantes a doses elevadas de radiação para aplicações em experiências relacionadas à física de altas energias (FAE). Estudos mais recentes conduzidos pelas colaborações internacionais, RD50 [17] e RD39 [62] do CERN, visam a aplicação de diodos semicondutores no futuro Super Colisor de Hádrons (SLHC), onde as doses serão ainda mais elevadas quando comparadas com as apresentadas pelo LHC [63].

\subsection{DosímeTros de SiLÍ́cio}

Dosímetros de silício são basicamente junções $p$-n que se comportam como uma câmara de ionização, gerando pares elétron-lacuna quando da interação da radiação com o meio. A coleta das cargas geradas forma uma corrente elétrica, denominada fotocorrente.

Umas das vantagens dos dosímetros eletrônicos é a grande sensibilidade, cerca de 18.000 vezes maior quando comparada a das câmaras de ionização, sendo este fator determinado a partir do produto entre a diferença de densidades do Si e dos gases comumente utilizados nas câmaras, que é por volta de 1.800 e a ordem de grandeza envolvida para a formação de um par elétron-lacuna no silício $(3,6 \mathrm{eV})$ que é 10 vezes menor do a energia de produção de um par de íons nos gases (35 eV) [64].

Os dosímetros semicondutores na maioria das vezes operam sem a aplicação de tensão de polarização reversa, ou no modo fotovoltaico [64-69], para minimizar o efeito da corrente de fuga do diodo. Entretanto, em algumas aplicações, como por exemplo, para medidas de taxa de dose eles podem ser operados com tensão de polarização [66].

A fotocorrente é composta basicamente por duas componentes: a primeira delas é a corrente gerada na região de depleção do diodo, devido aos pares elétron-lacuna produzidos pela radiação e rapidamente separados e coletados pela presença do campo elétrico e a segunda formada pelos portadores minoritários fora da região de depleção, ou seja, as lacunas e elétrons nas regiões $n$ e $p$, respectivamente, que podem difundir para região de depleção e ser coletados. A espessura da zona de sensibilidade do diodo para geração da fotocorrente então será a soma da espessura da zona de depleção do 
diodo $(d)$ e dos comprimentos de difusão das lacunas $\left(L_{p}\right)$ na região $\mathrm{n}$ e dos elétrons $\left(L_{n}\right)$ na região p. A intensidade de corrente induzida para um diodo completamente irradiado, onde a radiação deposita toda sua energia no volume sensível e que a eficiência de coleta de cargas é de $100 \%$, é dada por [64,66]:

$$
I_{F}=q g A\left(d+L_{n}+L_{p}\right)
$$

onde $q$ é carga elementar do elétron, $g$ é a taxa de produção dos pares elétron-lacuna por unidade de volume no silício e $A$ é a área da junção. É interessante chamar a atenção para o fato de $g$ ser diretamente proporcional à taxa de dose no diodo e, portanto, a medida da fotocorrente traduzirá a relação com tal grandeza, como pode ser visto no Apêndice A.

Entretanto, nem sempre as condições de deposição total de energia no volume sensível e de coleta total de cargas são satisfeitas devido, em muitos casos, à energia da radiação incidente ser muito elevada, depositando apenas uma pequena parcela da energia e também ao fato de que na junção sempre existem defeitos que armadilham as cargas geradas, causando perdas na carga total coletada.

$\mathrm{Na}$ literatura [69] encontra-se um estudo dos parâmetros que definem a fotocorrente gerada em uma junção do tipo $\mathrm{p}^{+} / \mathrm{n} / \mathrm{n}^{+}$quando submetida a uma irradiação com fótons como apresentada na Figura 3.4.1.

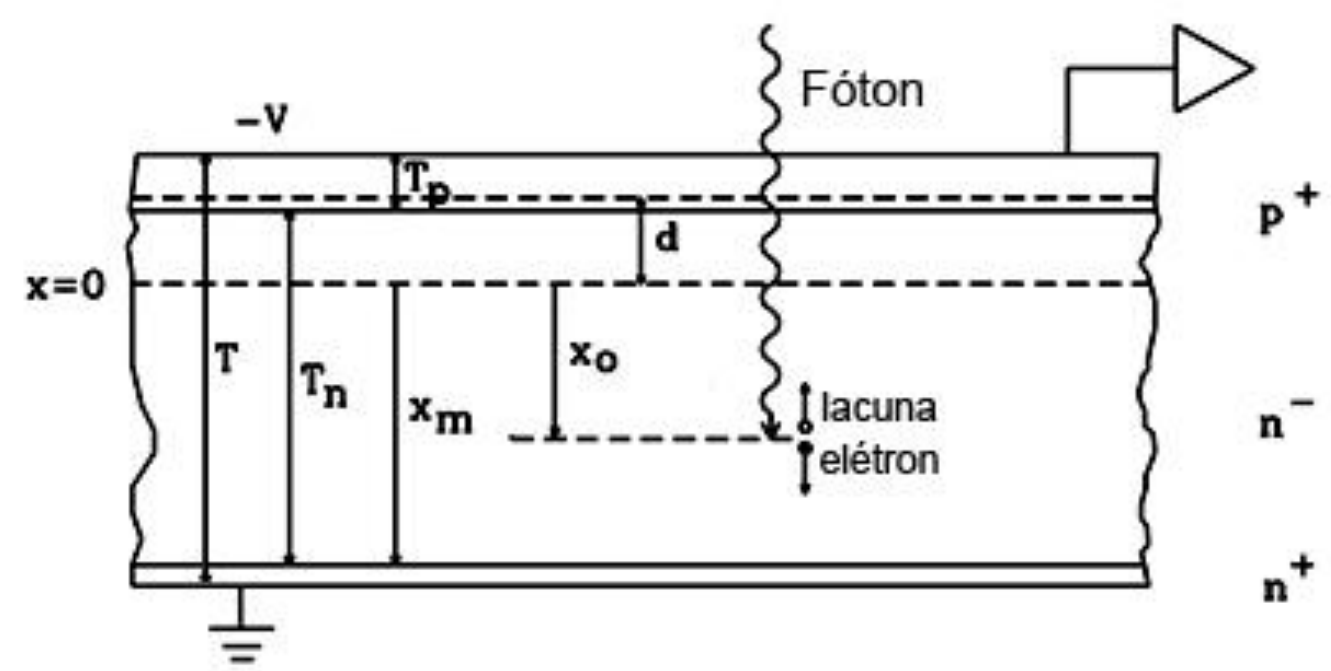

Figura 3.4.1 - Esquema da junção p-n de um diodo do tipo $\mathrm{p}^{+} / \mathrm{n} / \mathrm{n}^{+}$, com as respectivas espessuras [69]. 
A fotocorrente total produzida na junção (Equação 3.4.2.) considera as eficiências de geração da fotocorrente em cada uma das regiões da junção, ou seja, a quantidade de fótons que interage com cada região da junção gerando o sinal de corrente.

$$
\begin{aligned}
I_{F}=\Phi q A \frac{E}{E_{p a r}}\{ & \frac{L_{a} L_{n}}{L_{a}^{2}-L_{n}^{2}}\left[\left(\operatorname{coth} \frac{T_{p}}{L_{n}}+\frac{L_{n}}{L_{a}}\right) e^{-\frac{T_{p}}{L_{a}}}-\frac{1}{\operatorname{senh} \frac{T_{p}}{L_{n}}}\right]+e^{-\frac{T_{p}}{L_{a}}}\left[1-e^{-\frac{d}{L_{a}}}\right] \\
& \left.+\frac{L_{a} L_{p}}{L_{a}^{2}-L_{p}^{2}}\left[\left(\operatorname{coth} \frac{T-d-T_{p}}{L_{p}}-\frac{L_{p}}{L_{a}}\right) e^{-\frac{d+T_{p}}{L_{a}}}-\frac{e^{-\frac{T}{L_{a}}}}{\operatorname{senh} \frac{T-d-T_{p}}{L_{p}}}\right]\right\}
\end{aligned}
$$

sendo $\Phi$ a quantidade de fótons por segundo (taxa de fótons), $q$ a carga elementar do elétron, $A$ a área da junção, $E$ a energia do fóton, $E_{\text {par }}$ energia para geração de um par elétron-lacuna no Si (3,62 eV), $L_{a}$ o comprimento de absorção da radiação (definido como o inverso do coeficiente de absorção), $L_{n}$ e $L_{p}$ comprimentos de difusão dos elétrons e das lacunas nas regiões $\mathrm{p}$ e $\mathrm{n}$, respectivamente, $T$ espessura total do diodo, $T_{p}$ espessura da região $\mathrm{p}^{+}$e $d$ espessura da zona de depleção do diodo.

A análise da Equação 3.4.2 evidencia que os termos entre chaves somados correspondem às eficiências de geração de corrente em cada região do diodo, sendo: o primeiro devido à região $\mathrm{p}^{+}$não depletada, o segundo à região de depleção e o terceiro à região n não depletada da junção. Além disso, verifica-se que a fotocorrente depende diretamente do fluxo de partículas por segundo e também dos comprimentos de difusão dos portadores minoritários e do comprimento de absorção da radiação.

O comprimento de difusão dos portadores minoritários é a distância média que estes portadores conseguem percorrer antes que sejam recombinados ou capturados pelas armadilhas no semicondutor e está relacionado ao tempo de vida média do portador $\left(\tau_{n, p}\right)$ e ao coeficiente de difusão $\left(D_{n, p}\right)$ pela seguinte equação: 


$$
L_{n, p}=\sqrt{D_{n, p} \cdot \tau_{n, p}}=\sqrt{\frac{k T_{K}}{q} \mu_{n, p} \cdot \tau_{n, p}} \rightarrow\left\{\begin{array}{l}
L_{n}=\sqrt{D_{n} \cdot \tau_{n}}=\sqrt{\frac{k T_{K}}{q} \mu_{n} \cdot \tau_{n}} \\
L_{p}=\sqrt{D_{p} \cdot \tau_{p}}=\sqrt{\frac{k T_{K}}{q} \mu_{p} \cdot \tau_{p}}
\end{array}\right.
$$

sendo $k$ a constante de Boltzmann, $T_{\mathrm{K}}$ a temperatura absoluta, qq a carga elementar do elétron, $\tau_{n}$ e $\tau_{p}$ os tempos de vida médios e $\mu_{n}$ e $\mu_{p}$ as mobilidades dos portadores minoritários nas regiões $p$ e $n$, respectivamente.

Entretanto, quando a radiação interage com os átomos de silício que constituem a rede cristalina, dependendo da energia transferida, poderá ocorrer o deslocamento deste átomo da posição inicial, que passará a ser chamado de átomo intersticial e formar uma vacância no local. O átomo intersticial juntamente com a vacância é conhecido como par de Frenkel.

Os pares de Frenkel formados reagem com as impurezas do material, principalmente com o oxigênio e carbono, criando defeitos na estrutura cristalina que podem se tornar sorvedouros de cargas elétricas, o que causa uma redução na resposta dos diodos. A formação destes defeitos acaba se traduzindo numa redução dos comprimentos de difusão dos portadores minoritários, pois diminuem a vida média dos portadores gerados e dependendo da concentração de defeitos induzidos no material as suas propriedades elétricas se tornam inadequadas para as aplicações destes dispositivos.

\subsection{EFEITOS DA RADIAÇÃo}

Os dispositivos eletrônicos resistentes à radiação que eram empregados até poucos anos atrás nas áreas bélica, aeroespacial e de reatores nucleares [70,71], ganharam espaço recentemente em estudos conduzidos em aceleradores de partículas em função essencialmente da excelente qualidade de resposta temporal e espacial que apresentam, além de serem confeccionados de forma mais compacta [17].

Ensaios experimentais preliminares revelaram que os detectores de silício podem operar sob fluências da ordem de $10^{14} \mathrm{~cm}^{-2}$, todavia para serem utilizados em definitivo em aceleradores, eles devem ser resistentes o suficiente para suportarem uma dose equivalente a esta por um período de uma década aproximadamente. Embora os 
dispositivos tenham demonstrado funcionar em locais com fluência da ordem de $10^{15} \mathrm{~cm}^{-2}$ e para doses de até 10 MGy [18] é importante estender os seus limites de operação para outras ordens de magnitude.

Apenas como ilustração das doses e fluências encontradas nos aceleradores, tem-se que uma fluência de $3 \times 10^{13} \mathrm{~cm}^{-2}$ de partículas minimamente ionizantes corresponde a uma dose de 10 kGy, obtidos durante 1,5 anos de operação [70]. Por outro lado, em aplicações de processamento por radiação esta dose é típica nos processos [5759], sendo aplicada ao material em uma única irradiação que chega a durar de algumas horas até minutos, dependendo somente da taxa de dose do irradiador.

\subsubsection{MECANISMOS DOS DANOS DE RADIAÇÃo}

Os mecanismos de danos por radiação são similares para vários tipos de semicondutores, mas somente serão tratados neste trabalho dos manufaturados de silício, pois é o material mais extensamente estudado para aplicações em detectores de radiação. Entretanto, os conceitos apresentados poderão ser aplicados aos demais semicondutores guardando as especificações de cada material, quando for o caso.

O fato de realizar a medida da radiação pode promover danos aos materiais que são empregados como detectores. A interação da radiação ocorre com a nuvem de elétrons dos átomos, mas também pode interagir com os núcleos dos átomos da rede cristalina. Enquanto que na interação da radiação com a nuvem de elétrons dos átomos de silício tem-se um efeito transiente (ionização e excitação), empregado como princípio de funcionamento dos detectores de radiação, a interação com os átomos da rede cristalina podem causar danos permanentes à estrutura cristalina, o que provoca um detrimento na resposta natural dos detectores de radiação.

Dispositivos semicondutores são afetados basicamente por dois mecanismos de danos de radiação distintos [70]:

- Dano por deslocamento: A radiação incidente desloca os átomos de silício de seus locais de origem na estrutura cristalina e, como conseqüência, tem-se a criação de uma vacância. Este efeito é conhecido como geração do par de Frenkel. A formação dos pares de Frenkel promove alterações nas características elétricas do semicondutor, como a corrente de fuga, tensão de depleção e eficiência de coleta de carga. 
- Dano por ionização: A energia absorvida por ionização nas camadas isolantes, geralmente de $\mathrm{SiO}_{2}$, liberam portadores de cargas adicionais, os quais se difundem ou deslocam para outros locais onde se tornam armadilhas e, em função desta diferença de concentração de cargas, temse como conseqüência campos elétricos parasitas que interferem na resposta dos dispositivos.

Os mecanismos descritos anteriormente são importantes para os sistemas detectores quanto para os transistores e circuitos integrados. Alguns dispositivos são mais sensíveis aos danos por ionização (transistores de efeito de campo - FET), enquanto outros são influenciados seriamente pelos danos por deslocamento (diodos). Dificilmente um sistema é imune aos dois fenômenos, geralmente ele é sensível ou influenciável pelos dois.

Os efeitos por ionização dependem fundamentalmente da energia absorvida, independentemente da natureza da radiação incidente. Para energias típicas capazes de gerar ionização, o mecanismo de absorção é o predominante e, portanto, os efeitos por dano de radiação são proporcionais à dose. Uma vez que a carga liberada por uma determinada dose depende da composição do material absorvedor, a ionização por dose deve ser então expressa em termos do tipo de material absorvedor, por exemplo: $1 \mathrm{~Gy}(\mathrm{Si}), 1 \mathrm{~Gy}\left(\mathrm{SiO}_{2}\right)$ e $1 \mathrm{~Gy}(\mathrm{GaAs})$.

Os danos por deslocamento dependem da perda de energia por não-ionização, ou seja, do momento e da energia transferidos para os átomos da estrutura cristalina que podem ser deslocados gerando vacâncias ou não. Como para este tipo de dano não é possível realizar uma medida equivalente àquelas feitas para radiação ionizante, devem ser bem especificados quais os tipos de partículas e energias que causaram os efeitos.

Os processos de deslocamento importantes para a rede cristalina são [69]:

- o deslocamento dos átomos da rede cristalina da sua posição original, criando átomos intersticiais (átomos localizados entre as posições regulares da rede cristalina) e vacâncias (posições regulares vazias na rede cristalina); 
- processos secundários causados pelos átomos deslocados com energia suficiente para promover novos deslocamentos, ou seja, efeito cascata, chamados de clusters.

A maioria destes defeitos primários não é estável em temperatura ambiente e, portanto, os átomos intersticiais podem preencher as vacâncias vazias da rede cristalina e se tornarem estáveis para a temperatura em questão. Por exemplo, são bem conhecidos os seguintes defeitos: a combinação de uma vacância e um oxigênio (VO), este último presente à certa concentração quando do crescimento do cristal; a combinação de duas vacâncias $\left(V_{2}\right)$, denominadas de divacância; e a ligação de uma vacância e um átomo de fósforo (VP) [69]. Estes defeitos degradam na maioria das vezes as propriedades elétricas do material semicondutor.

\subsubsection{DANO POR DESLOCAMENTO}

Uma partícula ou fóton capaz de ceder energia de aproximadamente $25 \mathrm{eV}$ $[69,70]$ para os átomos de silício pode deslocá-los das suas posições iniciais da rede cristalina, formando o par de Frenkel. Danos por deslocamento podem criar grupos ou clusters de defeitos se a energia de recuo dos átomos for suficientemente grande para promover o deslocamento de outros átomos. Para exemplificar, nêutrons com $1 \mathrm{MeV}$ transferem da ordem de $60-70 \mathrm{keV}$ para cada átomo de recuo do $\mathrm{Si}$, o qual desloca, por sua vez, cerca de 1000 átomos adicionais em uma região de apenas 0,1 $\mu \mathrm{m}$ [70]. Portanto, danos de deslocamento estão diretamente ligados à perda de energia por nãoionização, da sigla em inglês NIEL (Non-lonising Energy Loss) [72], que não é proporcional à energia total absorvida, mas depende do tipo da partícula e da sua energia. A perda de energia por não-ionização para diferentes partículas foi calculada para um grande intervalo de energia e o dano por deslocamento vs. energia é mostrado na Figura 3.5.1, para nêutrons, prótons, píons e elétrons, sendo todos os valores normalizados em relação ao dano provocado por nêutrons de $1 \mathrm{MeV}$ [73]. Apesar destes dados não serem verificados quantitativamente, eles são utilizados para estimar efeitos relativos nos materiais semicondutores.

É interessante notar que raios-X não causam dano por deslocamento diretamente, uma vez que a conservação de momento prevê um limiar de energia de 
$250 \mathrm{keV}$ para fótons [70]. Entretanto, os raios gama provenientes do ${ }^{60}$ Co causam danos por deslocamento principalmente por meio dos elétrons Compton que possuem energia máxima de $1 \mathrm{MeV}$ [78]. A Tabela 3.5.1 apresenta uma comparação com valores aproximados do dano por deslocamento para nêutrons, prótons e elétrons com energia de $1 \mathrm{MeV}$.

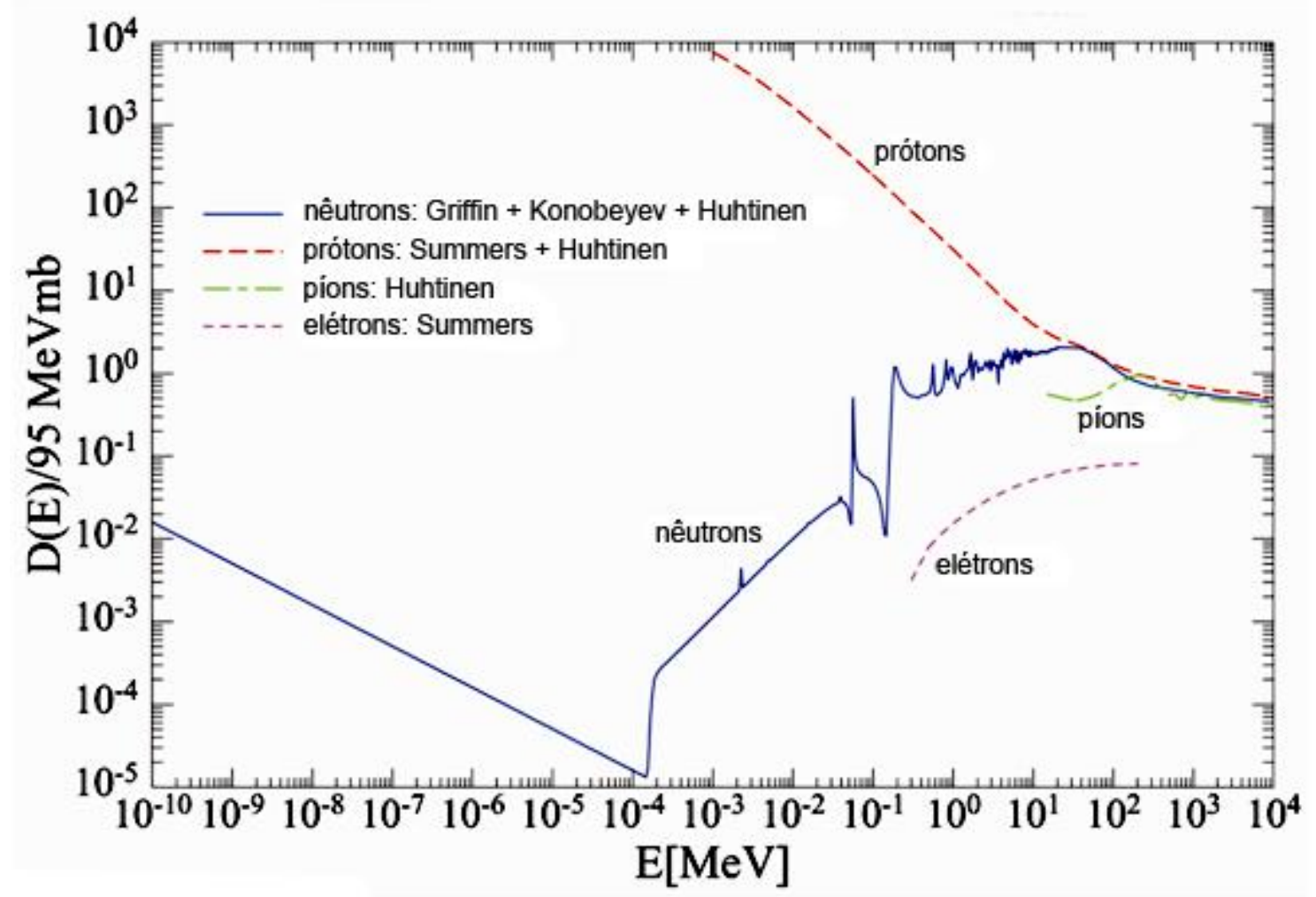

Figura 3.5.1 - Dano por deslocamento em função da energia de nêutrons, prótons, píons e elétrons calculados em relação a nêutrons de $1 \mathrm{MeV}$. Estes dados foram compilados por A. Vasilescu e G. Lindstroem [73], baseado nos dados de Griffin et al. [74], Konobeyev [75], Huhtinen and Aarnio [76] e Summers et al. [77].

Tabela 3.5.1 - Comparação simples do dano por deslocamento para próton, nêutron e elétron todos com energia de $1 \mathrm{MeV}$.

\begin{tabular}{r|ccc}
\hline Partícula & próton & nêutron & elétron \\
\hline Dano relativo & 30 & 1 & 0,015 \\
\hline
\end{tabular}

Os defeitos por deslocamentos podem ser simulados por meio de códigos computacionais que permitem a visualização da configuração interna e do tipo de deslocamento formado. A Figura 3.5.2 [79] ilustra a distribuição inicial de vacâncias 
produzidas no silício por prótons de $10 \mathrm{MeV}$ e $24 \mathrm{GeV} / \mathrm{c}$, bem como por nêutrons de $1 \mathrm{MeV}$, simulada para uma profundidade (z) de $1 \mu \mathrm{m}$ e fluência de $10^{14}$ partículas $/ \mathrm{cm}^{2}$.
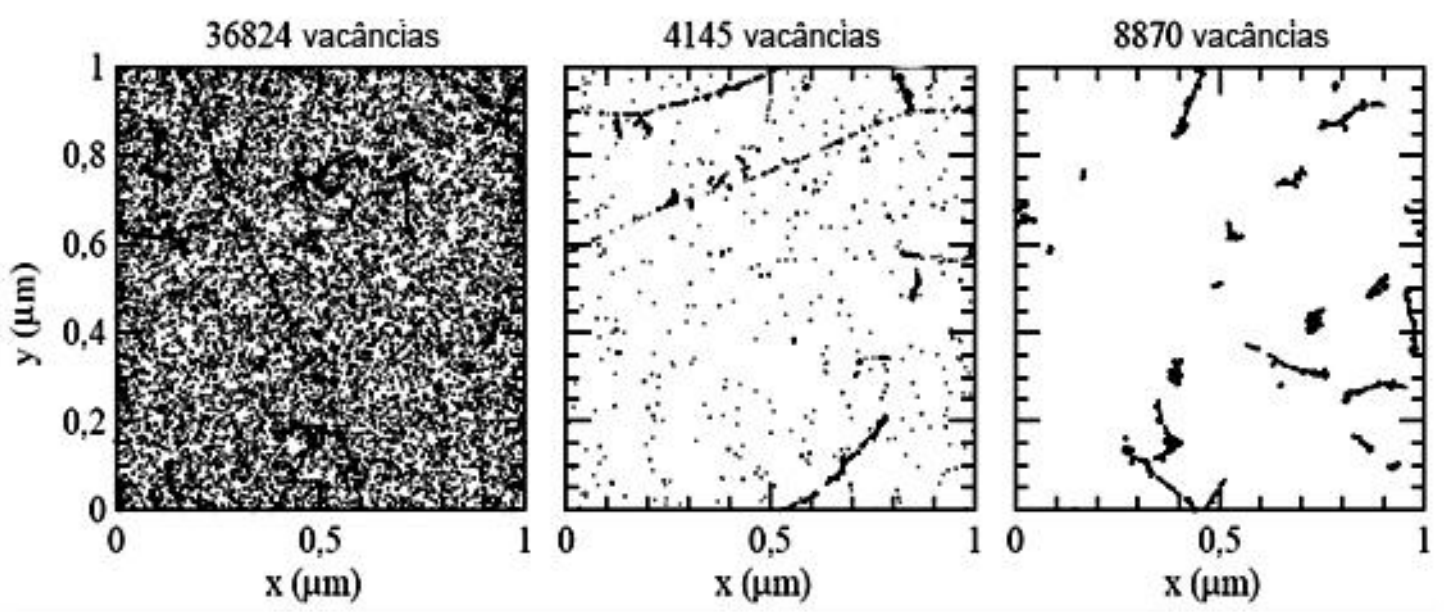

Figura 3.5.2 - Distribuição inicial de vacâncias produzidas no silício por prótons de $10 \mathrm{MeV}$ (esquerda), prótons de $24 \mathrm{GeV} / \mathrm{c}$ (centro) e nêutrons de $1 \mathrm{MeV}$ (direita). Os gráficos foram feitos à profundidade (z) de $1 \mu \mathrm{m}$ no plano cartesiano xy e correspondem à fluência de $10^{14}$ partículas $/ \mathrm{cm}^{2}$ [79].

A análise da Figura 3.5.2 evidencia que para nêutrons com energia de $1 \mathrm{MeV}$ a distribuição de vacâncias é altamente agrupada (clusters), enquanto que para prótons de $10 \mathrm{MeV}$ a distribuição é praticamente uniforme e pontual (defeitos pontuais); já para prótons de $24 \mathrm{GeV}$ há uma mistura de clusters com uma distribuição de defeitos pontuais. $\mathrm{Na}$ literatura não se encontrou este tipo de simulação para raios gama do ${ }^{60} \mathrm{Co}$, que produzem defeitos pontuais, como os observados para prótons com energia de $10 \mathrm{MeV}$ (Figura 3.5.2 - esquerda), só que com uma concentração de defeitos muito menor.

O dano por deslocamento pode se manifestar de três modos distintos, igualmente importantes e associados aos níveis de energia na estrutura cristalina do material:

- Formação de estados intermediários (próximos à metade da banda proibida) que facilitam a transição dos elétrons das bandas de valência para a de condução. Estes defeitos, se existirem na região de depleção, geram corrente, ou seja, provocam aumento na corrente de fuga. Por outro lado, em junções com polarização direta ou em regiões não depletadas, estes estados intermediários facilitam a recombinação, promovendo a perda de cargas. 
- Formação de estados mais próximos das bandas de valência e condução que facilitam o armadilhamento (trapping) dos portadores de cargas, sendo estes capturados e liberados após algum tempo.

- Alteração das características de dopagem do material (densidade efetiva) e, conseqüentemente, da tensão de depleção da junção, podendo propiciar a ocorrência de um efeito conhecido como inversão de tipo.

\subsubsection{DANO POR IONIZAÇ̃̃o}

Basicamente os detectores de radiação baseados em junções $p$ - $n$ são praticamente insensíveis aos danos causados por ionização, pois as cargas geradas no volume do detector são rapidamente separadas pela presença do campo elétrico na junção e fluem em direção aos eletrodos restabelecendo o equilíbrio [70].

Entretanto, nas estruturas periféricas, como nas camadas de óxido do dispositivo (isolantes), podem surgir problemas de acúmulo de cargas. Nesta região, os elétrons produzidos deslocam-se para o eletrodo positivo enquanto as lacunas acabam sendo armadilhadas próximas à interface óxido-silício, comportando-se como cargas positivas fixas (Figura 3.5.3), alterando assim o campo elétrico no local.

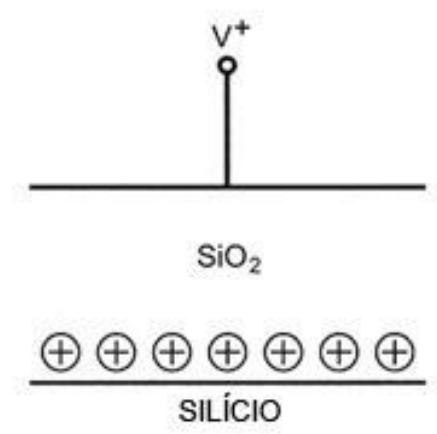

Figura 3.5.3 - Esquema das lacunas armadilhadas no óxido.

A camada de óxido nos diodos é importante no controle das correntes de fuga nas bordas do diodo e também tem papel essencial na isolação dos detectores segmentados. Portanto, o acúmulo de cargas positivas na interface óxido-silício atrai elétrons do volume do detector para a interface, exibindo alta densidade local de elétrons, que forma um canal condutivo, por exemplo, com o eletrodo do detector. 
Estes danos por ionização são mais críticos e manifestam-se predominantemente em MOSFET, pois as cargas acumuladas podem distorcer o campo elétrico na interface óxido-silício alterando o funcionamento do transistor [70].

\subsubsection{DANOS DE RADIAÇÃO EM DIODOS}

Diodos são constituídos por estruturas mais simples do que transistores bipolares ou de efeito de campo ou até mesmo circuitos integrados. As propriedades dos diodos dependem fundamentalmente das características volumétricas e, portanto, os defeitos de deslocamento são os mecanismos importantes de danos neste tipo de dispositivo.

Em sendo assim, as características elétricas que podem interferir na resposta do diodo como dosímetro são principalmente a corrente de fuga e a tensão de depleção que está intimamente relacionada à dopagem efetiva da junção.

Os autores Z. Li, C. J. Li e E. Verbitskaya [12] mostraram que diodos do tipo $\mathrm{Al} / \mathrm{p}^{+} / \mathrm{n} / \mathrm{n}^{+} / \mathrm{Al}$ com resistividade entre $6-10 \mathrm{k} \Omega \cdot \mathrm{cm}$, fabricados pelo método de fusão zonal padrão (STFZ - Standard Float Zone), com área de $0,1 \mathrm{~cm}^{2}$ e espessura de $368 \mu \mathrm{m}$, quando submetidos a altas doses gama $\left({ }^{60} \mathrm{Co}\right)$ apresentavam variação na corrente de fuga (curva IV) e capacitância (curva CV), como é mostrado na Figura 3.5.4.

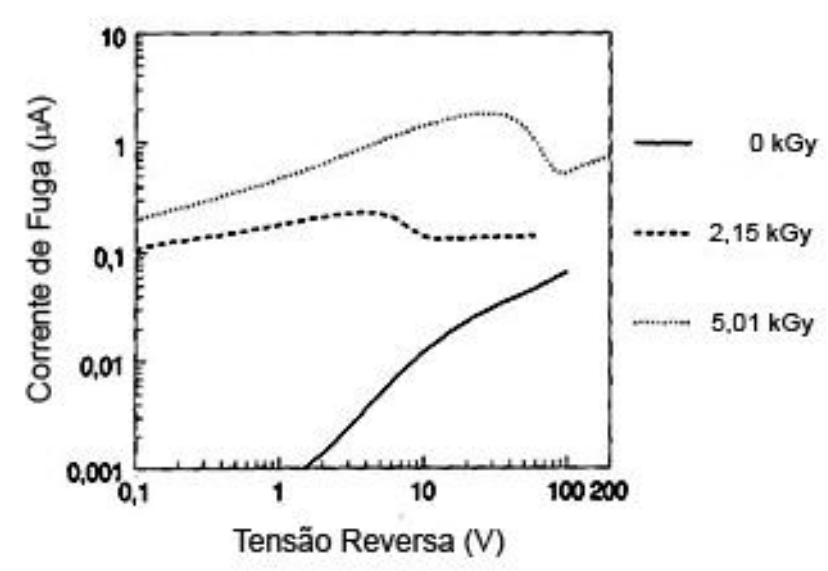

a)

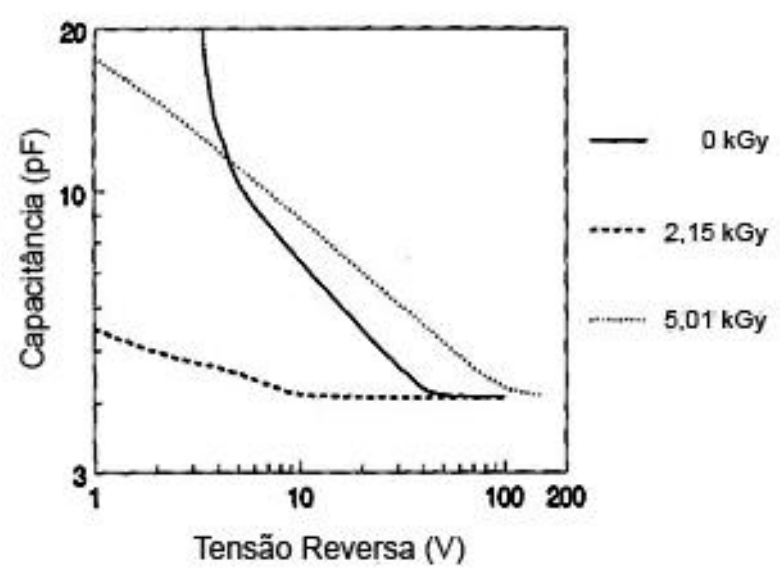

b)

Figura 3.5.4 - Curvas IV (a) e CV (b) dos diodos antes e depois da irradiação gama [12].

A análise da Figura 3.5.4 evidencia que a tensão de depleção do diodo antes de ser irradiado era de $45 \mathrm{~V}$ quando submetido à dose de 2,15 MGy (215 Mrad) ela diminui 
para $10 \mathrm{~V}$ e após a irradiação que totalizou a dose de 5,01 MGy (501 Mrad) ela aumentou para 110 V. Este comportamento de diminuição da tensão de depleção e em seguida um aumento drástico foi observado em amostras que sofreram inversão de tipo quando irradiadas com nêutrons. Portanto, pode-se concluir que estes dispositivos também sofreram inversão de tipo.

Por outro lado, quando se analisa a corrente de fuga (Figura 3.5.4) nota-se que esta aumentou aproximadamente três ordens de grandeza para as irradiações de 2,15 MGy e 5,01 MGy, respectivamente, quando os diodos foram polarizados a baixas tensões. O comportamento das curvas de corrente próximo às tensões de depleção quando irradiados apresentam uma variação abrupta devido ao efeito de inversão de tipo, que transformou a região $\mathrm{p}^{+}$em $\mathrm{n}^{+}$após a irradiação.

Para diodos do tipo $\mathrm{p}^{+} / \mathrm{n} / \mathrm{n}^{+}$com área sensível de $0,25 \mathrm{~cm}^{2}$ e espessura de aproximadamente $295 \mu \mathrm{m}$, E. Fretwurst et al. mostraram que a presença de oxigênio na rede cristalina dos diodos minimiza os efeitos de inversão de tipo até doses de 9 MGy (900 Mrad) com ${ }^{60} \mathrm{Co}$, como se pode observar na Figura 3.5.5 (a) [18].
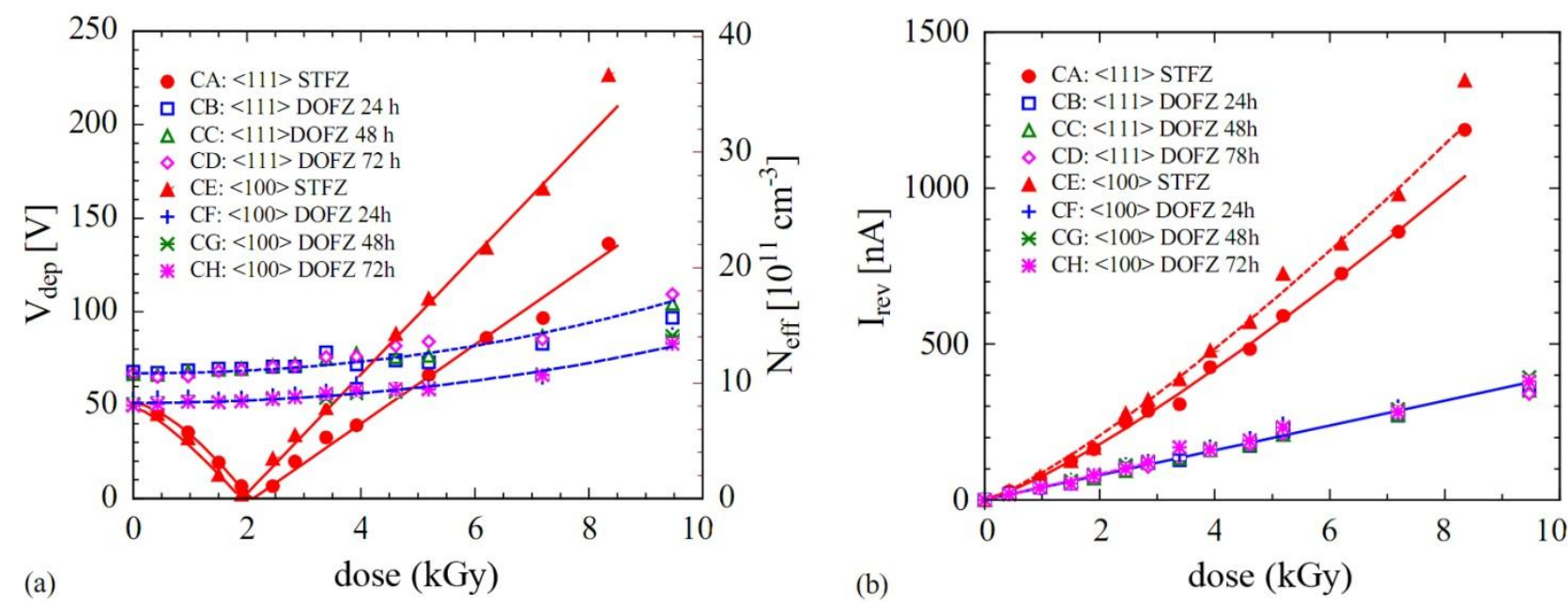

Figura 3.5.5 - Tensão de depleção e corrente de fuga para a tensão de depleção em função da dose para diodos do tipo STFZ e DOFZ [18].

Nota-se na Figura 3.5.5 (a) que para diodos crescidos pelo método convencional de fusão zonal para doses próximas a 2 MGy (200 Mrad) ocorre o fenômeno de inversão de tipo do diodo, sendo que para aqueles que foram fabricados pelo processo de fusão zonal e depois passaram por um processo de difusão de oxigênio, denominados DOFZ 
(Diffusion Oxigenated Float Zone), não sofreram a inversão de tipo, apenas sofrendo pouca variação na concentração efetiva da junção.

A análise da Figura 3.5.5 (b) mostra que a corrente de fuga do diodo na tensão de depleção cresce à medida que a dose absorvida pelo dispositivo aumenta tanto para os diodos STFZ quanto para os DOFZ. Contudo, a variação da corrente de fuga para os diodos enriquecidos com oxigênio (DOFZ) é menor do que os diodos padrão (STFZ). Além disso, as amostras estudadas no referido trabalho possuíam diferentes orientações de rede cristalina, verificando-se o mesmo comportamento para ambas em relação à dose absorvida. Entretanto, para a orientação $<100$, as tensões de depleção são menores do que aquelas para a outra orientação, após os dispositivos sofrerem o processo de difusão de oxigênio.

Para explicar o efeito da inversão de tipo, o aumento da corrente de fuga com a dose e da não inversão para diodos com altas concentrações de oxigênio na estrutura cristalina é necessário que sejam identificados e quantificados os defeitos criados com a irradiação gama do ${ }^{60} \mathrm{Co}$. Este trabalho de identificação e quantificação dos defeitos foi realizado por vários autores e compilado por I. Pintilie [80] (Figura 3.5.6).

I. Pintilie et al. [80,81] mostraram que as alterações elétricas e inversão de tipo sofridas pelos diodos STFZ durante a irradiação com fótons provenientes do ${ }^{60} \mathrm{Co}$ é devida à criação dos estados intermediários na banda de valência do diodo, denominados de níveis $\mathrm{BD}$ (Bistable Donor) e $\mathrm{I}_{\mathrm{p}}$ (via reação $\mathrm{VO}+\mathrm{V} \rightarrow \mathrm{V}_{2} \mathrm{O}$ ). Entretanto, quando se adiciona oxigênio nos diodos estes estados intermediários $I_{p}$ são suprimidos, porque o oxigênio é um excelente sorvedouro para vacâncias (reação $V+O \rightarrow V O$ ), portanto, não mais ocorre o efeito de inversão de tipo.

Fato há que se salientar que todos estes defeitos caracterizados mencionados na Figura 3.5.6 são medidos após a irradiação dos diodos em uma situação estática. No entanto, quando os diodos são usados como detectores de raios gama do ${ }^{60} \mathrm{Co}$ no modo fotovoltaico, o efeito de geração de defeitos ocorre simultaneamente com a geração da fotocorrente. Como estes defeitos são eletricamente ativos, tem-se a recombinação das cargas geradas, o que provoca redução na fotocorrente registrada com a dose acumulada. 
Tabela 3.5.2 - Defeitos pontuais gerados pela irradiação gama com ${ }^{60}$ Co identificados pelos métodos TSC (Thermally Stimulated Currents) e DLTS (Deep Level Transient Spectroscopy), com as respectivas seções de choque de captura $\left(\sigma_{\mathrm{n}}\right.$ e $\left.\sigma_{\mathrm{p}}\right)$, em diferentes detectores fabricados por processos de fusão zonal (STFZ) e fusão zonal com difusão de oxigênio (DOFZ), compilados por I. Pintilie [80].

\begin{tabular}{|c|c|c|c|c|c|}
\hline Nível & $\begin{array}{l}\text { Método de } \\
\text { Detecção }\end{array}$ & $\begin{array}{c}\text { Energia de } \\
\text { Ativação (eV) }\end{array}$ & $\begin{array}{c}\sigma_{\mathrm{n}} / \sigma_{\mathrm{p}} \\
\left(10^{-15} \mathrm{~cm}^{2}\right)\end{array}$ & Material & Observação \\
\hline$H(42 \mathrm{~K})$ & TSC & $+0,084$ & $/ 0,5$ & DOFZ & suprimido à $150^{\circ} \mathrm{C}$ annealing \\
\hline$H(47 \mathrm{~K})$ & TSC & $+0,1$ & $/ 1$ & DOFZ & \\
\hline $1 \mathrm{O}_{2}$ & TSC & $-0,11$ & $2 /$ & DOFZ & suprimido à $150^{\circ} \mathrm{C}$ annealing \\
\hline $\mathrm{VO}^{-10}$ & DLTS, TSC & & & & menos em STFZ \\
\hline$H(87 \mathrm{~K})$ & TSC & $+0,2$ & $/ 2$ & DOFZ & após $150^{\circ} \mathrm{C}$ annealing \\
\hline $\mathrm{I}_{\mathrm{p}}^{+/ 0}, \mathrm{~V}_{2} \mathrm{O}$ & TSC & $+0,225$ & $/ 1$ & STFZ & \\
\hline $\mathrm{BD}(98 \mathrm{~K})$ & TSC & $-0,225$ & $270 /$ & DOFZ & Doadora Biestável \\
\hline $\mathrm{VV}^{=/-}$ & DLTS & & & & \\
\hline $\mathrm{C}_{i} \mathrm{O}_{\mathrm{i}}^{+/ 0}$ & DLTS, TSC & & & & \\
\hline$E(30 \mathrm{~K})$ & TSC & $-0,1$ & $200 /$ & & doadora \\
\hline $\mathrm{VV}^{-10}$ & DLTS, TSC & & & & \\
\hline $\mathrm{I}_{\mathrm{p}} \mathrm{O/-}, \mathrm{V}_{2} \mathrm{O}$ & DLTS, TSC & $+0,545 /+0,58$ & $2 / 90$ & STFZ & suprimido no DOFZ \\
\hline$\Gamma^{-/ 0}$ & DLTS, TSC & $+0,66$ & $0,05 / 5$ & STFZ & suprimido no DOFZ \\
\hline
\end{tabular}

Entretanto, a taxa de geração dos pares elétron-lacuna no silício que é da ordem de $10^{18} \mathrm{~cm}^{-3} \mathrm{kGy} y^{-1}$ é muito superior às taxas de geração de defeitos em diodos de silício medidas por E. Fretwurst [18], que são da ordem de $10^{7} \mathrm{~cm}^{-3} k G y^{-1}$, para diodos do tipo STFZ e DOFZ.

Portanto mesmo nestas condições de geração de defeitos consegue-se empregar os diodos como detectores de altas doses de raios gama, como será descrito e mostrado nos capítulos seguintes desta Tese. 


\section{MATERIAIS E MÉTODOS}

Neste item serão descritos os diodos empregados como detectores de radiação gama para altas doses, bem como a instrumentação empregada na caracterização elétrica das amostras e nas medidas das correntes induzidas pela radiação em função da dose.

\subsection{DiOdos FZ, DOFZ E MCZ}

A aplicação de detectores semicondutores em medidas de altas doses exige que estes dispositivos sejam resistentes a danos de radiação. Atualmente, diodos com estas características vêm sendo estudados pela colaboração RD50 do CERN, visando sua aplicação no grande colisor de hádrons do CERN (LHC), o qual produzirá uma luminosidade da ordem de $10^{35} \mathrm{~cm}^{-2} \cdot \mathrm{s}^{-1}[17]$.

No âmbito da colaboração estabelecida com o Centro de Microeletrônica do Instituto de Física da Universidade Tecnológica de Helsinque (Finlândia), um dos responsáveis pelo desenvolvimento destes dispositivos especiais, foram recebidos três tipos de diodos: um deles crescido pelo método Magnetic Czochralski (MCz) [82-84] e os demais pelo método Float Zone (FZ) padrão e com o aumento da concentração de oxigênio por difusão na pastilha de Si, este último denominado Diffusion Oxygenated Float Zone (DOFZ) [9].

Esses diodos foram fabricados pelo processo de implantação iônica em um substrato do tipo $\mathrm{n}$, formando uma junção $\mathrm{p}^{+} / \mathrm{n} / \mathrm{n}^{+}$com resistividade em torno de $1 \mathrm{k} \Omega \cdot \mathrm{cm}$, espessura de $300 \mu \mathrm{m}$ e área total de $0,36 \mathrm{~cm}^{2}$, possuindo em sua estrutura 17 anéis de guarda. O primeiro anel de guarda possui uma espessura de $100 \mu \mathrm{m}$ e está a $10 \mu \mathrm{m}$ do volume sensível e também do segundo anel de guarda, enquanto que os demais possuem espessura de $16 \mu \mathrm{m}$, espaçados entre si por $24 \mu \mathrm{m}$. As fotografias 
apresentadas nas Figuras 4.1.1 (a e b), obtidas no Laboratório de Microeletrônica da Escola Politécnica da USP (LME/Poli-USP), mostram a estrutura desses diodos evidenciando os anéis de guarda e os pad's (região) de contato dos eletrodos de sinais. No centro da Figura 4.1.1a observa-se um círculo central mais escuro onde não há metalização da face $\mathrm{p}^{+}$, pois esta região é destinada à incidência de laser para estudos de danos de radiação deste dispositivo, pela técnica transiente de corrente (Transient Current Technique - TCT) [85].

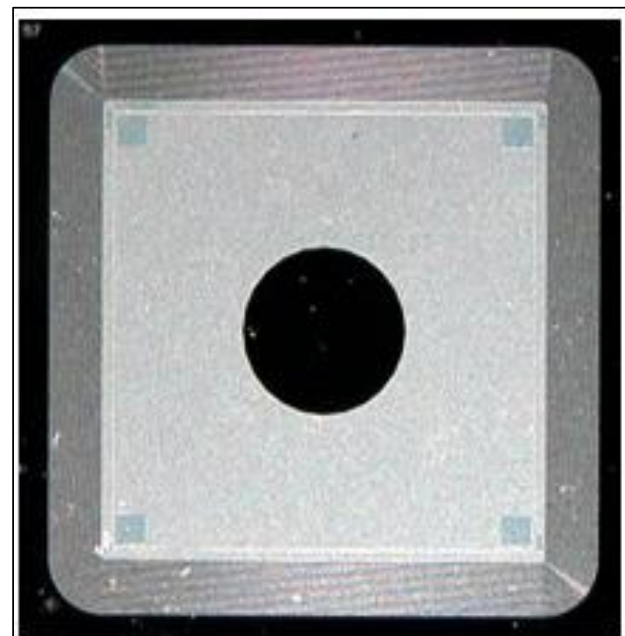

(a)

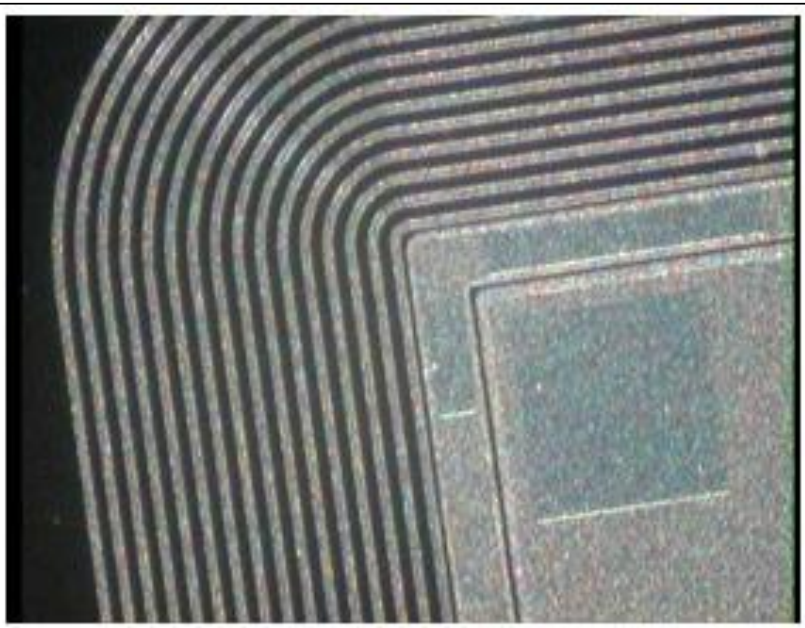

(b)

Figura 4.1.1 - (a) Layout dos diodos especiais. (b) Estrutura dos 17 anéis de guarda e pad's de contato dos eletrodos de sinais. Fotografias obtidas no LME/Poli-USP.

A Tabela 4.1.1 apresenta as principais características dos diodos estudados como área útil, tipo, resistividade $(\rho)$ e concentração de oxigênio $\left(\mathrm{O}_{\mathrm{i}}\right)$.

Tabela 4.1.1 - Características dos diodos.

\begin{tabular}{ccccc}
\hline Diodo & Área Útil $\left(\mathrm{cm}^{2}\right)$ & Tipo & $\rho(\mathbf{k} \Omega \cdot \mathrm{cm})$ & $\mathbf{O}_{\mathbf{i}}\left(\mathbf{c m}^{-3}\right)$ \\
\hline $\mathrm{MCz}$ & 0,25 & $\mathrm{p}^{+} / \mathrm{n} / \mathrm{n}^{+}$ & $\approx 1-1,1$ & $\approx 5 \cdot 10^{17}$ \\
$\mathrm{FZ}$ & 0,25 & $\mathrm{p}^{+} / \mathrm{n} / \mathrm{n}^{+}$ & $\approx 1,4$ & $<1 \cdot 10^{15}$ \\
DOFZ & 0,25 & $\mathrm{p}^{+} / \mathrm{n} / \mathrm{n}^{+}$ & $\approx 1,4$ & $\approx 1 \cdot 10^{17}$ \\
\hline
\end{tabular}

A nomenclatura de cada diodo foi feita de acordo com o posicionamento da amostra na lâmina de silício, como mostra a Figura 4.1.2, que apresenta a posição de cada diodo com os respectivos tipos. 


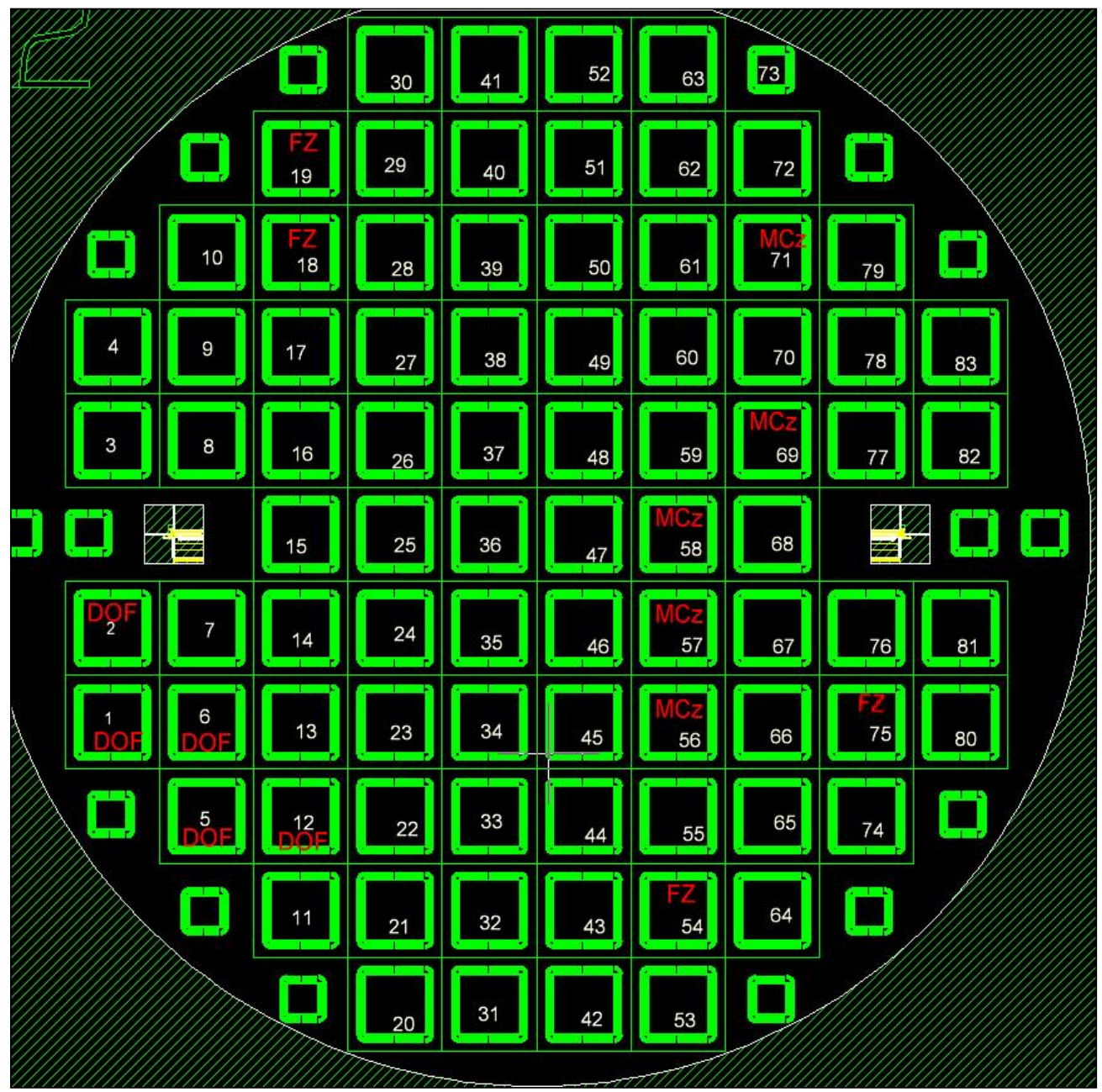

Figura 4.1.2 - Posicionamento dos diodos na lâmina de silício.

Como os dispositivos foram fornecidos sem os terminais elétricos, inicialmente tornou-se necessário montá-los em uma base projetada para permitir a ligação dos eletrodos de polarização e extração de sinais. Esta base foi projetada e construída com o auxílio da equipe do Laboratório de Microeletrônica da Escola Politécnica da USP (LME/Poli-USP), cujo processo será descrito a seguir.

A fabricação da base para montagem dos diodos foi realizada em lâminas de cerâmica (alumina) com constante dielétrica relativa igual a 10 , dimensões de 1 " $\times 1$ " e $0,7 \mathrm{~mm}$ de espessura. Estas lâminas passaram por um processo químico de limpeza (tricloro, acetona e álcool isopropanol) e em seguida, foram metalizadas pelo processo de sputtering para a formação de um filme fino de níquel cromo para aderência da fina camada de ouro (2 a $3 \mu \mathrm{m}$ ) eletrodepositada (Figura 4.1.3a). 
Para a confecção da configuração (layout) de montagem do diodo, aplicou-se fotoresiste sobre a lâmina submetendo-a ao processo de fotogravação empregando o fotolito apresentado na Figura 4.1.3b. Posteriormente, as lâminas foram corroídas quimicamente (retirando toda metalização onde a luz incidiu), limpas e cortadas, formando a base para montagem dos diodos (Figura 4.1.3c).

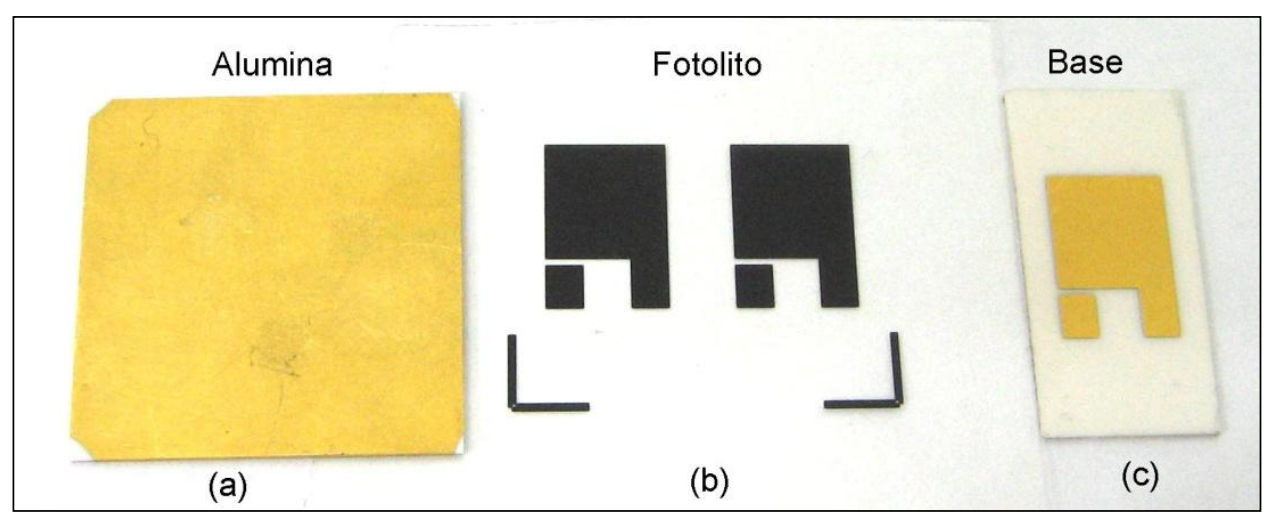

Figura 4.1.3 - (a) Lâmina de alumina com camada de ouro, (b) fotolito com layout e (c) base para montagem dos diodos.

Os diodos foram fixados sobre essas bases de alumina (Figura 4.1.3c) empregando-se adesivo condutor para que o backplane (face $\mathrm{n}^{+}$) do diodo pudesse ser polarizado. A extração do sinal foi feita por meio de um eletrodo soldado na face $\mathrm{p}^{+}$. As fotografias dos diodos FZ, DOFZ e MCz montados na base de alumina são mostradas na Figura 4.1.4.

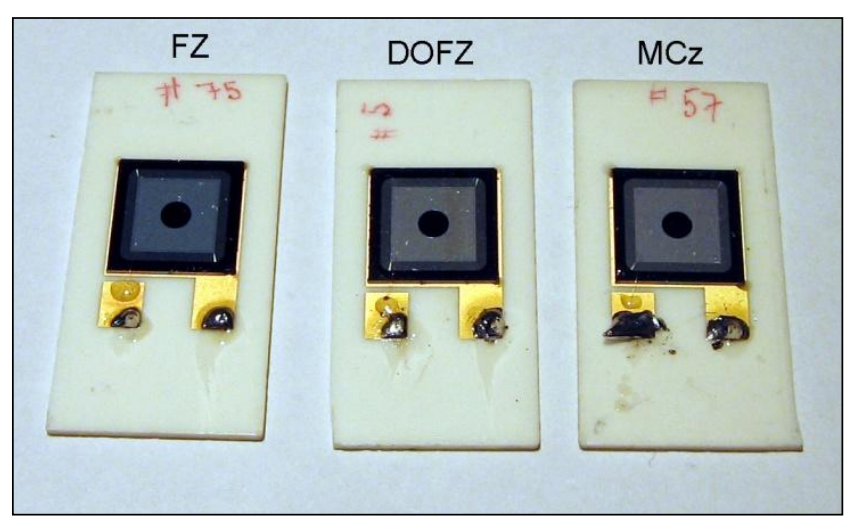

Figura 4.1.4 - Diodos montados na base de alumina. 


\subsection{CARACTERIZAÇÃo ElÉtrica}

As curvas de corrente e capacitância em função da tensão de polarização reversa, curvas IV e CV, respectivamente, foram realizadas utilizando o circuito [86] mostrado na Figura 4.2.1, composto pelo amplificador operacional (OPA656U) [87] com várias resistências de realimentação permitindo ter diferentes ganhos de amplificação.

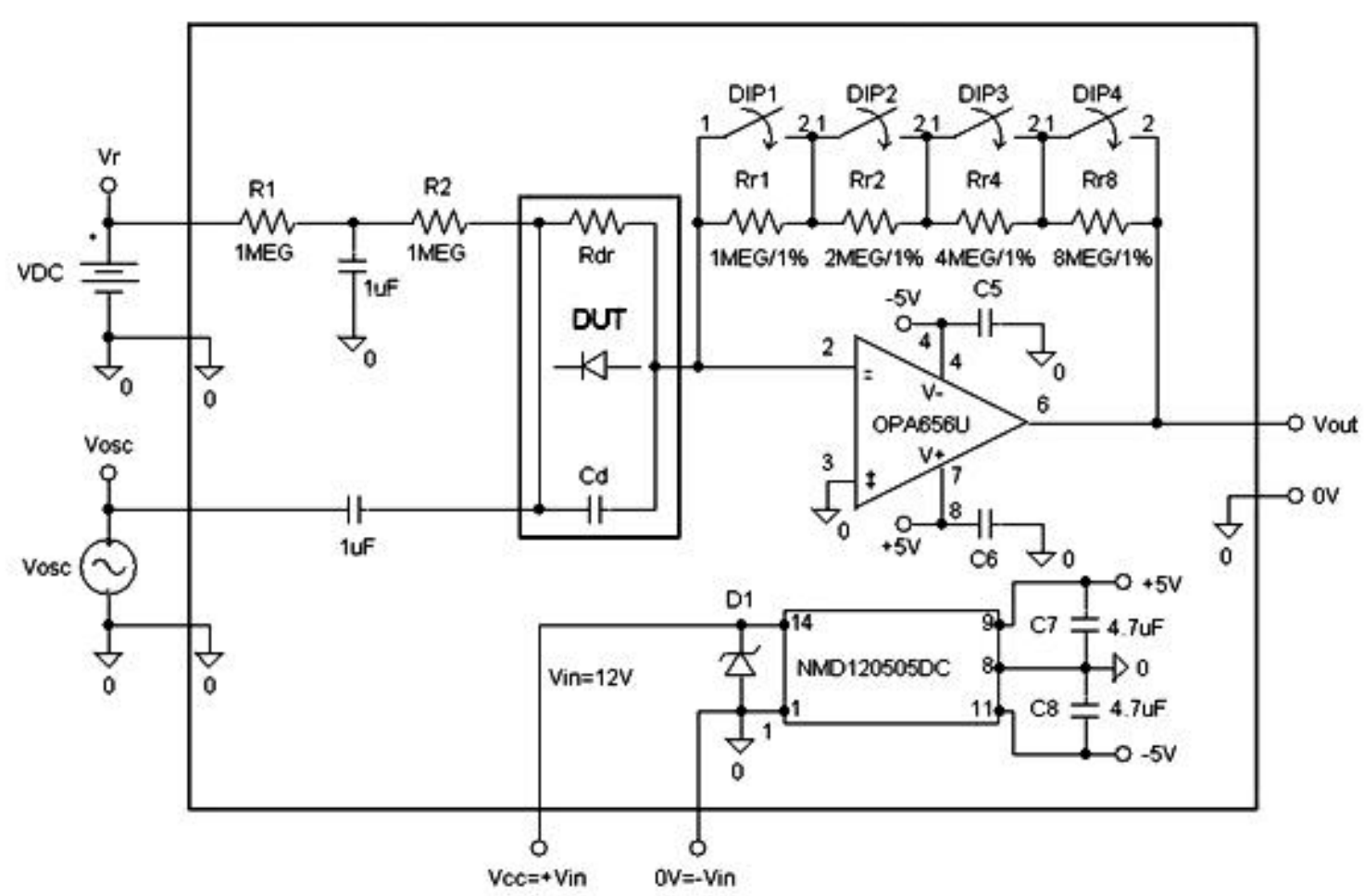

Figura 4.2.1 - Esquema do circuito empregado nas caracterizações elétricas dos diodos.

O circuito eletrônico (Figura 4.2.1) foi montado em uma placa de circuito impresso, fixada dentro de uma caixa metálica de alumínio com porta basculante, pintada de preto, com o objetivo de bloquear a entrada de luz. Na placa de circuito impresso foi instalado um porta-amostra de acrílico construído para colocar os diodos na base de cerâmica (Figura 4.1.4). As fotos das vistas frontal e traseira deste sistema, que a partir de agora será denominado de medidor IV-CV, estão apresentadas na Figura 4.2.2.

Para realizar a caracterização elétrica dos diodos foram utilizados o gerador de funções Minipa MFG-4220, a fonte de tensão Ortec 659, o osciloscópio Tektronix TDS3034B e o multímetro Keithley 2000 (Figura 4.2.3). A descrição de como cada instrumento foi empregado será feita a seguir nos itens 4.2.1 e 4.2.2. 


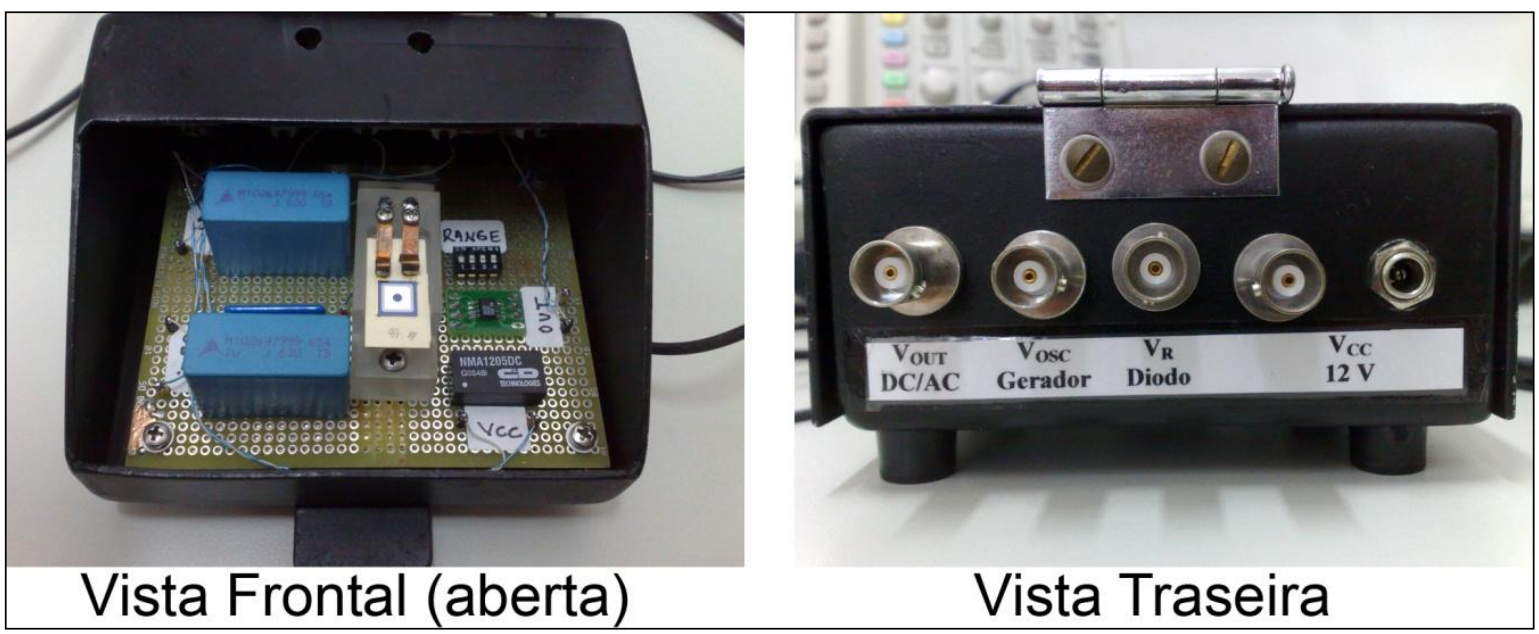

Figura 4.2.2 - Medidor IV-CV, utilizado na caracterização elétrica das amostras.

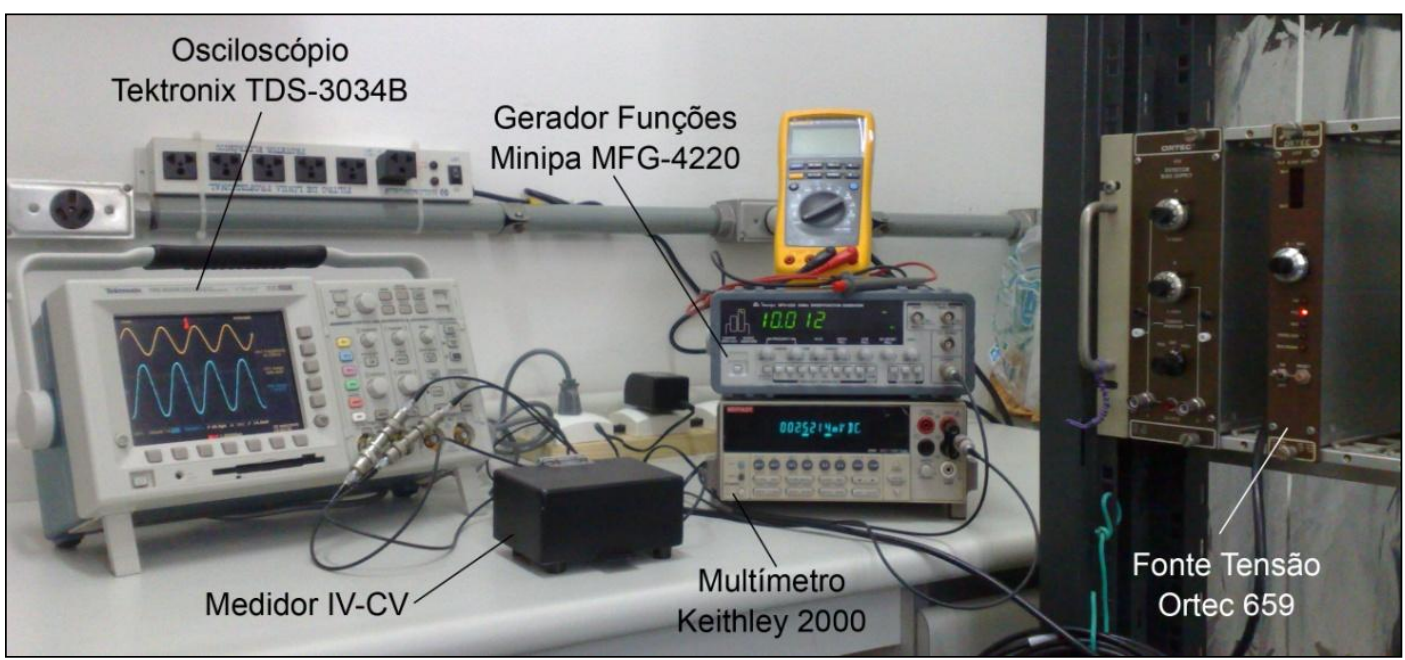

Figura 4.2.3 - Instrumentos utilizados na caracterização elétrica dos diodos.

As caracterizações elétricas foram feitas seguindo as recomendações do grupo de trabalho RD 50 do CERN [88], que sugere a realização das medidas com a tensão de polarização reversa em modo decrescente. Portanto, o procedimento empregado na caracterização elétrica consistiu na aplicação da tensão de polarização nas amostras até o valor máximo desejado, por meio da fonte Ortec 659. As componentes de tensão amplificadas AC e DC foram obtidas a cada 1 minuto, empregando o osciloscópio Tektronix TDS-3034B e o multímetro Keithley 2000, respectivamente, ambos ajustados para fornecer a média de 16 medidas. 


\subsubsection{CuRva IV}

Como a impedância de entrada do amplificador operacional $\left(Z_{a m p}\right)$ OPA656U é da ordem de $10^{12} \Omega$ [87] e a máxima resistência de realimentação do circuito amplificador é $15 \mathrm{M} \Omega$, cerca $10^{5}$ ordens de grandeza menor, a corrente que flui no amplificador passará quase que integralmente pela resistência de realimentação. Desta forma, pode-se determinar a corrente de fuga $\left(I_{f u g a}\right)$ do diodo aplicando-se a Lei de Ohm, considerando a resistência de realimentação $\left(R_{r}\right)$ ajustada durante a medida, conforme a equação:

$$
V_{D C}=R_{r} \cdot I_{f u g a} \cdot
$$

A curva IV do diodo foi construída medindo-se a componente DC da tensão do sinal amplificado $\left(V_{D C}\right)$ pelo amplificador operacional (Figura 4.2.1) com o multímetro para cada uma das tensões aplicadas ao diodo.

\subsubsection{Curva CV}

O método de obtenção da curva CV baseia-se na amplificação AC de um sinal externo, proveniente de um gerador de função. A análise do circuito (Figura 4.2.1.) mostra que o ganho do amplificador $(G)$ é função da reatância capacitiva do circuito $\left(X_{C}\right)$, de forma que a injeção de um sinal senoidal de freqüência $f$ e amplitude $V_{\text {in }}$ resultará em um sinal de saída com amplitude $V_{A C}$ que contêm informações sobre a capacitância do diodo. De fato, como o ganho do amplificador é dado pela razão entre a resistência de realimentação negativa $\left(R_{r}\right)$ e a reatância do circuito $\left(X_{C}\right)$ que corresponde às amplitudes dos sinais de saída e de entrada, tem-se a seguinte equação:

$$
|G|=\frac{R_{r}}{X_{C}}=\left|\frac{V_{A C}}{V_{\text {in }}}\right|=2 \pi f C_{d} R_{r}
$$

É importante salientar que o ganho do amplificador também é afetado pela resistência do diodo $\left(R_{d} \approx 100 \Omega\right)$, mas como a reatância capacitiva $\left(X_{C} \approx 1 \mathrm{M} \Omega\right.$ ) é bem maior que o valor de $R_{d}$, este foi desconsiderado neste trabalho. Entretanto, em caso de considerar a resistência do diodo, esta deve ser associada em paralelo com a reatância capacitiva e alterada a equação do ganho. 
Portanto, desprezando-se a resistência do diodo nos cálculos, tem-se que a capacitância $\left(C_{d}\right)$ será:

$$
C_{d}=\left|\frac{V_{A C}}{V_{\text {in }}}\right| \times \frac{1}{2 \pi f R_{r}}
$$

Para a determinação da curva CV introduziram-se na entrada do circuito sinais com aproximadamente $200 \mathrm{mV}$ de amplitude e $10 \mathrm{kHz}$ de freqüência provenientes do gerador de funções da Minipa MFG-4220. Com o auxílio do osciloscópio, foram medidos os sinais amplificados de saída $\left(V_{A C}\right)$ do circuito para cada tensão de polarização do diodo.

\subsection{SONDA DOSIMÉTRICA}

Após a montagem dos diodos nas bases de cerâmica, para polarização e extração de sinal, foi necessário construir uma sonda acrílica na cor preta para acomodar cada diodo, protegendo-o da luz ambiente, diminuindo o espalhamento da radiação na sua resposta e atribuindo-Ihe resistência mecânica para fácil manuseio visando aplicá-lo na dosimetria de raios gama em processos industriais. Esta sonda foi confeccionada com um conector do tipo $\operatorname{LEMO}^{\circledast}$ de engate rápido, permitindo que esta ficasse independente do cabo de ligação, evitando assim que a vibração sofrida pelo cabo fosse transmitida para o diodo e, eventualmente, rompesse as microsoldas dos eletrodos. Além disso, após a montagem do diodo, cobriu-se a sonda com uma fita plástica preta com 0,15 mm de espessura para uma melhor vedação contra luz. A Figura 4.3.1 apresenta as fotografias da sonda que será empregada nas medidas de dose.

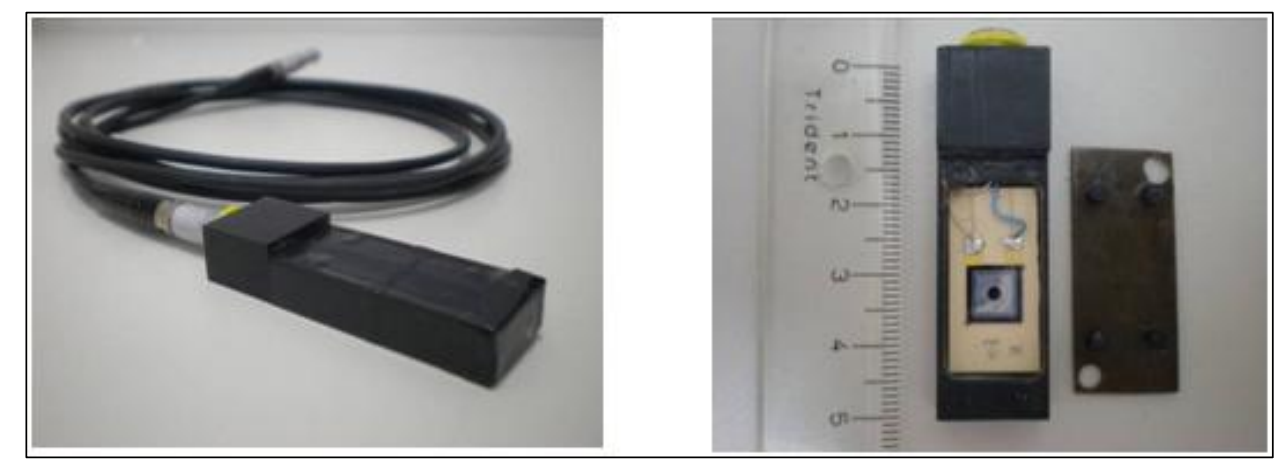

Figura 4.3.1 - Fotografias da sonda dosimétrica. 


\subsection{DOSIMETRIA}

\subsubsection{IRRADIADOR GAMMACELL 220}

$\mathrm{O}$ sistema de irradiação utilizado nas medidas foi o irradiador gama de ${ }^{60} \mathrm{Co}$, Gammacell 220, da Nordion, que possui uma câmara de irradiação com capacidade útil de 3,6 I e apresenta formato cilíndrico com 27 lápis constituídos individualmente por 7 pastilhas de ${ }^{60} \mathrm{Co}$ (Figura 4.4.1a). A taxa de dose no centro da câmara, de 3,97 kGy/h, foi determinada empregando dosímetros de alanina em 01/11/2004, segundo o programa de certificação da Agência Internacional de Energia Atômica (IDAS-IAEA), com uma incerteza de 1,7\%. Portanto, para cada medida foi necessário realizar a correção da taxa de dose pelo fator de decaimento da fonte, uma vez que o irradiador foi certificado em data diferente daquela em que se realizou a medida.

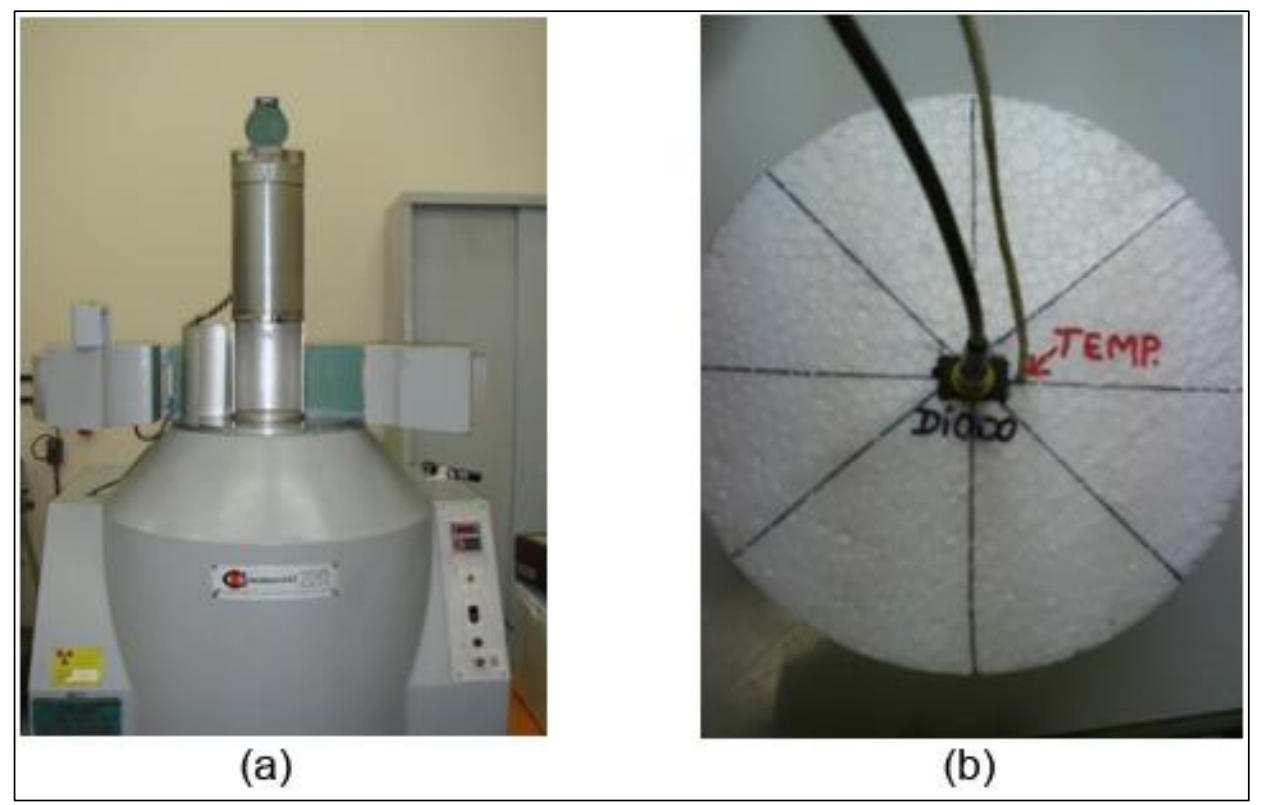

Figura 4.4.1 - Fotografias (a) do irradiador Gammacell 220 - Nordion e (b) do cilindro de isopor com a sonda dosimétrica e o termopar do tipo $\mathrm{K}$.

A sonda dosimétrica foi montada na posição central do interior de um cilindro de isopor (Figura 4.4.1b) com dimensões um pouco menores do que a câmara de irradiação, a uma altura de $10 \mathrm{~cm}$ da base da câmara de irradiação até o centro do diodo, para garantir que ela ficasse posicionada onde a taxa de dose é constante. Ao lado da sonda dosimétrica foi colocado um termopar do tipo $\mathrm{K}$, para monitorar a temperatura durante todo o processo de irradiação. 


\subsubsection{IRRADIADOR PANORÂMICO}

Para algumas medidas (Apêndice A) foi empregado o irradiador gama Panorâmico, cuja fonte de ${ }^{60} \mathrm{Co}$ (um único lápis) é içada por um cabo de aço dentro de um cilindro de aço inoxidável a uma determinada altura, ajustável pelo controlador, irradiando em todas as direções. Este cilindro fica localizado no centro de uma mesa que permite o posicionamento de produtos ou materiais a serem irradiados (Figura 4.4.2).

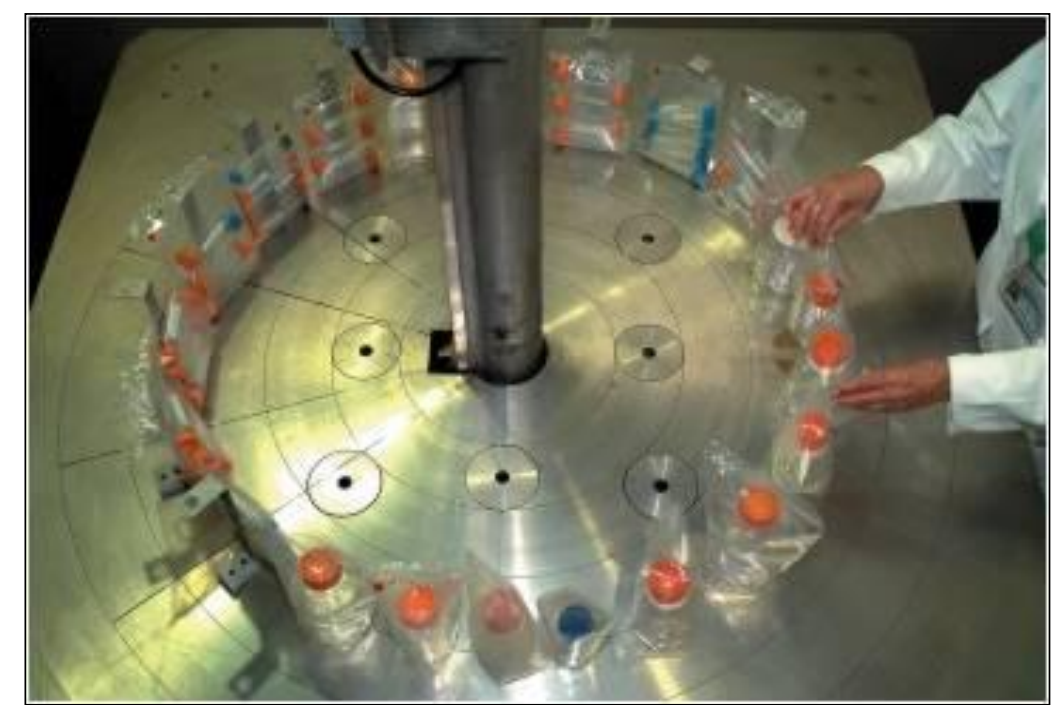

Figura 4.4.2 - Fotografia do irradiador Panorâmico do Laboratório de Fontes Intensas de Radiação do CTR.

As taxas de dose para as diferentes posições da mesa (Tabela 4.4.1) foram calibradas utilizando dosímetros de alanina em 01/11/2004, segundo o programa de certificação da Agência Internacional de Energia Atômica (IDAS-IAEA), com uma incerteza de 1,7\%. Do mesmo modo que para o irradiador anterior foi necessário a correção da taxa de dose pelo decaimento da fonte quando da utilização deste equipamento.

Tabela 4.4.1 - Taxas de dose para as diferentes distâncias do irradiador Panorâmico de ${ }^{60} \mathrm{Co}$, calibradas e certificadas pelo IDAS-IAEA em 01/11/2004.

\begin{tabular}{cc}
\hline Distância (cm) & $\dot{\boldsymbol{D}}\left(\frac{\boldsymbol{k} \boldsymbol{G} \boldsymbol{y}}{\boldsymbol{h}}\right)$ \\
\hline 10 & 0,3575 \\
20 & 0,1430 \\
40 & 0,0499 \\
\hline
\end{tabular}




\subsubsection{MEDIDA DA FotocoRRENTE INDUZIDA}

As fotocorrentes induzidas no diodo pela radiação gama foram medidas com a sonda dosimétrica acoplada diretamente ao multímetro Fluke 189, no modo fotovoltaico, por meio de um cabo coaxial com impedância nominal de $50 \Omega$ da marca LEMO ${ }^{\circledR}$.

O sistema de aquisição de dados (FlukeView Forms ${ }^{\circledR}$ ), acoplado ao multímetro, permitiu registrar o valor da fotocorrente gerada durante todo o tempo de exposição e, posteriormente, obter a carga média associada a cada dose fazendo a integração da curva da fotocorrente em função do tempo (Figura 4.4.3a). Este procedimento tornou possível a observação on-line da estabilidade do processo de irradiação, uma vez que a fotocorrente está diretamente relacionada à taxa de dose, bem como a influência das taxas devidas ao deslocamento das fontes de ${ }^{60} \mathrm{Co}$ (dose de trânsito).

A Figura 4.4.3b mostra a fotografia dos equipamentos empregados na obtenção das fotocorrentes em função do tempo.

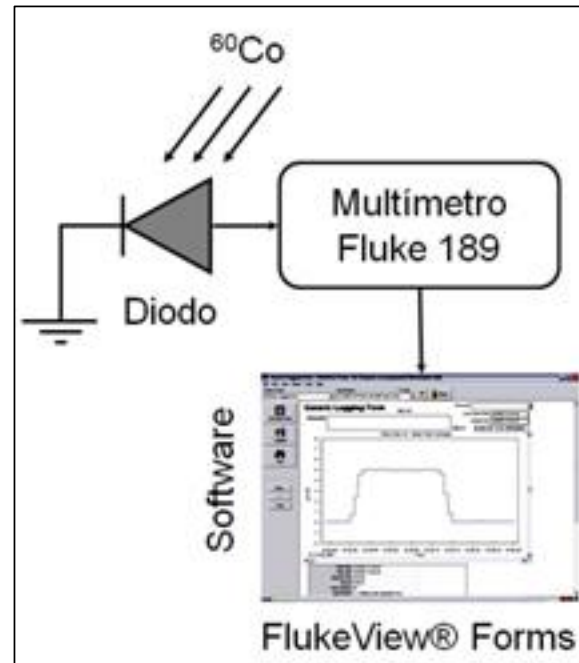

(a)

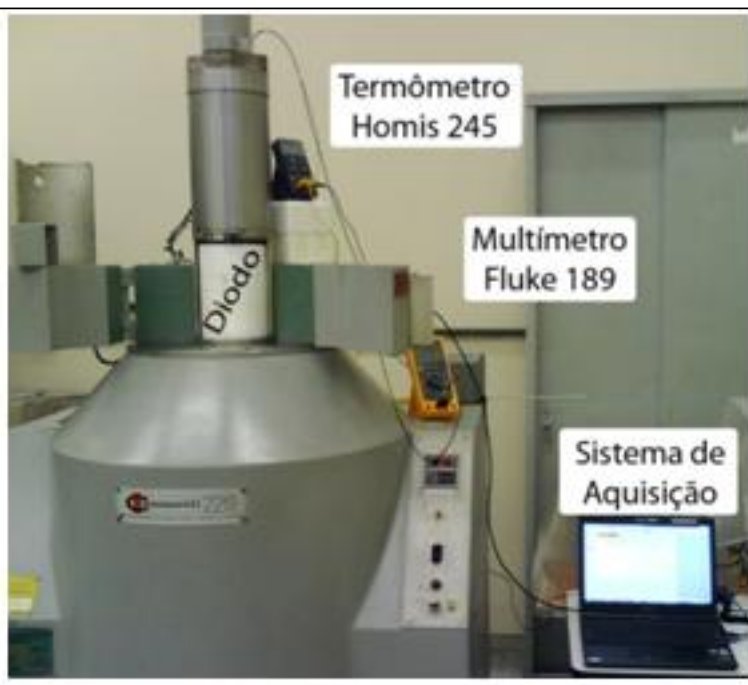

(b)

Figura 4.4.3 - Desenho esquemático do sistema de medidas (a) e fotografia dos equipamentos empregados na obtenção das fotocorrentes (b).

\subsubsection{CuRva ReSPosta}

Cada amostra em análise foi submetida a doses de 5 até 50 kGy, em intervalos de $5 \mathrm{kGy}$, de maneira consecutiva, obtendo para cada dose a fotocorrente gerada em função do tempo de exposição à fonte. É importante salientar que cada dose foi medida 
individualmente e não acumulada para obtenção da dose máxima de 50 kGy. Desta maneira, a dose total absorvida para determinar a curva de resposta de cada amostra foi de 275 kGy.

As curvas resposta de cada diodo, representadas pela carga média depositada durante todo o processo de exposição do diodo em função da dose, foram obtidas a partir da integração dos sinais das fotocorrentes medidas em função do tempo de irradiação para cada dose desejada.

\subsection{DETERMINAÇÃO DAS INCERTEZAS NAS MEDIDAS}

É importante mencionar que todas as medidas realizadas neste trabalho foram determinadas com as respectivas incertezas padrão combinada, sendo esta igual à raiz quadrada positiva da soma quadrática das incertezas padrão do tipo A (estatísticas) e do tipo B (não estatísticas), segundo recomendações do Guia para a Expressão da Incerteza de Medição [89]. 


\section{RESULTADOS EXPERIMENTAIS E ANÁLISES}

Para a definição dos parâmetros de irradiação e as condições de tratamento dos diodos realizou-se um estudo preliminar da resposta do dispositivo MCz\#57 como dosímetro de radiação gama. A partir dos resultados obtidos (Apêndice A), foram definidos o intervalo de fotocorrentes para as diferentes taxas de dose empregadas e as condições de pré-irradiação das amostras.

Na Tabela 5.1 são apresentados os seis dispositivos dos tipos FZ, DOFZ e MCZ estudados. Para identificação dos diodos, a partir de agora, a nomenclatura empregada nas legendas dos gráficos será a indicada na referida tabela.

Tabela 5.1 - Condições de pré-irradiação e taxas de doses empregadas no estudo das amostras.

\begin{tabular}{cccc}
\hline Pré-irradiação & Nomenclatura & Amostras & $\dot{\mathbf{D}}(\mathbf{k G y} / \mathbf{h})$ \\
\hline \multirow{2}{*}{ Nenhuma } & Original & DOFZ\#2 & $2,52 \pm 0,04$ \\
& & MCZ\#56 & $2,39 \pm 0,04$ \\
& & FZ\#54 & $2,33 \pm 0,04$ \\
\hline \multirow{2}{*}{$700 \mathrm{kGy}$} & Pré-Dose & MOFZ\#6 & $2,49 \pm 0,04$ \\
& & FZ\#69 & $2,44 \pm 0,04$ \\
& & & $2,31 \pm 0,04$ \\
\hline
\end{tabular}

\subsection{DANOS DE RADIAÇÃo - CARACTERIZAÇÃo ElÉTRICA}

A caracterização elétrica dos diodos foi realizada antes e depois da construção das suas curvas resposta como detectores de radiação para altas doses. Contudo, para os diodos pré-irradiados as curvas IV e CV também foram construídas individualmente para 
cada intervalo de dose absorvida precedendo o estudo da resposta dosimétrica de cada amostra.

O dispositivo FZ\#54 não foi caracterizado eletricamente por apresentar ruído eletrônico elevado e gerar instabilidade no medidor IV\&CV. Entretanto, segundo informações do fabricante, a corrente de fuga deste dispositivo era da ordem de $8 \mathrm{nA}$ quando operado sob a tensão de depleção total $(\approx 220 \mathrm{~V})$ e, portanto, no mínimo 3 ordens de grandeza menor do que as fotocorrentes geradas quando expostas à fonte de ${ }^{60}$ Co do irradiador Gammacell. Diante do exposto, o diodo foi empregado normalmente como dosímetro sem nenhum prejuízo a sua resposta.

\subsubsection{CoRrente DE FugA}

Como a corrente de fuga depende da temperatura e as medidas de caracterização IV foram realizadas em condições de temperatura diferentes, foi necessário corrigi-las para a temperatura de referência $\left(20^{\circ} \mathrm{C}\right)$, empregando a Equação 5.1.1 [70,90]:

$$
I_{f u g a}\left(T_{r e f}\right)=\left(\frac{T_{r e f}}{T_{K}}\right) \exp \left[-\frac{E_{g}}{2 k}\left(\frac{1}{T_{r e f}}-\frac{1}{T_{K}}\right)\right] I_{f u g a}\left(T_{K}\right)
$$

onde $T_{r e f}$ e $T_{K}$ são as temperaturas de referência e da medida expressas em Kelvin, $E_{g}$ é a energia da banda proibida do silício e $k$ é a constante de Boltzmann.

As Figuras 5.1.1 e 5.1.2 mostram as correntes de fuga em função da tensão de polarização reversa para os diodos pré-irradiados com diferentes doses absorvidas. Para comparação, também são apresentadas as medidas dinâmicas de correntes para os respectivos diodos originais (sem irradiação prévia). As incertezas nas medidas de corrente de fuga são de 1 \% e não foram representadas nos gráficos por serem menores do que as dimensões dos pontos. 

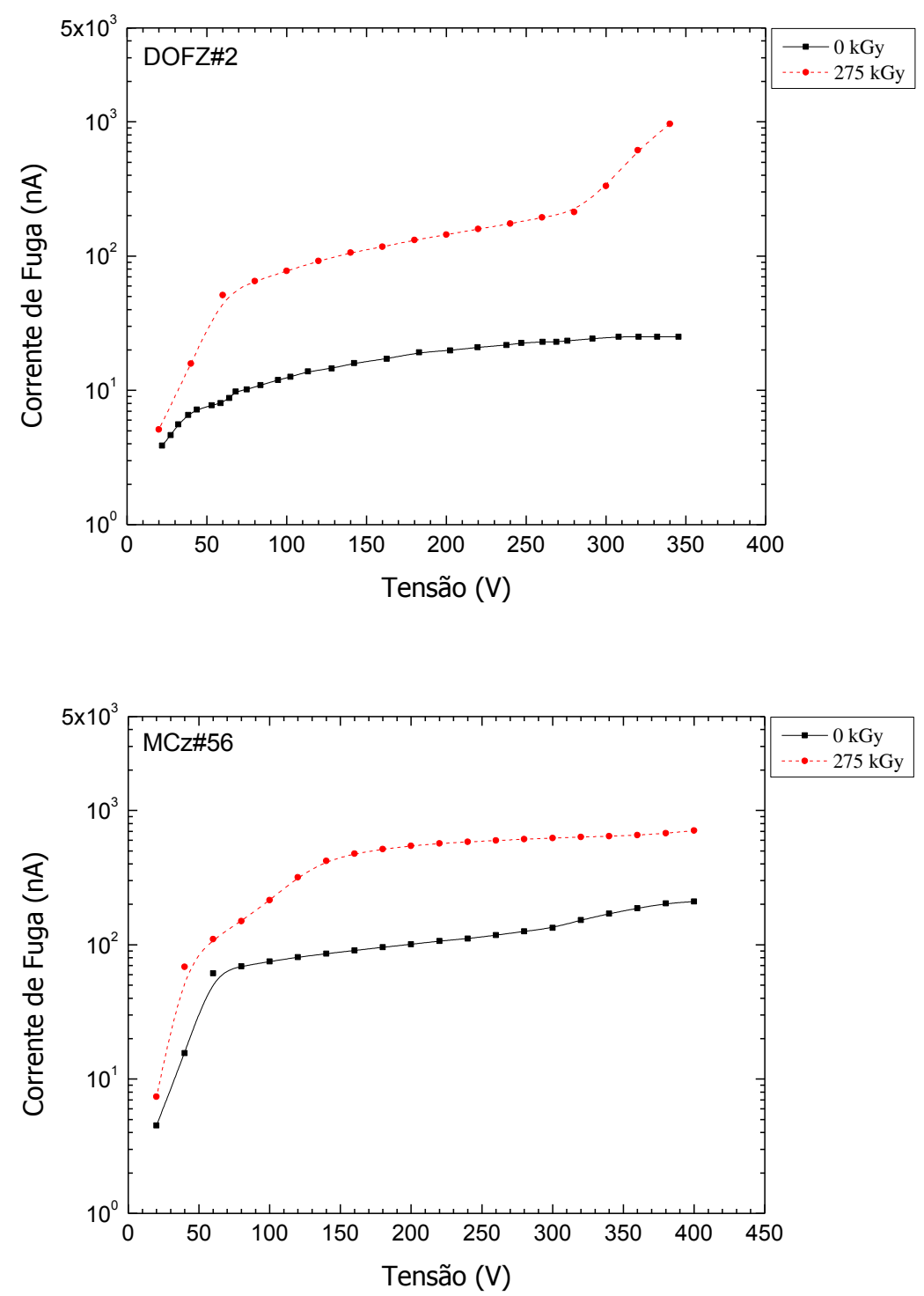

Figura 5.1.1 - Curvas IV dos diodos originais: DOFZ\#2 e MCZ\#56.

A Figura 5.1.1 evidencia que as correntes de fuga dos diodos DOFZ\#2 e MCZ\#56 aumentam após a absorção da dose de 275 kGy. Este fato era esperado uma vez que a radiação gama gera defeitos pontuais na estrutura do material responsáveis pelo acréscimo na corrente. 

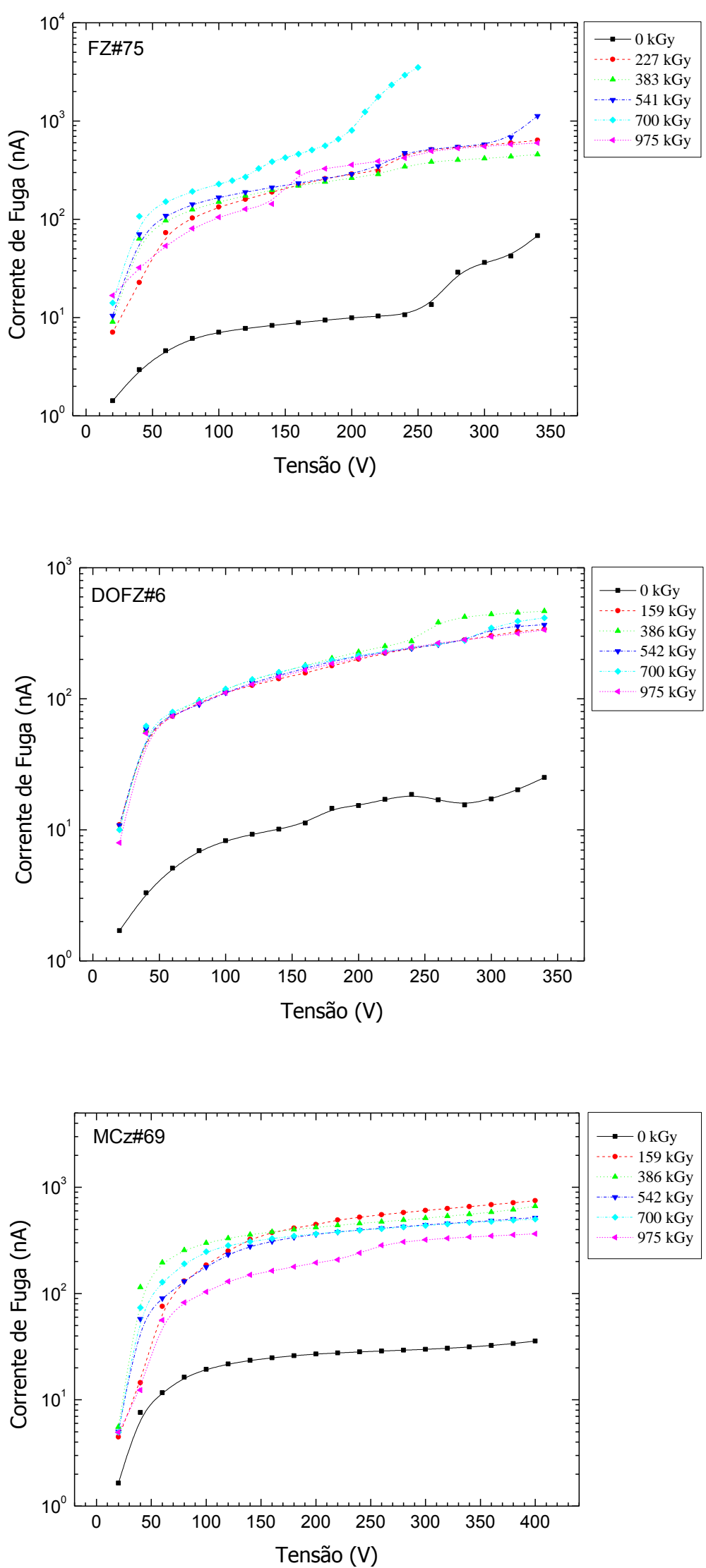

Figura 5.1.2 - Curvas IV dos diodos pré-irradiados: FZ\#75, DOFZ\#6 e MCz\#69. 
A análise dos dados da Figura 5.1.2 evidencia que, independentemente do tipo de diodo, a corrente de fuga aumenta com a dose absorvida. Vale notar que acima de 975 kGy, as correntes de fuga do dispositivo FZ\#75 são superiores àquelas das amostras DOFZ e MCz, o que indica menor resistência a danos de radiação dos diodos produzidos pela técnica de fusão zonal padrão.

Apesar do aumento das correntes de fuga com a dose total absorvida, nota-se que na situação de menor tensão de polarização estudada (20 V) a máxima corrente observada foi de $15 \mathrm{nA}$ para o diodo FZ\#75, sendo este valor no mínimo mil vezes menor do que as fotocorrentes medidas (ordem de $\mu \mathrm{A}$ ), como será mostrado no item 5.2.1.

Entretanto, como neste trabalho o diodo não é polarizado, as correntes de fuga são ainda menores do que as medidas a $20 \mathrm{~V}$ e, portanto, desprezíveis em relação às fotocorrentes medidas mesmo após doses absorvidas de 1 MGy.

\subsubsection{CAPACITÂNCIA}

As curvas CV que mostram as medidas da capacitância de diodos em função da tensão de polarização reversa desempenham um papel importante na caracterização elétrica destes dispositivos. Neste trabalho, as curvas CV também serão utilizadas para determinar as tensões de depleção dos diodos e avaliação dos possíveis danos neles produzidos pela radiação.

As Figuras 5.1.3 e 5.1.4 apresentam as curvas CV obtidas para os diodos originais e pré-irradiados com as respectivas incertezas ( $\cong 6 \%$ ) nas medidas.

Como esperado, em todas as curvas CV observa-se que a capacitância reduz com o aumento da tensão de polarização reversa em conseqüência do crescimento da zona de depleção do diodo. Idealmente, este crescimento é limitado pela espessura da pastilha de Si e quando este limite é atingido mesmo com o aumento da tensão a capacitância permanece constante. Nesta condição o diodo está totalmente depletado e a tensão mínima necessária para que isto ocorra é denominada tensão de depleção total. 

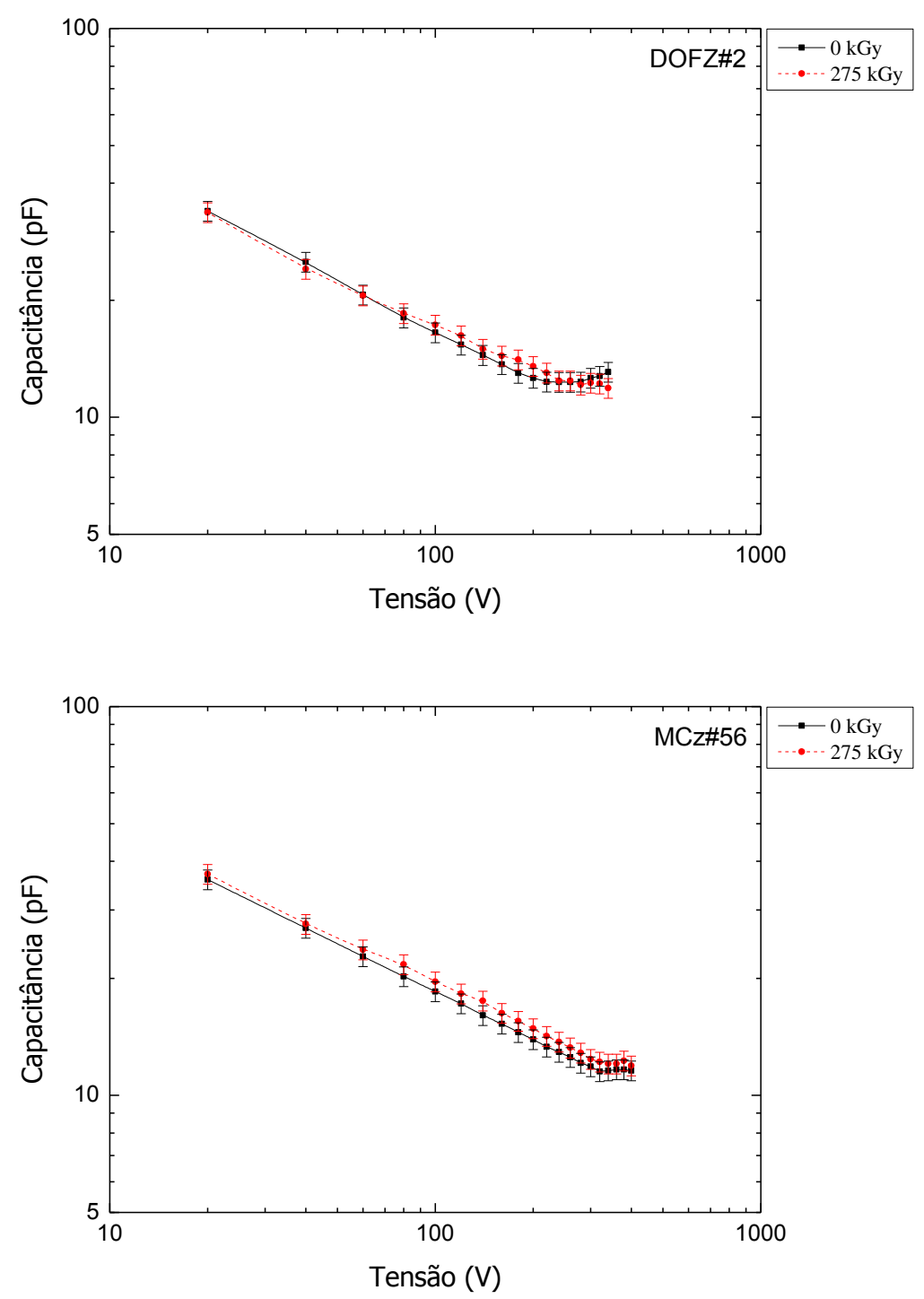

Figura 5.1.3 - Curvas CV dos diodos originais: DOFZ\#2 e MCZ\#56.

As medidas da capacitância em função da dose absorvida para os diodos estudados estão representadas nas Figuras 5.1.3 e 5.1.4. De uma forma geral, os resultados evidenciam que, para o intervalo de dose investigado, as variações das capacitâncias em função da dose absorvida são desprezíveis em uma análise estatística com nível de confiança de três desvios padrão.

As Figuras 5.1.3 e 5.1.4 também indicam que as tensões de depleção total dos diodos não se alteraram com o aumento da dose total absorvida. No entanto, para verificar este comportamento, decidiu-se construir gráficos da tensão de depleção em função da dose total absorvida para cada tipo de amostra estudada e estes resultados serão apresentados no item seguinte. 

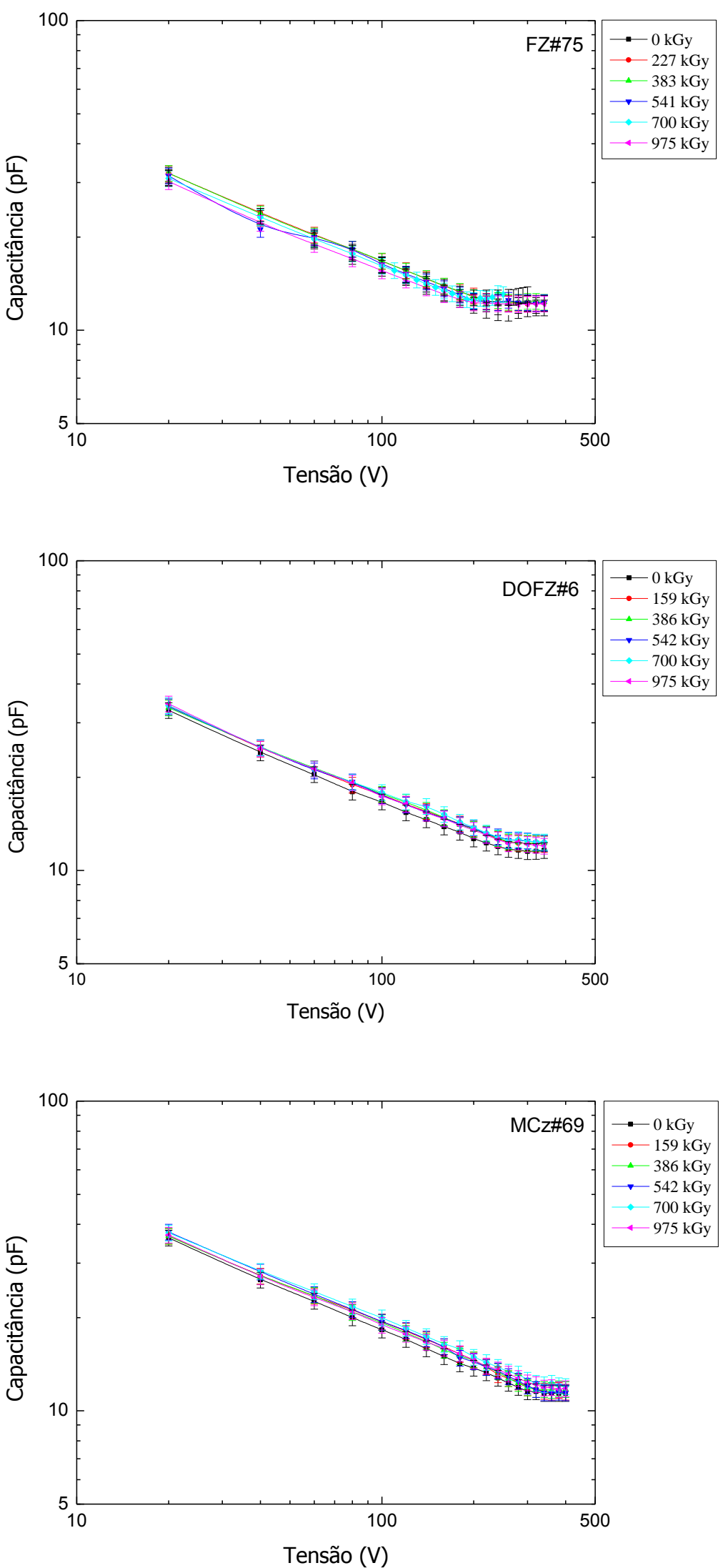

Figura 5.1.4 - Curvas CV dos diodos pré-irradiados: FZ\#75, DOFZ\#6 e MCz\#69. 


\subsubsection{TENSÃo DE DEPLEÇÃo}

A determinação da tensão de depleção total $\left(V_{d}\right)$ dos dispositivos foi feita utilizando a metodologia sugerida pela colaboração RD50 do CERN [88]. Por este método, o valor de $V_{d}$ corresponde ao ponto de intersecção das duas retas traçadas nas regiões de saturação e decréscimo da capacitância com a tensão nas curvas CV.

A tensão de depleção é uma grandeza importante no estudo de danos de radiação, pois possui uma relação direta com a concentração efetiva de portadores na junção $\left(N_{e f}\right)$, como mostra a Equação $5.1 .2[69,70,90]$ :

$$
N_{e f}=N_{D}-N_{A}=\frac{2 \varepsilon_{S i}}{q d^{2}} V_{d}
$$

onde $N_{D}$ e $N_{A}$ são as concentrações de doadores e aceitadores na junção, $\varepsilon_{S i}$ é a permissividade elétrica do silício, $q$ é a carga elementar do elétron e $d$ é a espessura da zona de depleção dos diodos.

A partir da análise das Figuras 5.1.3 e 5.1.4 construíram-se as curvas da tensão de depleção e da respectiva concentração efetiva da junção em função da dose total absorvida para cada tipo de dispositivo (Figura 5.1.5).

A análise da Figura 5.1.5 mostra que, dentro do nível de confiança de 99,7 \%, as tensões de depleção dos diodos estudados são praticamente independentes da dose total absorvida até aproximadamente 1 MGy.

Os valores médios das tensões de depleção e concentrações efetivas, obtidos para cada diodo mediante a Figura 5.1.5, com as respectivas incertezas estão representados na Tabela 5.1.1.

Tabela 5.1.1 - Valores médios das tensões de depleção $\left(V_{d}\right)$ e concentrações efetivas $\left(N_{e f}\right)$ para os diodos FZ, DOFZ e MCZ.

\begin{tabular}{|c|c|c|c|c|c|}
\hline \multicolumn{3}{|c|}{ Original } & \multicolumn{3}{|c|}{ Pré-Dose } \\
\hline Amostra & $V_{d}(\mathrm{~V})$ & $N_{e f}\left(10^{12} \mathrm{~cm}^{-3}\right)$ & Amostra & $V_{d}(\mathrm{~V})$ & $N_{e f}\left(10^{12} \mathrm{~cm}^{-3}\right)$ \\
\hline FZ\#54 & $(*)$ & $(*)$ & FZ\#75 & $208 \pm 14$ & $2,98 \pm 0,20$ \\
\hline DOFZ\#2 & $221 \pm 16$ & $3,17 \pm 0,23$ & DOFZ\#6 & $255 \pm 15$ & $3,67 \pm 0,22$ \\
\hline MCz\#56 & $319 \pm 19$ & $4,59 \pm 0,27$ & MCz\#69 & $320 \pm 19$ & $4,60 \pm 0,27$ \\
\hline
\end{tabular}

$\left({ }^{*}\right)$ A caracterização elétrica não foi realizada. 

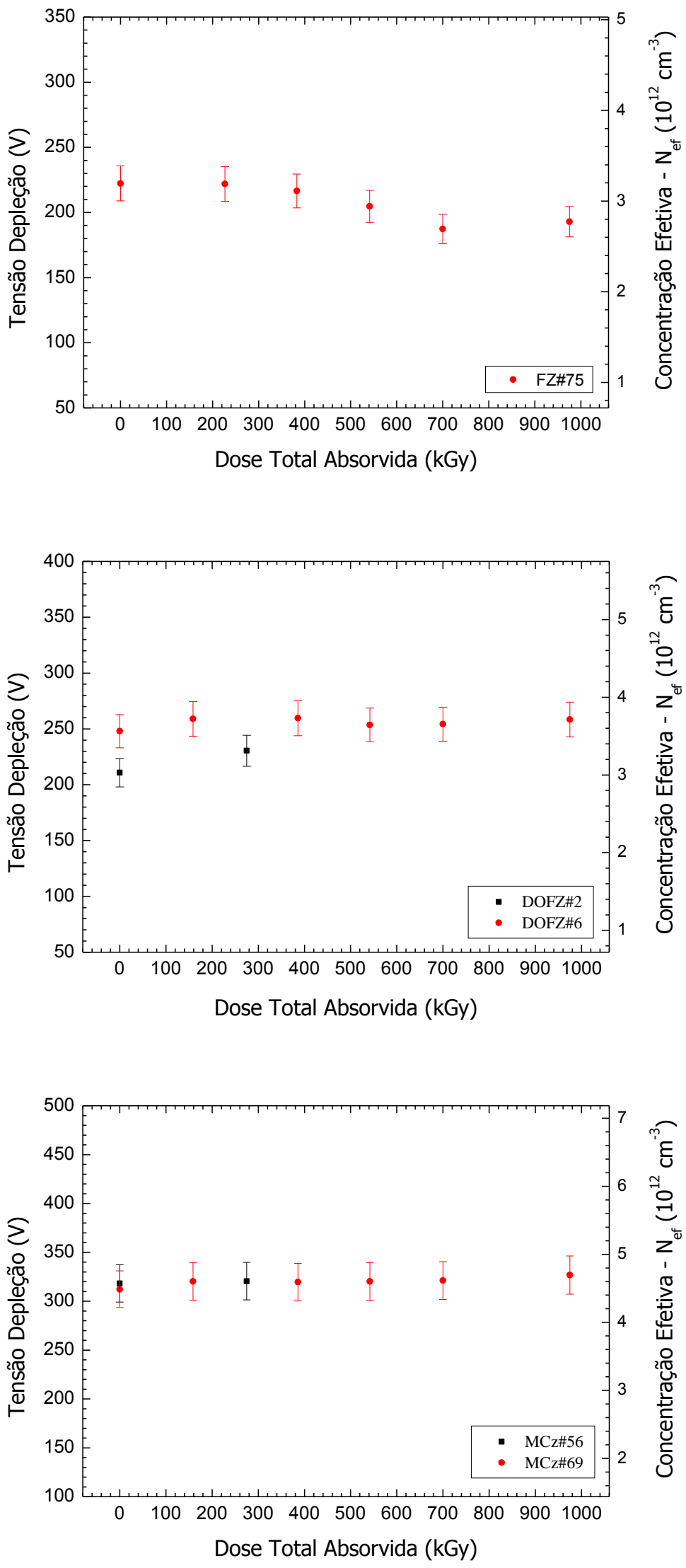

Figura 5.1.5 - Tensão de depleção e concentração efetiva vs. dose total absorvida para cada tipo de diodo. 
A análise da Tabela 5.1.1 revela que as tensões de depleção medidas coincidem, dentro das incertezas, com os valores calculados para os diodos crescidos por fusão zonal (FZ ou DOFZ) e Czochralski magnético (MCz). Os valores teóricos das capacitâncias e zonas de depleção dos diodos em função da tensão de polarização estão representados na Figura 5.1.6, onde também são mostradas as equações e os dados empregados nos cálculos [91].

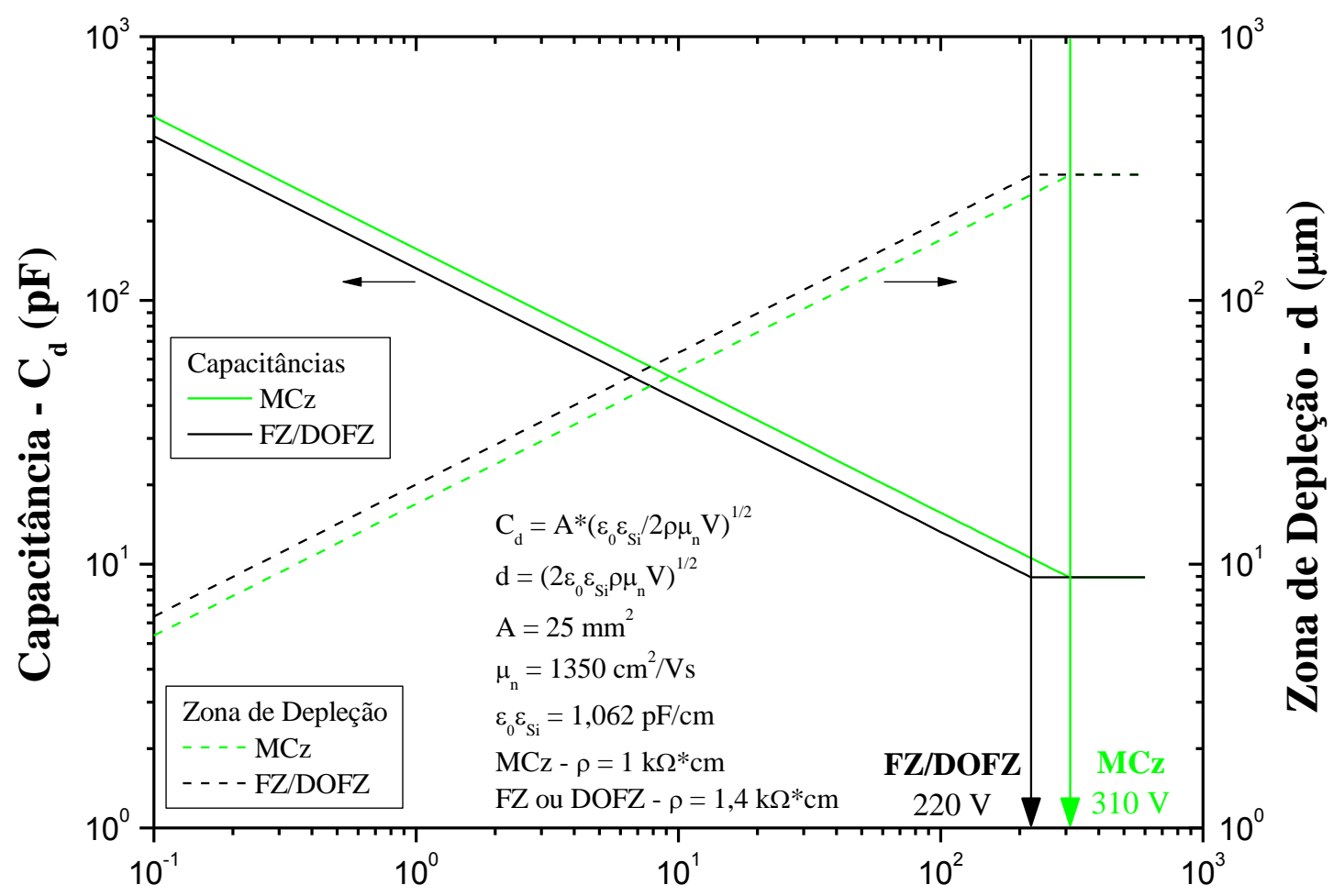

Tensão de Polarização (V)

Figura 5.1.6 - Valores teóricos de capacitância $\left(C_{d}\right)$ e zona de depleção (d) dos diodos crescidos pela tecnologia de fusão zonal (FZ ou DOFZ) e Czochralski magnético (MCZ).

Vale notar que nenhum dos diodos estudados apresentou o efeito de inversão de tipo ou variações significativas nas características elétricas que pudessem inviabilizar a aplicação destes dispositivos como dosímetros. 


\subsection{RESPOSTA COMO DOSÍMETRO}

\subsubsection{FOTOCORRENTE $\times$ TEMPO DE EXPOSIÇ̃̃o}

As Figuras 5.2.1 e 5.2.2 apresentam as curvas das fotocorrentes em função do tempo de irradiação dos diodos $F Z$, DOFZ e MCz originais e pré-irradiados com a dose de 700 kGy, respectivamente.

A análise das curvas das correntes registradas nos diodos originais em função do tempo de irradiação (Figura 5.2.1) evidencia um decréscimo significativo das fotocorrentes com o aumento da dose absorvida. Este fato pode ser explicado pelos defeitos pontuais gerados no volume do detector que armadilham as cargas geradas quando da incidência da radiação, traduzindo-se na queda da fotocorrente medida.

Por outro lado, para os dispositivos pré-irradiados (Figura 5.2.2), apesar da redução das suas sensibilidades, as fotocorrentes são praticamente estáveis e reprodutíveis durante todo o tempo de irradiação. Este fato, que pode ser atribuído à saturação dos danos gerados pela radiação, é confirmado pelos valores médios das fotocorrentes das amostras FZ\#75, DOFZ\#6 e MCZ\#69 mostradas na Tabela 5.2.1. Nesta tabela também são apresentadas as sensibilidades médias de cada amostra para as taxas de dose indicadas na Tabela 5.1.

Tabela 5.2.1 - Fotocorrentes médias $\left(\overline{I_{F}}\right)$ e sensibilidade $(S)$ dos diodos FZ\#75, DOFZ\#6 e MCZ\#69 préirradiados.

\begin{tabular}{ccccc}
\hline Amostra & $\dot{\boldsymbol{D}}(\mathrm{kGy} / \mathrm{h})$ & $\overline{\boldsymbol{I}}_{\boldsymbol{F}}(\boldsymbol{\mu} \mathrm{A})$ & $\boldsymbol{S}(\boldsymbol{\mu A h} / \mathbf{k G y})$ & $\boldsymbol{S}(\mathbf{m C} / \mathrm{kGy})$ \\
\hline FZ\#75 & $2,31 \pm 0,04$ & $0,60 \pm 0,03$ & $0,26 \pm 0,01$ & $0,928 \pm 0,043$ \\
DOFZ\#6 & $2,49 \pm 0,04$ & $0,55 \pm 0,02$ & $0,22 \pm 0,01$ & $0,792 \pm 0,038$ \\
MCZ\#69 & $2,44 \pm 0,04$ & $0,73 \pm 0,03$ & $0,30 \pm 0,01$ & $1,071 \pm 0,041$ \\
\hline
\end{tabular}

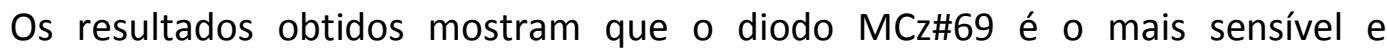
apresenta uma fotocorrente maior do que os demais dispositivos pré-irradiados quando submetidos a uma mesma taxa de dose. 

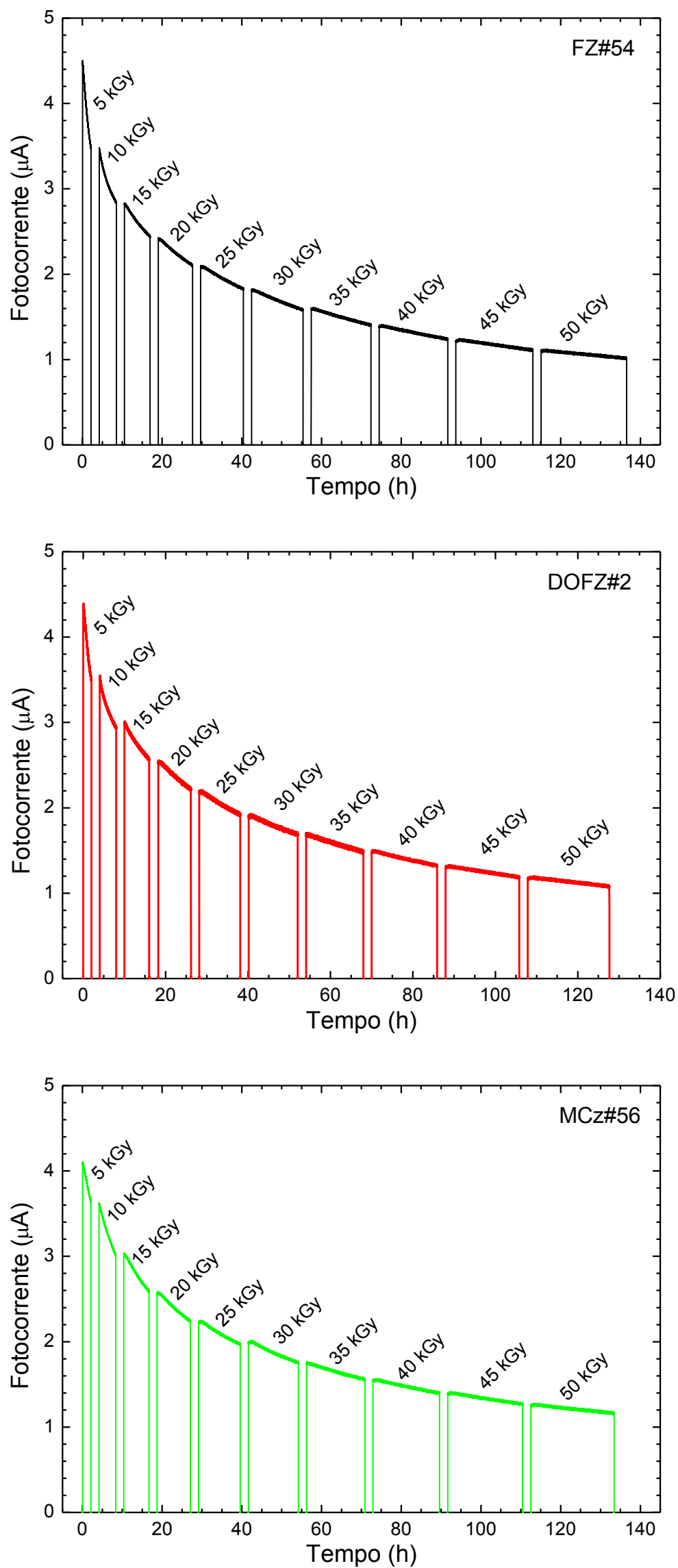

Figura 5.2.1 - Fotocorrentes dos diodos originais FZ\#54, DOFZ\#2 e MC\#56 para diferentes doses. 

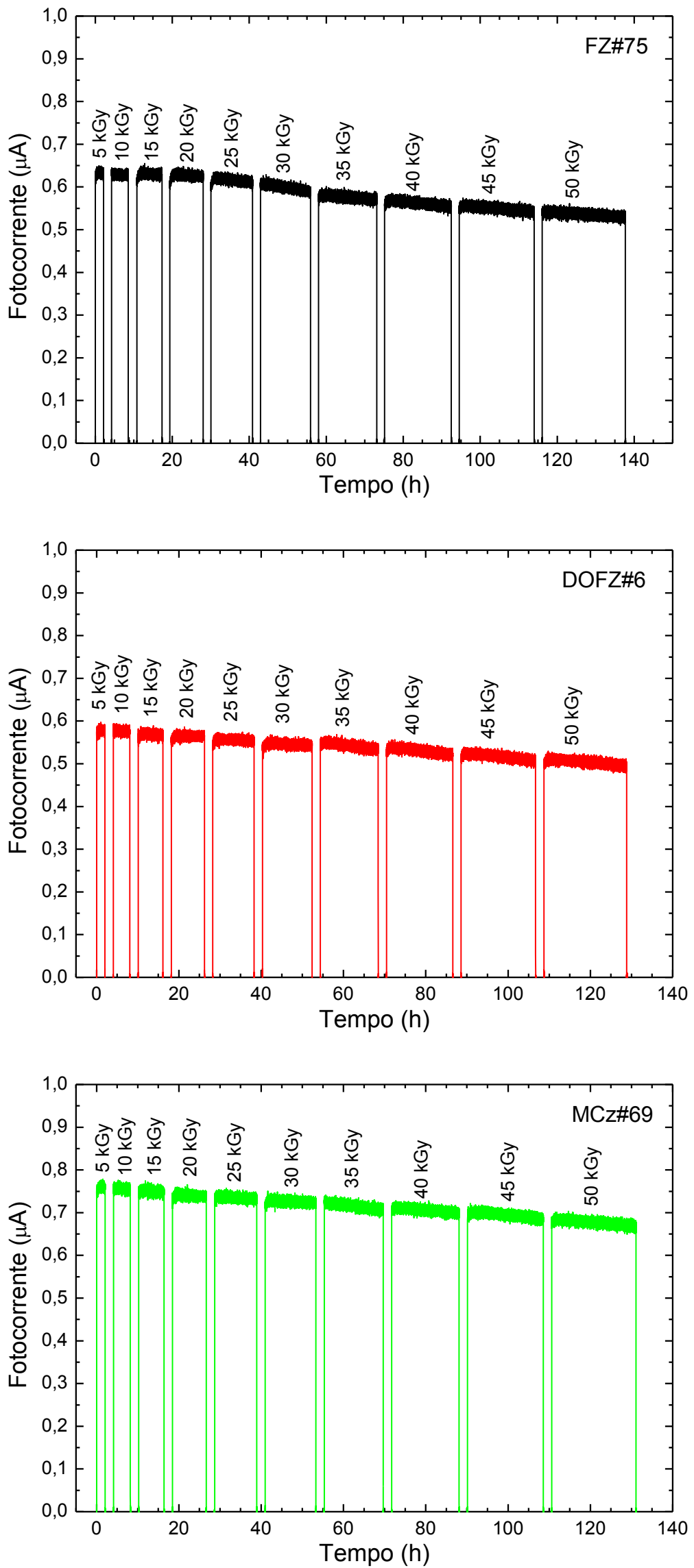

Figura 5.2.2 - Fotocorrentes dos diodos pré-irradiados FZ\#75, DOFZ\#12 e MC\#69, para diferentes doses. 


\subsubsection{FotOCORRENTE $\times$ DOSE TOTAL ABSORVIDA}

As fotocorrentes geradas nas amostras FZ, DOFZ e MCz originais e pré-irradiadas em função da dose total absorvida estão apresentadas nas Figuras 5.2.3 e 5.2.4, respectivamente. De uma forma geral, para doses inferiores a $25 \mathrm{kGy}$, todos os diodos originais sofreram uma queda significativa na fotocorrente. No entanto, para doses maiores a redução da corrente é menos significativa indicando uma condição mais estável de operação dos dispositivos. Este fato é confirmado pelos resultados obtidos com os diodos pré-irradiados (Figura 5.2.4), onde, apesar da queda de sensibilidade de todos os dispositivos, tem-se uma redução muito menor da fotocorrente com a dose total absorvida.

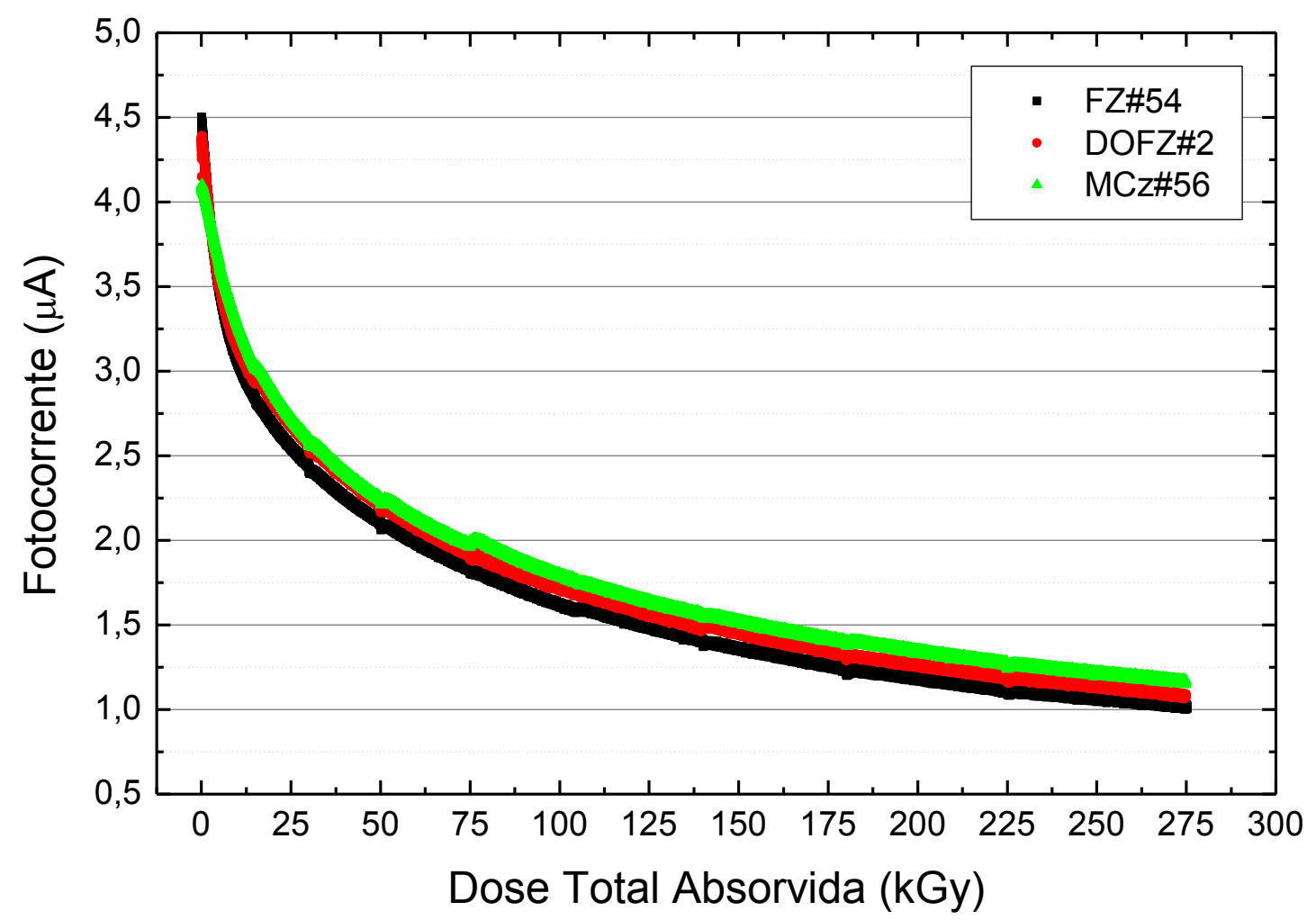

Figura 5.2.3 - Fotocorrentes em função da dose total absorvida para os diodos originais FZ\#54, DOFZ\#2 e MCz\#56. 


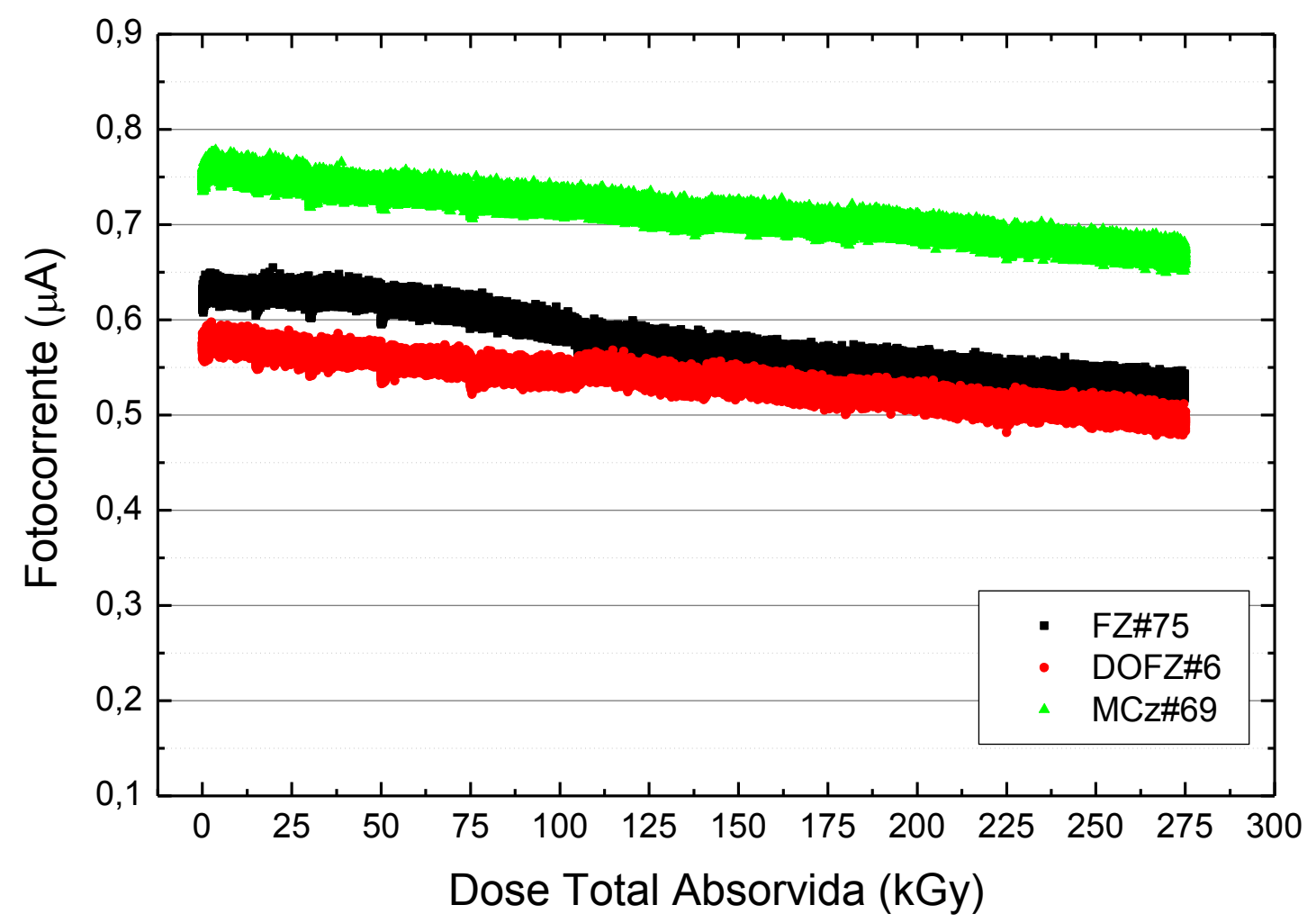

Figura 5.2.4 - Fotocorrentes em função da dose total absorvida para os diodos FZ\#75, DOFZ\#6 e MCz\#69 pré-irradiados.

A partir da Figura 5.2.4 verifica-se que as fotocorrentes dos diodos pré-irradiados decrescem linearmente com a dose total absorvida. Os parâmetros de ajuste destas funções lineares estão apresentados na Tabela 5.2.2 juntamente com os valores das doses máximas permitidas para a operação dos diodos.

Tabela 5.2.2 - Parâmetros dos ajustes lineares realizados nas fotocorrentes em função da dose total absorvida nas amostras pré-irradiadas.

\begin{tabular}{ccccc}
\hline \multirow{2}{*}{ Amostra } & \multicolumn{2}{c}{ Reta: $\mathbf{I}_{\mathbf{F}}(\mathbf{n A})=\mathbf{A}+\mathbf{B} \times \mathbf{D}(\mathbf{k G y})$} & \multirow{2}{*}{$\begin{array}{c}\text { Dose Máxima } \\
\text { (MGy) }\end{array}$} \\
\cline { 2 - 4 } & $\mathbf{A}(\mathbf{n A})$ & $\mathbf{B}(\mathbf{n A} / \mathbf{k G y})$ & $\mathbf{R}^{2}$ & 1,5 \\
FZ\#75 & $635,85 \pm 0,05$ & $-0,4205 \pm 0,003$ & 0,94871 & 2,0 \\
DOFZ\#6 & $575,17 \pm 0,04$ & $-0,2861 \pm 0,002$ & 0,93662 & 2,4 \\
MCZ\#69 & $754,74 \pm 0,04$ & $-0,3083 \pm 0,002$ & 0,94602 & \\
\hline
\end{tabular}

Vale observar que na determinação da dose máxima, admitiu-se que a queda linear da fotocorrente em função da dose permaneça constante para doses maiores do que as utilizadas neste trabalho. 
Uma análise comparativa do comportamento das fotocorrentes em função da dose total absorvida nos diodos originais e pré-irradiados pode ser feita mediante as Figuras 5.2.5 e 5.2.6, respectivamente. Para eliminar a influência das diferentes taxas de dose utilizadas nas medidas com os diodos FZ, DOFZ e MCz (v. Tabela 5.2.1), optou-se por representar os valores normalizados das fotocorrentes em relação ao valor máximo medido no início da irradiação de cada dispositivo.

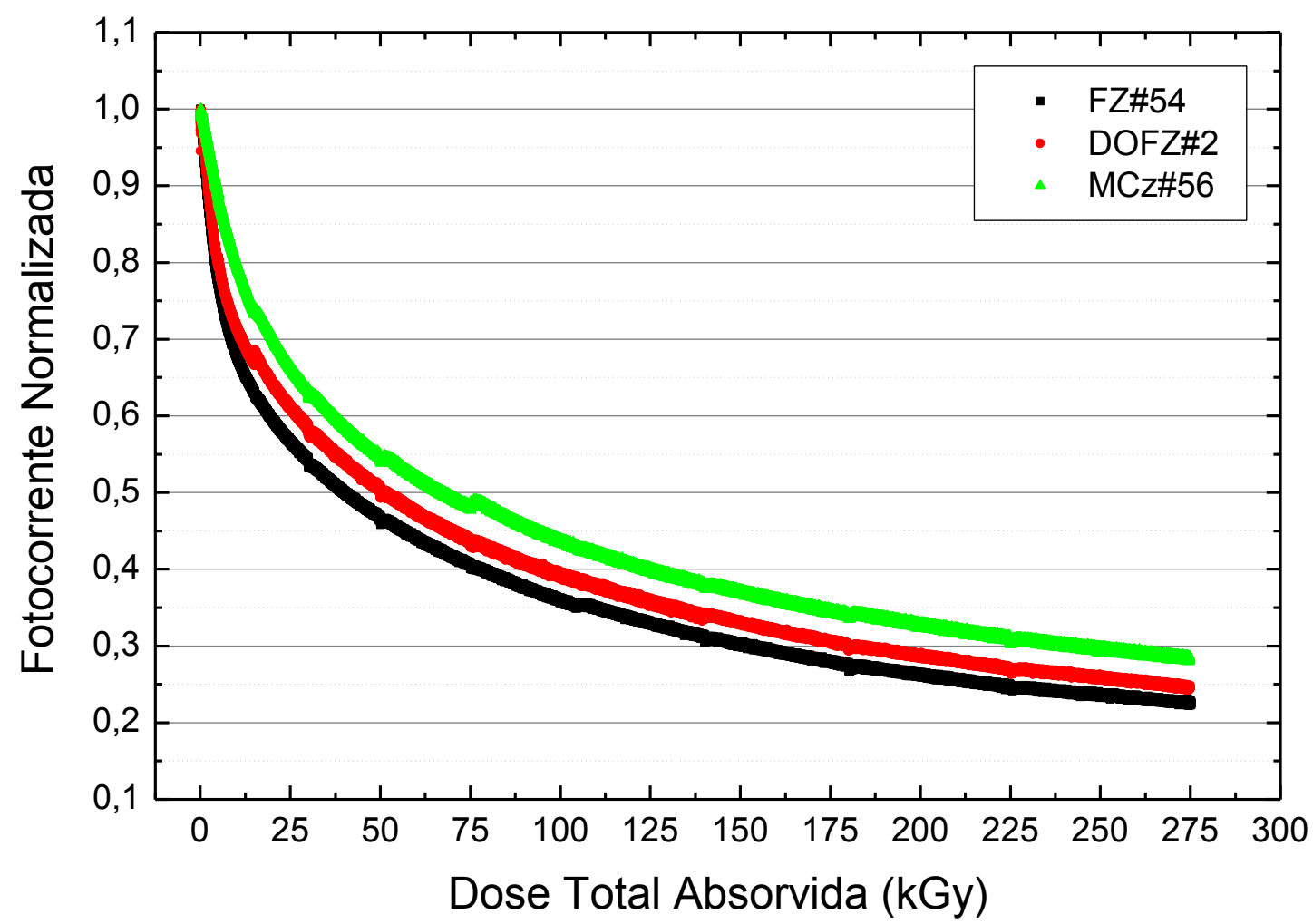

Figura 5.2.5 - Fotocorrentes normalizadas em função da dose total absorvida para os diodos originais.

Pela análise dos resultados mostrados nas Figuras 5.2.5, nota-se que as fotocorrentes para a máxima dose absorvida pelas amostras originais $\mathrm{MCz}$, DOFZ e FZ decrescem em torno de $72 \%, 75 \%$ e $77 \%$, respectivamente. Por outro lado, os dados da Figura 5.2.6 evidenciam que com a pré-irradiação de 700 kGy, as fotocorrentes se tornam mais estáveis e apresentam um declínio na sua resposta de aproximadamente 14 \%, $18 \%$ e $19 \%$, respectivamente, para os diodos MCZ, DOFZ e FZ. 


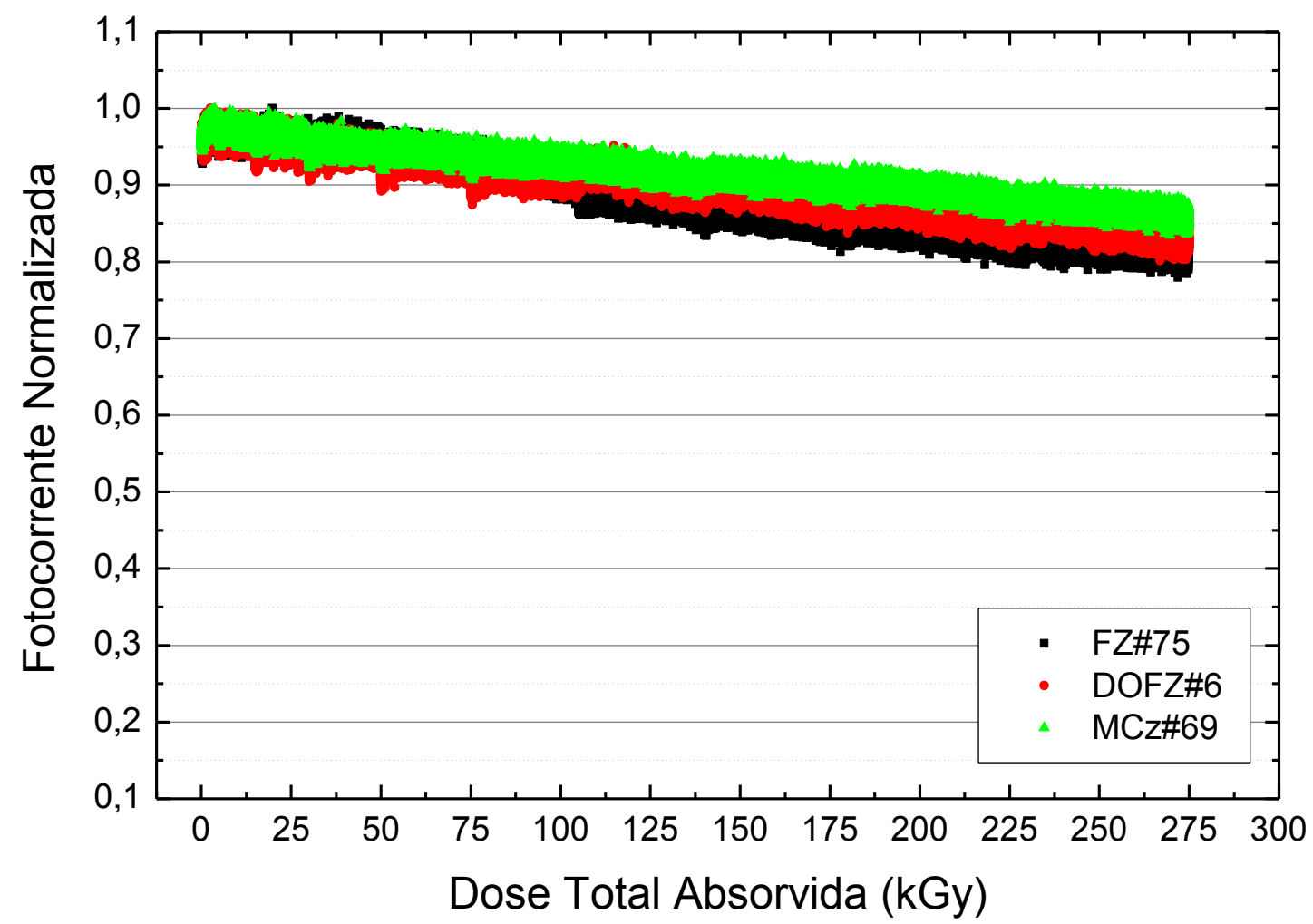

Figura 5.2.6 - Fotocorrentes normalizadas em função da dose total absorvida para os diodos pré-irradiados.

Nas Figuras 5.2.5 e 5.2.6 ainda evidencia-se que a variação da fotocorrente foi menor para as amostras com maior quantidade de oxigênio na estrutura, indicando que para a radiação gama a presença de oxigênio pode ser um parâmetro importante na supressão dos defeitos gerados. Além disso, verifica-se que as fotocorrentes possuem o mesmo comportamento de redução para todos os diodos estudados, evidenciando que os danos gerados devem estar relacionados a processos de interação mais fundamentais com o silício independentemente dos métodos de fabricação dos dispositivos.

\subsubsection{CuRva Resposta com a Dose AbSORVIDA}

O desempenho dos diodos como dosímetros de radiação foi estudado considerando-se como parâmetro dosimétrico a carga gerada no dispositivo em função da dose absorvida. Estas cargas foram obtidas pela integração dos sinais de corrente medidos durante o tempo de irradiação em cada intervalo de dose (Figuras 5.2.3 a 5.2.4). As curvas resposta das amostras $F Z$, DOFZ e $M C Z$, dadas pela carga em função da dose absorvida, são mostradas na Figura 5.2.7. 

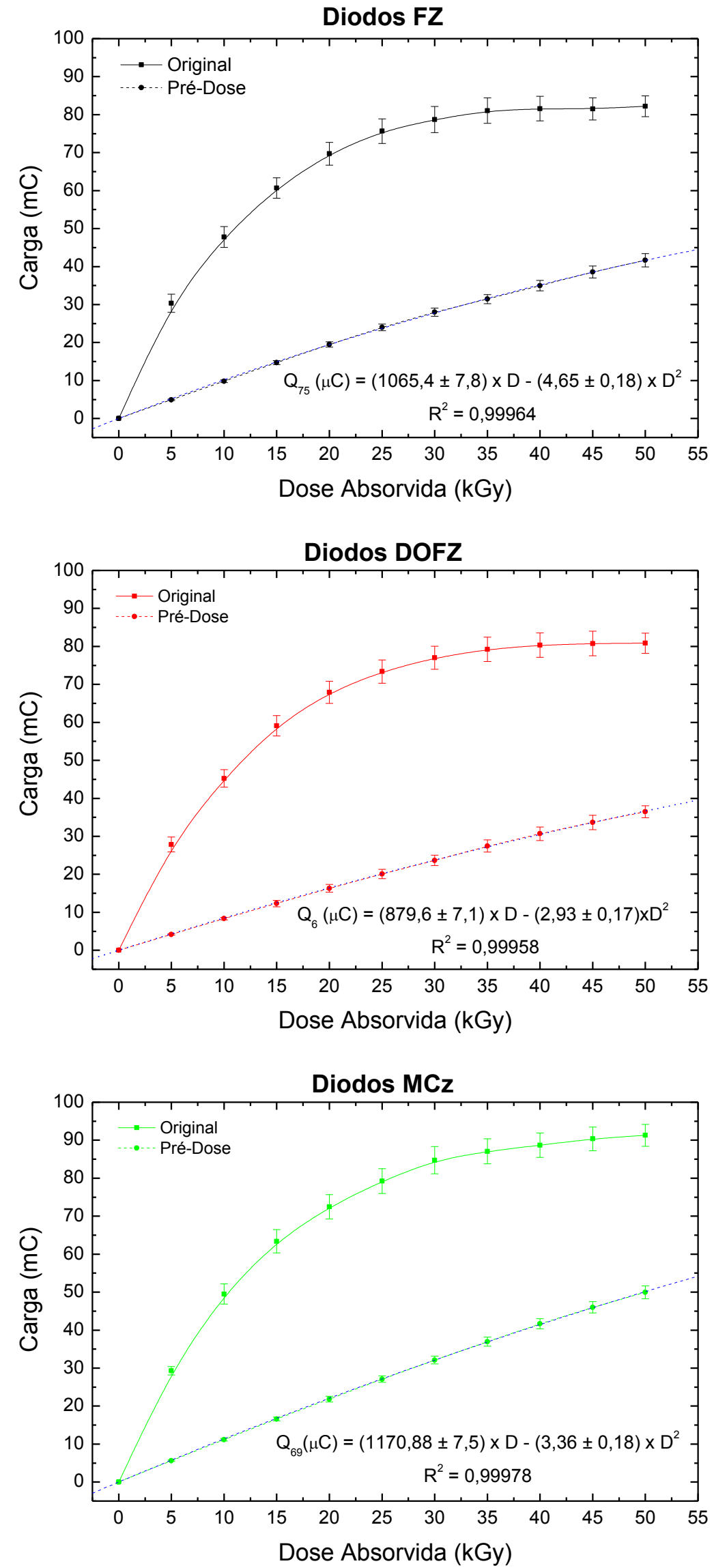

Figura 5.2.7 - Curvas resposta com a dose para os diodos FZ, DOFZ e MCZ (originais e pré-irradiados). 
Para facilitar a análise e comparação dos resultados obtidos, a Figura 5.2.8 mostra as curvas resposta dos diodos FZ, DOFZ e MCz originais e pré-irradiados.

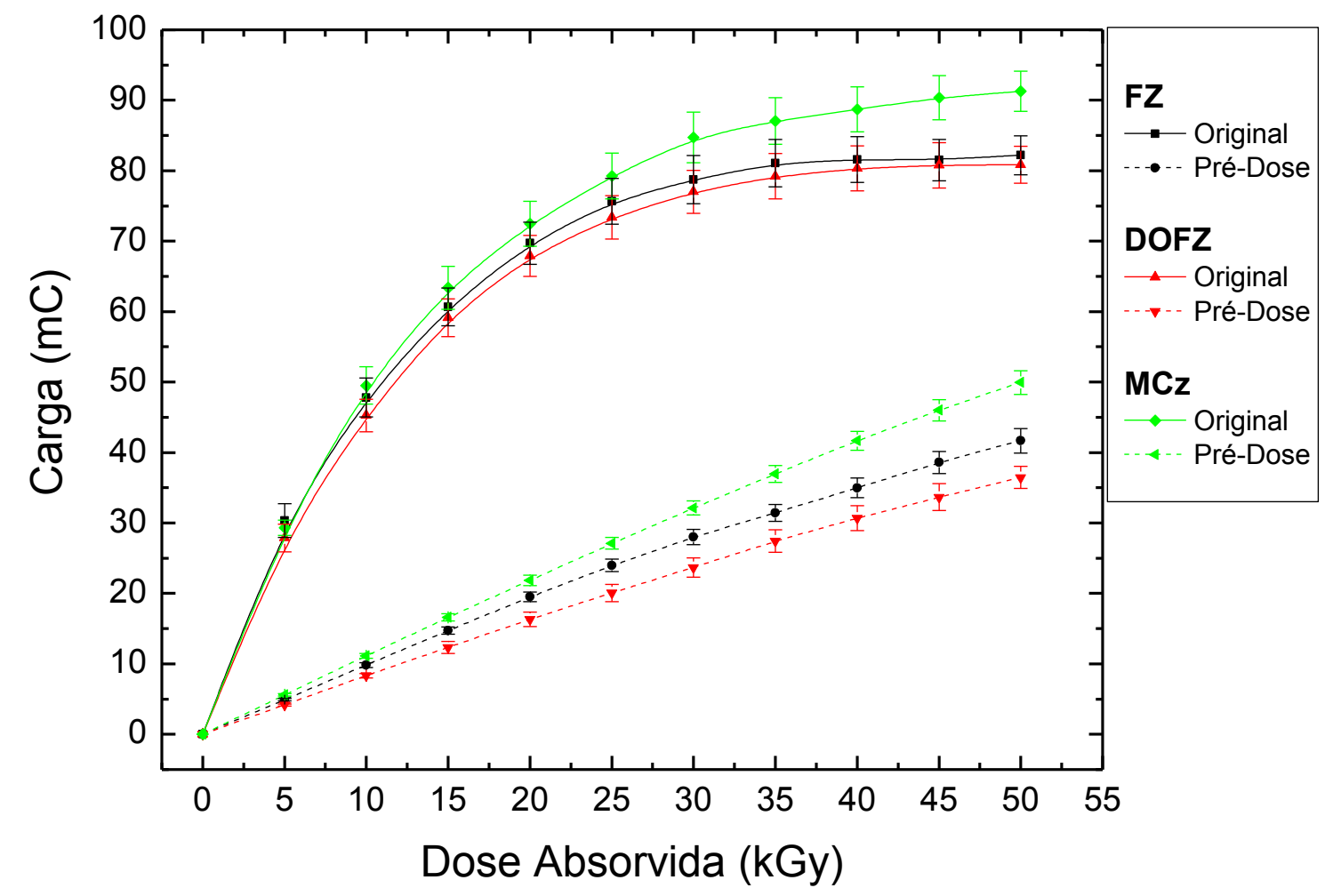

Figura 5.2.8 - Comparação das curvas resposta com a dose para as amostras FZ, DOFZ e MCZ.

A análise destas curvas evidencia que as respostas de todos os diodos originais apresentam saturação para doses superiores a $10 \mathrm{kGy}$. Este comportamento é explicado pela queda acentuada da corrente gerada nestes dispositivos principalmente no início da irradiação como mostrado na Figura 5.2.1. Vale notar que as curvas resposta dos dispositivos originais crescidos pela tecnologia de fusão zonal (FZ e DOFZ) são coincidentes dentro do erro experimental em todo o intervalo de dose estudado.

Por outro lado, as cargas geradas nos diodos pré-irradiados crescem quadraticamente com a dose absorvida em decorrência da queda linear dos sinais de fotocorrente registrados em função do tempo de irradiação (v. Figura 5.2.2). A Tabela 5.2.3 mostra os parâmetros dos ajustes realizados nas curvas resposta das amostras pré-irradiadas (curvas azuis na Figura 5.2.7), onde se notam coeficientes de correlação superiores a 0,999. 
Tabela 5.2.3 - Parâmetros dos ajustes quadráticos realizados nas curvas resposta em função da dose absorvida nas amostras pré-irradiadas.

\begin{tabular}{cccc}
\hline \multirow{2}{*}{ Amostra } & \multicolumn{3}{c}{ Ajuste: $\mathbf{Q}(\boldsymbol{\mu C})=\mathbf{a} \times \mathbf{D}+\mathbf{b} \times \mathbf{D}^{\mathbf{2}}$} \\
\cline { 2 - 4 } & $\mathbf{a}$ & $\mathbf{b}$ & $\mathbf{R}^{\mathbf{2}}$ \\
\hline FZ\#75 & $1065,4 \pm 7,8$ & $4,65 \pm 0,18$ & 0,99964 \\
DOFZ\#6 & $879,6 \pm 7,1$ & $2,93 \pm 0,17$ & 0,99958 \\
MCZ\#69 & $1170,88 \pm 7,5$ & $3,36 \pm 0,18$ & 0,99978 \\
\hline
\end{tabular}

As sensibilidades em carga dos diodos, apresentadas na Figura 5.2.8, revelam que o diodo $\mathrm{MCz}$ é mais sensível do que os demais. Este resultado indica que, nas condições de irradiação deste trabalho, a amostra $\mathrm{MCz}$ é mais resistente a danos de radiação do que as demais uma vez que a queda de sensibilidade com a dose está relacionada à geração de defeitos na estrutura do diodo. Estes defeitos atuam como armadilhas ou centros de recombinação responsáveis pela redução da fotocorrente em função do tempo de irradiação e, conseqüentemente, da carga armazenada no dispositivo. De fato, este comportamento foi igualmente observado com o diodo original $\mathrm{MCz}$ que, mesmo saturado, apresentou maior sensibilidade do que os dispositivos FZ e DOFZ.

\subsubsection{Curva Resposta com a Dose Total Absorvida}

As curvas das cargas geradas nos diodos em função das doses absorvidas (Figuras 5.2.7 e 5.2.8) em intervalos crescentes de 5 kGy não levam em consideração a contribuição acumulativa das doses absorvidas nas diferentes etapas de irradiação dos dispositivos. Desta forma, nas Figuras 5.2.1 e 5.2.2 os sinais de corrente registrados e as cargas a eles associadas representam apenas os efeitos produzidos nos dispositivos em cada exposição isolada. No entanto, como as medidas foram realizadas em temperatura ambiente, sem tratamento térmico das amostras após as irradiações, os danos produzidos nestes dispositivos devem ser acumulativos. Para verificar esta hipótese estudou-se a resposta dosimétrica dos diodos FZ, DOFZ e MCz mediante a construção das curvas das cargas neles acumuladas em função da dose total absorvida.

A Figura 5.2.9 apresenta estas curvas obtidas para as amostras originais e préirradiadas dos três tipos de diodos estudados. Os resultados obtidos são semelhantes aos mostrados na Figura 5.2.7 indicando também a saturação da resposta dos diodos originais. 

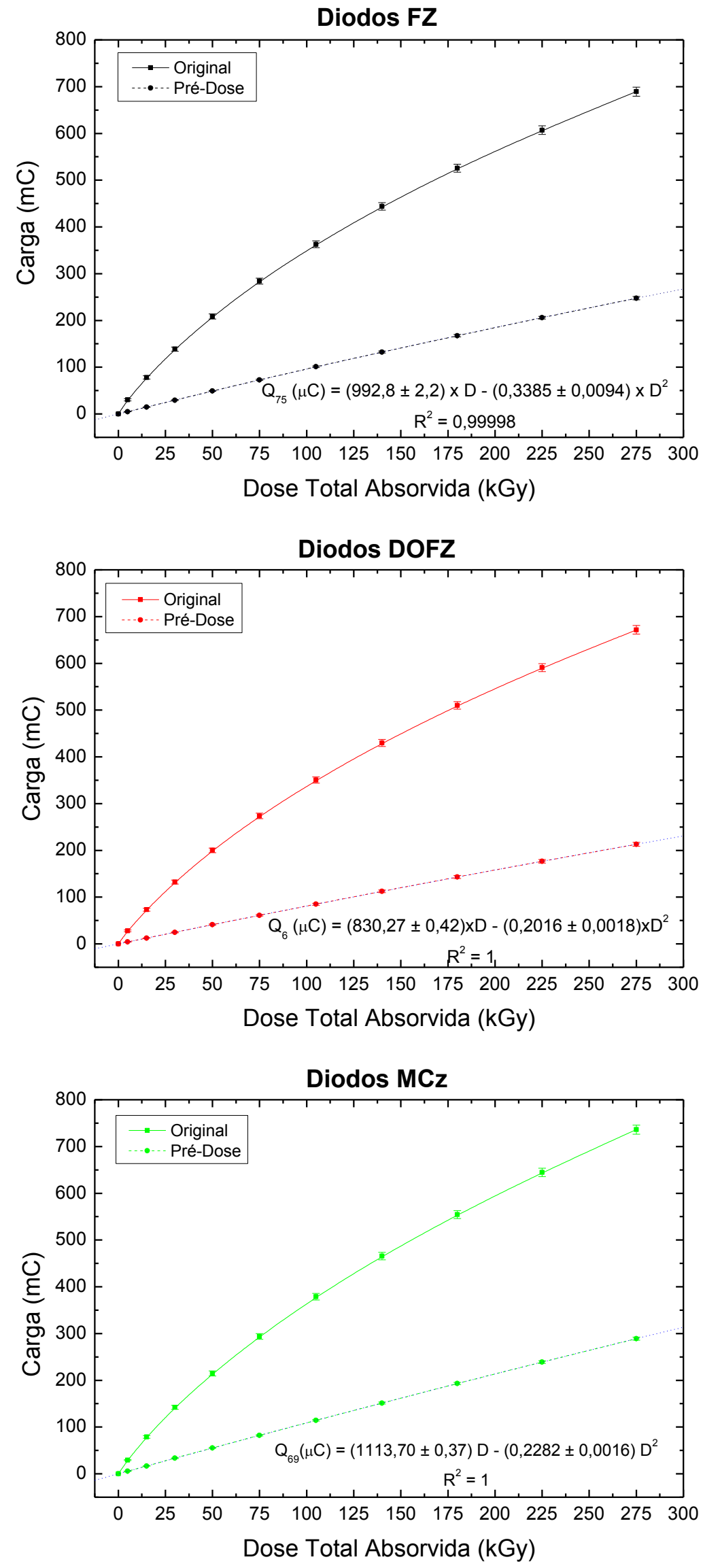

Figura 5.2.9 - Curvas resposta em função da dose total absorvida para os dispositivos FZ, DOFZ e MCZ. 
Uma análise comparativa entre as curvas resposta das amostras originais em função da dose total absorvida pode ser feita mediante a Figura 5.2.10. Nela verifica-se que todos os diodos apresentam saturação em doses superiores a 25 kGy e é confirmada a maior sensibilidade do dispositivo $\mathrm{MCz}$ em relação aos de fusão zonal padrão e com difusão de oxigênio. Cabe também observar a discrepância entre as curvas resposta destes diodos relativas às doses totais e àquelas absorvidas individualmente em cada exposição (vista ampliada na Figura 5.2.10). Estes resultados evidenciam que na região de baixas doses, a queda acentuada da carga é devida à brusca geração de defeitos na estrutura dos dispositivos. No entanto, com a continuação da irradiação tem-se uma melhora nas respostas dos diodos em concordância com os resultados obtidos com os dispositivos pré-irradiados.

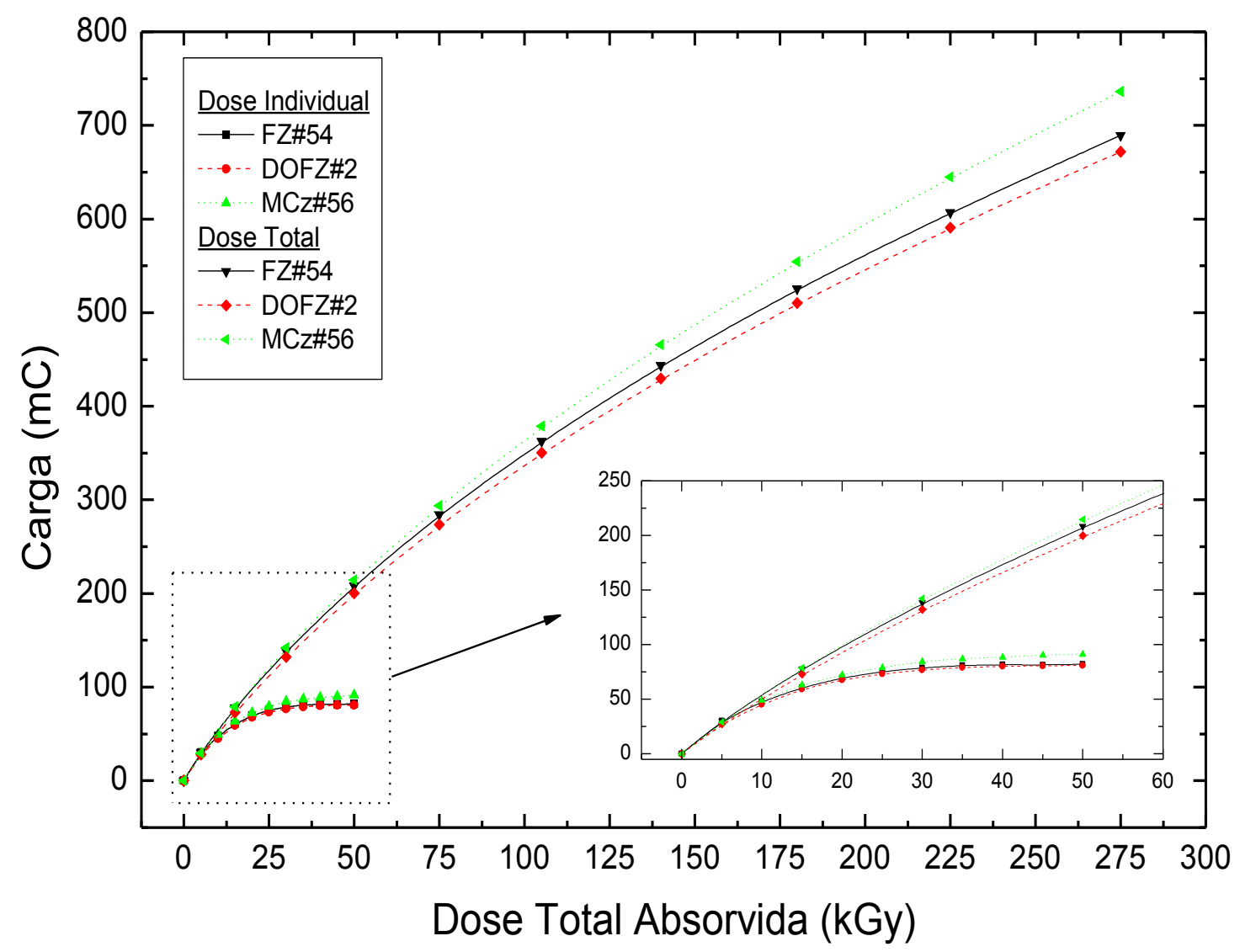

Figura 5.2.10 - Curvas resposta em função da dose total absorvida para os diodos originais FZ, DOFZ e MCZ. 


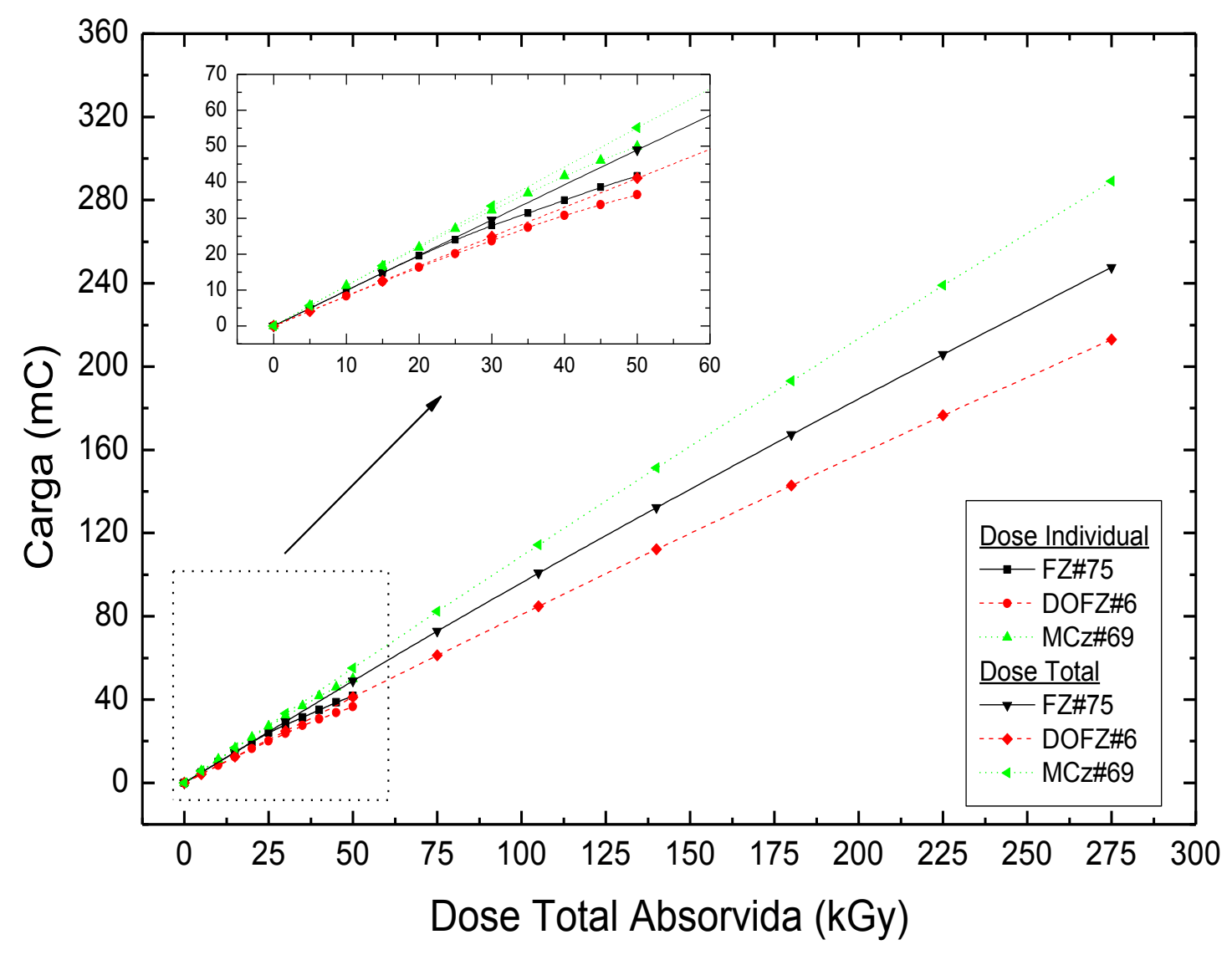

Figura 5.2.11 - Curvas resposta em função da dose total absorvida dos diodos FZ, DOFZ e MCZ préirradiados.

A Figura 5.2.11 mostra as cargas geradas nos diodos FZ, DOFZ e MCz préirradiados em função da dose total absorvida. As respostas destes dispositivos praticamente coincidem com aquelas correspondentes às doses absorvidas em cada intervalo de irradiação (parte em destaque no gráfico) e são quadráticas com a dose até aproximadamente $300 \mathrm{kGy}$. Os ajustes das curvas resposta dos diodos estão mostrados na Tabela 5.2.4, onde se evidencia a resposta quadrática para doses absorvidas de até $300 \mathrm{kGy}$ em todas as amostras estudadas.

Tabela 5.2.4 - Parâmetros dos ajustes quadráticos realizados nas curvas resposta em função da dose total absorvida nas amostras pré-irradiadas.

\begin{tabular}{cccc}
\hline \multirow{2}{*}{ Amostra } & \multicolumn{3}{c}{ Ajuste: $\mathbf{Q}(\boldsymbol{\mu C})=\mathbf{a} \times \mathbf{D}+\mathbf{b} \times \mathbf{D}^{\mathbf{2}}$} \\
\cline { 2 - 4 } & $\mathbf{a}$ & $\mathbf{b}$ & $\mathbf{R}^{\mathbf{2}}$ \\
\hline FZ\#75 & $992,8 \pm 2,2$ & $0,3385 \pm 0,0094$ & 0,99998 \\
DOFZ\#6 & $830,27 \pm 0,42$ & $0,2016 \pm 0,0018$ & 1 \\
MCZ\#69 & $1113,70 \pm 0,37$ & $0,2282 \pm 0,0016$ & 1 \\
\hline
\end{tabular}


A comparação entre as respostas dos diferentes diodos evidencia que o mais sensível dentre os detectores estudados é o do tipo $\mathrm{MCz}$, tanto para as amostras originais quanto pré irradiadas.

Cabe salientar que, nas condições de irradiação praticamente uniforme em toda amostra com elevada taxa de dose, não foram observadas diferenças significativas entre as respostas dos diodos produzidos por fusão zonal padrão e com difusão de oxigênio. A explicação para este resultado exige um detalhamento do papel do oxigênio na criação de defeitos em dispositivos semicondutores que extrapola os objetivos deste trabalho. Não obstante, os resultados das cargas geradas nos dosímetros em função da dose total absorvida indicam que os danos produzidos são estáveis em temperatura ambiente, como observado por F. Lemeilleur et al. [92].

Vale ressaltar que os testes de reprodutibilidade dos diodos FZ, DOFZ e $M C z$ não foram realizados em virtude da pequena taxa de dose e da indisponibilidade de tempo do irradiador Gammacell do CTR. 


\section{CONCLUSÃO}

Os estudos dos danos causados por elevadas doses de radiação gama em diodos de Si produzidos pelas técnicas de fusão zonal padrão (FZ), fusão zonal com difusão de oxigênio (DOFZ) e Czochraski magnético ( $\mathrm{MCz}$ ), demonstraram que as correntes de fuga destes dispositivos polarizados reversamente aumentam com a dose absorvida. No entanto, apesar deste crescimento indicar a presença de danos nas estruturas dos diodos, os valores máximos de correntes de fuga observados são em torno de mil vezes menores do que as fotocorrentes registradas.

Por outro lado, as medidas dinâmicas da capacitância dos dispositivos em função da dose absorvida permitiram concluir que mesmo para doses de $\approx 1 \mathrm{MGy}$ as curvas CV não apresentam alterações significativas quando comparadas àquelas dos dispositivos não irradiados. Resultados semelhantes foram obtidos com as tensões de depleção total dos diodos, o que nos permite concluir que no intervalo de dose estudado nenhum deles sofreu a inversão de tipo observada em dispositivos danificados por radiação.

No tocante à resposta dosimétrica das amostras originais, para uma mesma taxa de dose, foi observada uma queda significativa da corrente gerada com o tempo de exposição. Esta redução da sensibilidade, atribuída à geração de defeitos pontuais na estrutura dos dispositivos, se traduziu experimentalmente na saturação das curvas resposta da carga em função da dose absorvida. Como este comportamento é similar para os três tipos de diodos estudados, pode-se concluir que a produção dos danos deve estar relacionada a processos fundamentais de interação com a estrutura do silício, independentemente dos métodos de fabricação dos dispositivos.

O estudo da influência da pré-irradiação na resposta dos dosímetros evidenciou que, apesar da redução de sensibilidade, a carga gerada nos diodos é quadraticamente 
dependente da dose absorvida até aproximadamente $300 \mathrm{kGy}$. Os resultados obtidos também revelaram maior sensibilidade dos dispositivos $\mathrm{MCz}$ em relação aos produzidos por fusão zonal padrão e com difusão de oxigênio. Em particular, não foram observadas diferenças significativas na sensibilidade e na resposta dos diodos FZ e DOFZ, o que pode ser explicado pelas condições extremas de irradiação em todo o volume dos dispositivos.

Por outro lado, as curvas resposta com a dose total absorvida também mostraram que os danos provocados pela radiação são acumulativos e estáveis em temperatura ambiente. Esta característica é fundamental para garantir a reprodutibilidade de resposta de dosímetros semicondutores.

A análise comparativa do desempenho dos três tipos de diodos estudados evidenciou que o $\mathrm{MCz}$, além de mais sensível, é mais resistente a danos de radiação do que os demais. Em função destes resultados, e considerando o menor custo de produção dos diodos $\mathrm{MCz}$, é possível concluir que este dispositivo é o mais adequado para a aplicação em dosimetria de rotina de processos de irradiação com altas doses. 


\section{APÊNDICE}

\section{A. ESTUDOS PRELIMINARES - AMOSTRA MCz\#57}

Para iniciar os estudos dos diodos especiais como dosímetros, tomou-se uma amostra do tipo $\mathrm{MCz}$ (MCz\#57) e fez-se várias exposições para diferentes doses e taxas de doses, medindo a fotocorrente gerada pelo diodo e verificando o seu comportamento com a dose total absorvida. Nestas irradiações foi observado que a fotocorrente gerada decrescia com a dose total absorvida, mostrando que o diodo apresentava danos de radiação. A amostra $\mathrm{MCz} \# 57$ não foi caracterizada eletricamente antes e depois de cada irradiação, o que permitiria avaliar melhor os danos de radiação, devido ao fato do circuito empregado para caracterização elétrica não estar em plenas condições de uso no período das irradiações.

Para verificar a diminuição da fotocorrente do diodo construiu-se a curva da fotocorrente média para cada exposição efetuada em função da dose total absorvida considerando todo o intervalo de estudo da amostra (MCz\#57). Entretanto, este estudo exigiu a introdução de um fator de correção no valor da fotocorrente em cada conjunto de medidas realizadas, como se todas tivessem sido registradas sob a mesma taxa de dose.

A obtenção do fator de correção baseou-se na proporcionalidade da fotocorrente $\left(I_{F}\right)$ com a taxa de dose $(\dot{D})$ à qual o dispositivo foi exposto, que pode ser expressa pela seguinte equação:

$$
I_{F}=S \times \dot{D}
$$

onde S é a sensibilidade do diodo, determinada por meio de medidas experimentais. 
A sensibilidade do diodo MCZ\#57 foi obtida mediante a curva da fotocorrente registrada em função da taxa de dose fornecida por fontes calibradas de ${ }^{60} \mathrm{Co}$ (Gammacell e Panorâmica). Os resultados obtidos mostrados na Figura A.1 demonstram a linearidade de resposta do dispositivo com sensibilidade de $0,461 \mu \mathrm{A} /(\mathrm{kGy} / \mathrm{h})$, definida pelo coeficiente angular da reta. Este valor foi considerado constante desprezando-se os danos de radiação que se manifestam com o aumento da dose e resultam em um decréscimo da fotocorrente.

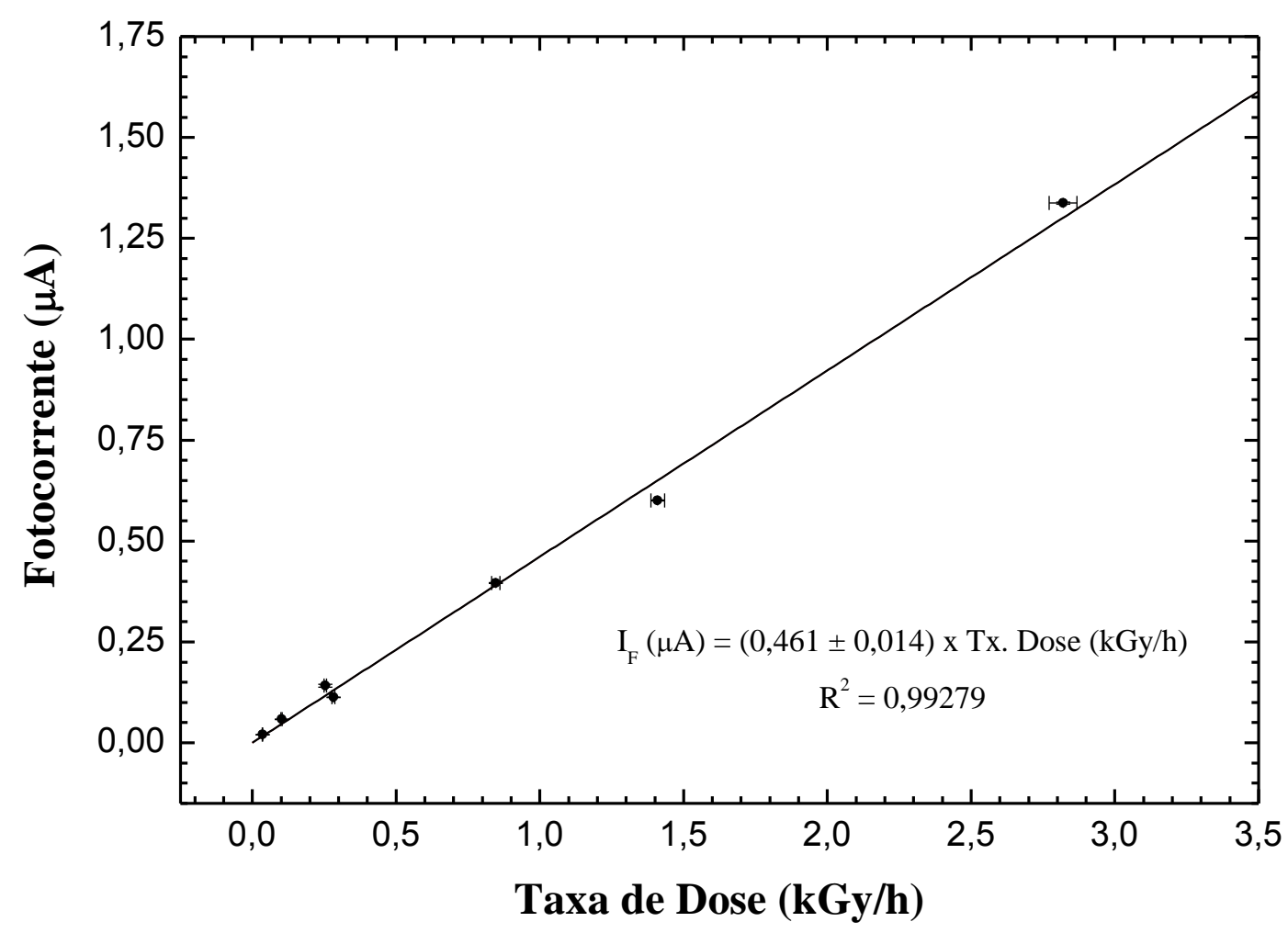

Figura A.1 - Fotocorrentes médias em função da taxa de dose para o diodo MCz\#57 (sensibilidade). As incertezas representadas na fotocorrente são menores do que os pontos experimentais e são a composição das incertezas do tipo A e B.

Assim, para duas taxas de doses diferentes $\left(\dot{D}_{1}\right.$ e $\left.\dot{D}_{2}\right)$ as fotocorrentes geradas $\left(I_{F_{1}}\right.$ e $\left.I_{F_{2}}\right)$ são:

$$
\begin{aligned}
& I_{F_{1}}=S \times \dot{D}_{1} \\
& I_{F_{2}}=S \times \dot{D}_{2}
\end{aligned}
$$


A diferença entre as Equações A.2 e A.3 permite obter o fator de correção $(\mathbb{F})$ definido pelo produto da sensibilidade do diodo $(\boldsymbol{S})$ e variação das taxas de doses $\left(\Delta \dot{D}_{12}\right)$ relacionadas ao decaimento da fonte radioativa.

$$
I_{F_{1}}-I_{F_{2}}=S \times\left(\dot{D}_{1}-\dot{D}_{2}\right)=S \times \Delta \dot{D}_{12}=\Gamma
$$

Desta forma, aplicando-se a Equação A.4 às fotocorrentes médias obtidas durante todo o estudo com o diodo MCZ\#57 e empregando-se os fatores de correção apresentados na Tabela A.1, construiu-se a curva das fotocorrentes médias em função da dose total absorvida (Figura A.2) adotando-se como referência a taxa de dose o mês de Janeiro de 2007. Na Figura A.2 também é apresentada a normalização das fotocorrentes para o primeiro valor de fotocorrente média determinado para o diodo (dose de $100 \mathrm{~Gy}$ ), o que permite avaliar a variação percentual da corrente com a dose total absorvida.

Tabela A.1 - Fatores de correção empregados na correção das fotocorrentes médias do diodo MCz\#57.

\begin{tabular}{ccc}
\hline $\begin{array}{c}\text { Mês de Referência } \\
\text { (Ano 2007) }\end{array}$ & $\begin{array}{c}\dot{\boldsymbol{D}} \\
(\mathrm{kGy} / \mathrm{h})\end{array}$ & $\begin{array}{c}\boldsymbol{\Gamma} \\
(\boldsymbol{\mu A})\end{array}$ \\
\hline Janeiro & 2,98 & 0 \\
Fevereiro & 2,94 & 0,0184 \\
Abril & 2,88 & 0,0461 \\
Maio & 2,85 & 0,0599 \\
Junho & 2,82 & 0,0738 \\
Outubro & 2,69 & 0,1337 \\
Dezembro & 2,64 & 0,1567 \\
\hline
\end{tabular}

A descontinuidade observada na curva da Figura A.2 é devida ao fato de que durante a irradiação da amostra MCZ\#57 para se obter a dose de aproximadamente 133 kGy a fotocorrente não foi registrada.

A análise dos dados da Figura A.2 evidencia que as fotocorrentes do diodo diminuem com a dose total absorvida indicando a presença de danos de radiação no volume sensível do dispositivo. Além disto, admitindo-se que esta taxa de redução da fotocorrente se mantenha constante, é possível prever a dose absorvida máxima para a qual a fotocorrente registrada é da ordem da corrente de fundo. 


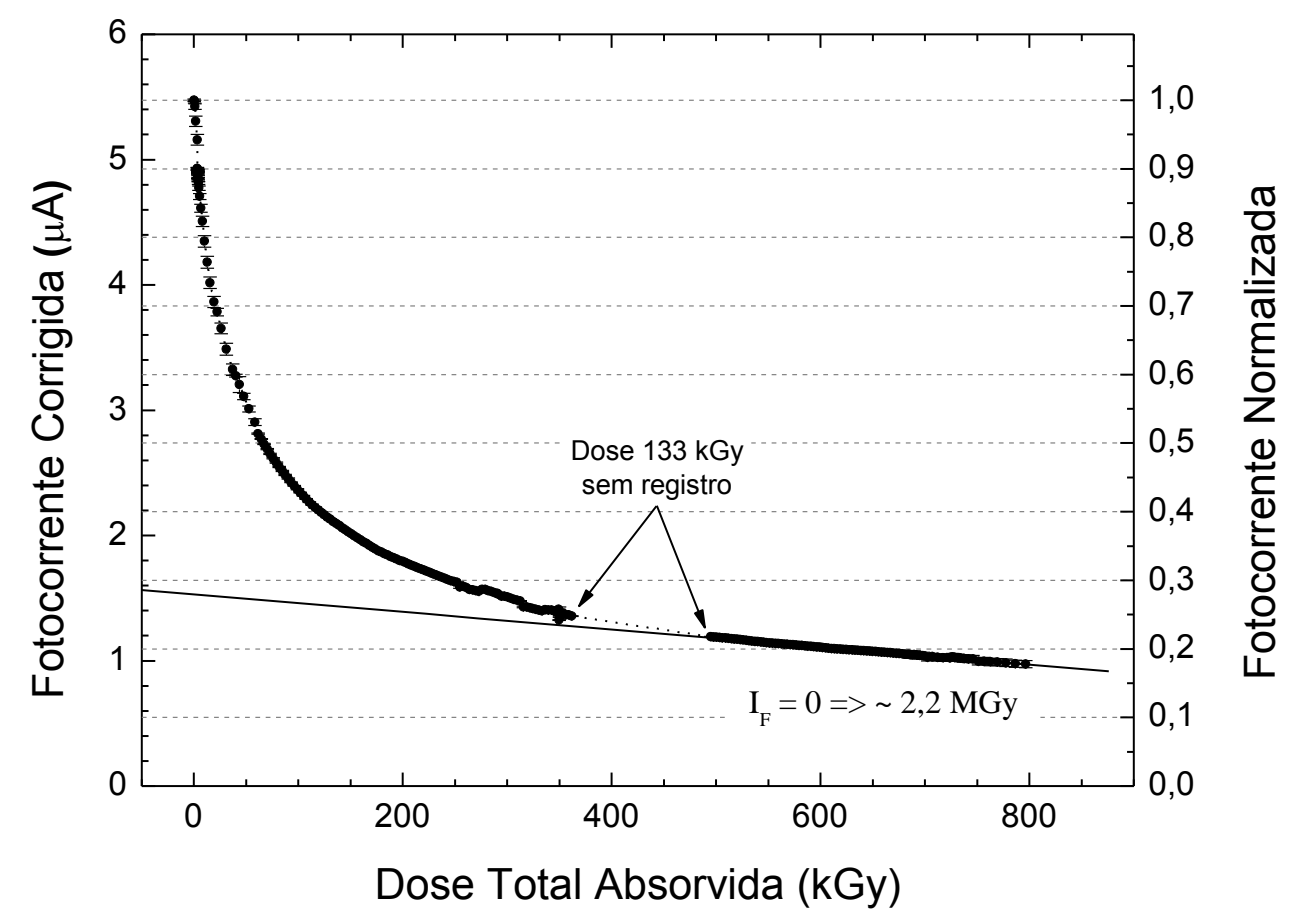

Figura A.2 - Fotocorrentes médias do diodo MCZ\#57 em função da dose total absorvida.

Admitindo-se que a taxa de redução da fotocorrente e a sensibilidade do diodo mantêm-se constantes durante a irradiação, estimou-se a dose máxima de utilização do MCz\#57 em 2,2 MGy mediante a extrapolação da reta de ajuste para as fotocorrentes a partir de 680 kGy como mostrado na Figura A.2.

Esta dose máxima é menor do que a esperada para os diodos produzidos por fusão zonal enriquecido com oxigênio (DOFZ) e por Czochraski magnético ( $M C Z$ ) nas aplicações como reconstrutores de trajetória de partículas no LHC do CERN . De fato, pela literatura [18,93], estes dispositivos não apresentam danos de radiação consideráveis para doses absorvidas de até 10 MGy (1 Grad). Além disto, o diodo MCz é apresentado como promissor substituto dos atuais diodos DOFZ no futuro super colisor de hádrons (SLHC, da sigla em inglês) no CERN, onde as doses serão ainda maiores [94]. Contudo, vale ressaltar que nessas aplicações de física de altas energias os dispositivos são polarizados reversamente o que, a priori, reduz o efeito de recombinação das cargas no volume sensível do diodo, o que não ocorre com o diodo em regime fotovoltaico como é o presente caso.

No entanto, apesar da diminuição da fotocorrente com a dose total absorvida, observa-se que após uma dose de aproximadamente 700 kGy a variação da fotocorrente 
é da ordem de 0,01\%/kGy. Este resultado nos motivou a pré-irradiar os dispositivos com uma dose de $700 \mathrm{kGy}$, visando melhorar a estabilidade de resposta dos diodos como dosímetros de radiação.

A pré-dose foi realizada de maneira fracionada durante quatro finais de semanas consecutivos dependendo da disponibilidade do irradiador. Para evitar possíveis efeitos de tratamento térmico (annealing) em temperatura ambiente os diodos de silício foram mantidos a uma temperatura média de $1{ }^{\circ} \mathrm{C}$, com o objetivo de preservar os defeitos gerados pelas irradiações. Este procedimento foi realizado nas amostras até o momento de serem montadas na sonda dosimétrica para o estudo de resposta em função das doses.

\section{A.1 CoMParaÇÃo dAS RESPOSTAS dos DiOdOS MCZ}

Para verificar e validar a metodologia empregada na correção das fotocorrentes medidas sob diferentes taxas de dose, confeccionou-se a Figura A.3, que compara as respostas normalizadas em função da dose total absorvida dos diodos MCz \#56 (Figura 5.2.5) e \#57 (Figura A.2).

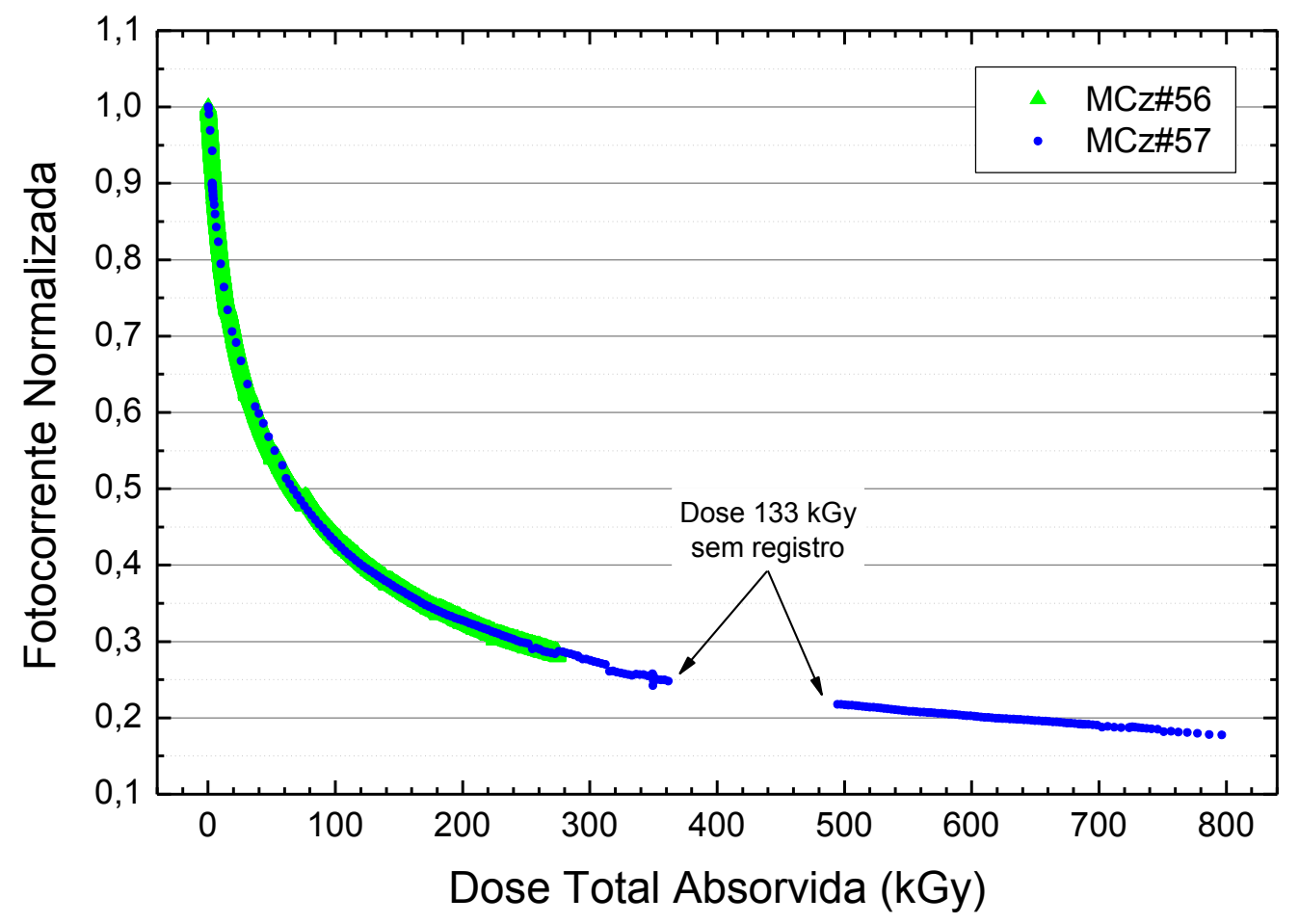

Figura A.3 - Comparação das fotocorrentes normalizadas em função da dose total absorvida para os diodos MCz \#56 e \#57. 
Pela comparação dos resultados apresentados na Figura A.3 constata-se que existe uma excelente concordância entre as fotocorrentes das amostras MCz \#56 e \#57 para o intervalo de até $275 \mathrm{kGy}$, corroborando com a metodologia empregada na correção das fotocorrentes medidas sob diferentes taxas de dose. 


\section{REFERÊNCIAS BIBLIOGRÁFICAS}

[1] The NA50 Proposal - Study of muon pairs and vector mesons produced in high energy Pb-Pb interaction. CERN/SPSLC 91-55, SPSLC/P265-Rev, 1991.

Disponível em: <http://na50.web.cern.ch/NA50/publications.html>.

Acessado em: 2 de março de 2009.

[2] ALESSANDRO, B.; ALEXELINE, M.; BAGLIN, C.; BEOLÉ, S.; BOLLITO, E.; BONAZZOLA, G.; BUSSIÈRE, A.; CAPONY, V.; DĄBROWSKY, W.; REMIGIS, P. de; WITT, J. De; FORLEN, M.; GIUBELLINO, P.; IDZIK, M.; MARZARI-CHIESA, A.; MASERA, M.; SILVA, W. P. da; RAMELLO, L.; MENDES, P. R.; RICCATI, L.; SARTORI, M. S.; SITTA, M. Design and operation of a fast high-granularity silicon detector system in a high-radiation environment. Nucl. Instrum. Methods Phys. Res., v. 409, p. 167-172, 1998. Section A.

[3] ALESSANDRO, B; BEOLÉ, S.; BONAZZOLA, G.; CRESCIO, E.; DĄBROWSKY, W.; GIUBELLINO, P.; GRYBOS, P.; IDZIK, M.; MARTINETTO, M.; MARZARI-CHIESA, A.; MASERA, M.; PRINO, F.; RAMELLO, L.; MENDES, P. R.; RICCATI, L.; SITTA, M. Analysis of radiation effects on silicon strip detectors in the NA50 experiment. Nucl. Instrum. Methods Phys. Res., v. 432, p. 342-357, 1999. Section A.

[4] ŽONTAR, Z. Radiation monitoring at Belle. Nucl. Instrum. Methods Phys. Res., v. 501, p. 164-166, 2003. Section A.

[5] ANTUNOVIC, Z.; BRITVITCH, I.; DEITERS, K.; GODINOVIC, N.; INGRAM, Q.; KUZNETSOV, A.; MUSIENKO, Y.; PULJAK, I.; RENKER, D.; REUCROFT, S.; RUSACK, R.; SAKHELASSHVILI, T.; SINGOVISKI, A.; SORIC, I.; SWAIN, J. Radiation hard avalanche photodiodes for the CMS detector. Nucl. Instrum. Methods Phys. Res., v. 537, p. 379-382, 2005. Section A.

[6] ALESSANDRO, B; BEOLÉ, S.; BONAZZOLA, G.; CRESCIO, E.; DĄBROWSKY, W.; GIUBELLINO, P.; GRYBOS, P.; IDZIK, M.; MARTINETTO, M.; MARZARI-CHIESA, A.; MASERA, M.; PRINO, F.; RAMELLO, L.; MENDES, P. R.; RICCATI, L.; SITTA, M. Radiation damage of silicon strip detectors in the NA50 experiment. Nucl. Instrum. Methods Phys. Res., v. 419, p. 556-569, 1998. Section A.

[7] PINTILLIE. I.; FRETWURST, E.; LINDSTRÖM, G.; STAHL, J. Results on defects induced by ${ }^{60} \mathrm{Co}$ gamma irradiation in standard and oxygen-enriched silicon. Nucl. Instrum. Methods Phys. Res., v. 514, p. 18-24, 2003. Section A.

[8] STAHL, J.; FRETWURST, E.; LINDSTRÖM, G.; PINTILLIE. I. Deep defect levels in standard and oxygen enriched silicon detectors before and after ${ }^{60} \mathrm{Co}-\gamma$-irradiation. Nucl. Instrum. Methods Phys. Res., v. 512, p. 111-116, 2003. Section A.

[9] HÄRKÖNEN, J.; TUOVINEN, E.; LUUKKA, P.; TUOMINEN, E.; LASSILA-PERINI, K.; MEHTÄLÄ, P.; NUMMELA, S.; NYSTEN, J.; ZIBELLINI, A.; LI, Z.; FRETWURST, E.; LINDSTRÖM, G; STAHL, J.; HÖNNIGER, F.; EREMIN, V.; IVANOV, A.; VERBITSKAYA, E.; HEIKKILÄ, P.; OVCHINNIKOV, V.; YLI-KOSKI, M.; LAITINEN, P.; PIROJENKO, A.; RIIHIMÄKI, I.; VIRTANEN, A. Radiation hardness of silicon, Float Zone silicon and 
oxygenated Float Zone silicon studied by low energy protons. Nucl. Instrum. Methods Phys. Res., v. 518, p. 346-348, 2004. Section A.

[10] ANDRICEK, L.; GEBHART, T.; HAUFF, D.; KEMMER, J.; KOFFEMAN, E.; LUTZ, G.; RICHTER, R. H.; ROHE, T.; WUNSTORI, R. Single sided $p^{+} n$ and double-sided silicon strip detectors exposed to fluencies up to $2 \times 10^{14} / \mathrm{cm}^{2} 24 \mathrm{GeV}$ protons. Nucl. Instrum. Methods Phys. Res., v. 409, p. 184-193, 1998. Section A.

[11] BORER, K.; JANOS, S.; LI, Z.; DEZILLIE, B.; VIÁ, C. Da; GRANATA, V.; CASAGRANDE, L.; BOER, R. W. I. de; LOURENÇO, C.; NIINIKOSKI, T. O.; PALMIERI, V. G.; CHAPUY, S.; DIMCOVSKI, Z.; GRIGORIEV, E.; BELL, W.; DEVINE, S. R. H.; RUGGIERO, G.; O'SHEA, V.; SMITH, K.; BERGLUND, P.; BOER, W. de; HAULER, F.; HEISING, S.; JUNGERMANN, L.; ABREU, M.; RATO, P.; SOUSA, P.; CINDRO, V.; MIKUZ, M.; ZAVRTANIK, M.; ESPOSITO, A.; PAUL, S.; BUONTEMPO, S.; D'AMBROSIO, N.; PAGANO, S.; EREMIN, V.; VERBITSKAYA, E. Charge collection efficiency of an irradiated cryogenic double-p silicon detector. Nucl. Instrum. Methods Phys. Res., v. 462, p. 474-483, 2001. Section A.

[12] LI, Z.; LI, C. J.; VERBITSKAYA, E. Study of bulk damage in high resistivity silicon detectors irradiated by high dose of ${ }^{60}$ Co $\gamma$-radiation. IEEE Trans. Nucl. Sci., v. 44, n. 3, p. 834-839, 1997.

[13] LINDSTRÖM, G.; MOLL, M.; FRETWURST, E. Radiation hardness of silicon detectors a challenge from high-energy physics. Nucl. Instrum. Methods Phys. Res., v. 426, p. 1-15, 1999. Section A.

[14] BOSISIO, L.; DITTONGO, S.; QUAI, E.; RACHEVSKAIA, I. Observation of substrate-type inversion in high-resistivity silicon structures irradiated with high-energy electrons. IEEE Trans. Nucl. Sci., v. 50, n. 1, p. 219-225, 2003.

[15] RUZIN, A.; CASSE, G.; GLASER, M.; ZANET, A.; LEMEILLEUR, F.; WATTS, F. Comparison of radiation damage in silicon induced by proton and neutron irradiation. IEEE Trans. Nucl. Sci., v. 46, n. 5, p. 1310-1313, 1999.

[16] LI, Z.; DEZILLIE, B.; BRUZZI, M.; CHEN, W.; EREMIN, V.; VERBITSKAYA, E.; WEILHAMMER, P. HTLT oxygenated silicon detectors: radiation hardness and longterm stability. Nucl. Instrum. Methods Phys. Res., v. 461, p. 126-132, 2001. Section A.

[17] RD50 Status Report 2002/2003: Radiation hard semiconductor devices for very high luminosity colliders. CERN-LHCC-2003-058/LHCC-RD-002.

Disponível em: <http://rd50.web.cern.ch/rd50/default.htm $>$.

Acesso em: 5 março 2009.

[18] FRETWURST, E.; LINDSTRÖM, G.; STAHL, J.; PINTILIE, I.; LI, Z.; KIERSTEAD, J.; VERBITSKAYA, E.; RÖDER, R. Bulk damage effects in standard and oxygen-enriched silicon detectors induced by ${ }^{60} \mathrm{Co}$-gamma radiation. Nucl. Instrum. Methods Phys. Res., v. 514, p. 1-8, 2003. Section A.

[19] LINDSTRÖM, G.; AHMED, M.; ALBERGO, S.; ALLPORT, P.; ANDERSON, D.; ANDRICEK, L.; ANGARANO, M.M.; AUGELLI, V.; BACCHETTA, N.; BARTALINI, P.; BATES, R.; BIGGERI, U.; BILEI, G.M.; BISELLO, D.; BOEMI, D.; BORCHI, E.; BOTILA, T.; BRODBECK, 
T.J.; BRUZZI, M.; BUDZYNSKI, T.; BURGER, P.; CAMPABADAL, F.; CASSE, G.; CATACCHINI, E.; CHILINGAROV, A.; CIAMPOLINI, P.; CINDRO, V.; COSTA, M. J.; CREANZA, D.; CLAUWS, P.; VIA, C. Da; DAVIES, G.; BOER, W. De; DELLI'ORSO, R. ; PALMA, M. De; DEZILLIE, B.; EREMIN, V.; EVRARD, O.; FALLICA, G.; FANOURAKIS, G.; FEICK, H.; FOCARDI, E.; FONSECA, L.; FRETWURST, E.; FUSTER, J.; GABATHULER, K.; GLASER, M.; GRABIEC, P.; GRIGORIEV, E.; HALL, G.; HANLON, M.; HAULER, F.; HEISING, S.; HOLMES-SIEDLE, A.; HORISBERGER, R.; HUGHES, G.; HUHTINEN, M.; ILYASHENKO, I.; IVANOV, A.; JONES, B. K.; JUNGERMANN, L.; KAMINSKY, A.; KOHOUT, Z.; KRAMBERGER, G.; KUHNKE, M.; KWAN, S.; LEMEILLEUR, F.; LEROY, C.; LETHEREN, M.; LI, Z.; LIGONZO, T.; LINHART, V.; LITOVCHENKO, P.; LOUKAS, D.; LOZANO, M.; LUCZYNSKI, Z.; LUTZ, G.; MACEVOY, B.; MANOLOPOULOS, S.; MARKOU, A.; MARTINEZ, C.; MESSINEO, A.; MIKU, M.; MOLL, M.; NOSSARZEWSKA, E.; OTTAVIANI, G.; OSHEA, V.; PARRINI, G.; PASSERI, D.; PETRE, D.; PICKFORD, A.; PINTILIE, I.; PINTILIE, L.; POSPISIL, S.; POTENZA, R.; RADICCI, V.; RAINE, C.; RAFI, J. M.; RATOFF, P. N.; RICHTER, R. H.; RIEDLER, P.; ROE, S.; ROY, P.; RUZIN, A.; RYAZANOV, A. I.; SANTOCCHIA, A.; SCHIAVULLI, L.; SICHO, P.; SIOTIS, I.; SLOAN, T.; SLYSZ, W.; SMITH, K.; SOLANKY, M.; SOPKO, B.; STOLZE, K.; Avset, B. S.; SVENSSON, B.; TIVARUS, C.; TONELLI, G.; TRICOMI, A.; TZAMARIAS, S.; VALVO, G.; VASILESCU, A.; VAYAKI, A.; VERBITSKAYA, E.; VERDINI, P.; VRBA, V.; WATTS, S.; WEBER, E. R.; WEGRZECKI, M.; WEGRZECKA, I.; WEILHAMMER, P.; WHEADON, R.; WILBURN, C.; WILHELM, I.; WUNSTORF, R.; WUSTENFELD, J.; WYSS, J.; ZANKEL, K.; ZABIEROWSKI, P.; ZONTAR, D. Developments for radiation hard silicon detectors by defect engineering-results by the CERN RD48 (ROSE) Collaboration. Nucl. Instrum. Methods Phys. Res., v. 465, p. 60-69, 2001. Section A.

[20] LINDSTRÖM, G.; AHMED, M.; ALBERGO, S.; ALLPORT, P.; ANDERSON, D.; ANDRICEK, L.; ANGARANO, M. M.; AUGELLI, V.; BACCHETTA, N.; BARTALINI, P.; BATES, R.; BIGGERI, U.; BILEI, G. M.; BISELLO, D.; BOEMI, D.; BORCHI, E.; BOTILA, T.; BRODBECK, T. J.; BRUZZI, M.; BUDZYNSKI, T.; BURGER, P.; CAMPABADAL, F.; CASSE, G.; CATACCHINI, E.; CHILINGAROV, A.; CIAMPOLINI, P.; CINDRO, V.; COSTA, M. J.; CREANZA, D.; CLAUWS, P.; VIA, C. Da; DAVIES, G.; BOER, W. De; DELLI'ORSO, R.; PALMA, M. De ; DEZILLIE, B.; EREMIN, V.; EVRARD, O.; FALLICA, G.; FANOURAKIS, G.; FEICK, H.; FOCARDI, E.; FONSECA, L.; FRETWURST, E.; FUSTER, J.; GABATHULER, K.; GLASER, M.; GRABIEC, P.; GRIGORIEV, E.; HALL, G.; HANLON, M.; HAULER, F.; HEISING, S.; HOLMES-SIEDLE, A.; HORISBERGER, R.; HUGHES, G.; HUHTINEN, M.; ILYASHENKO, I.; IVANOV, A.; JONES, B. K.; JUNGERMANN, L.; KAMINSKY, A.; KOHOUT, Z.; KRAMBERGER, G.; KUHNKE, M.; KWAN, S.; LEMEILLEUR, F.; LEROY, C.; LETHEREN, M.; LI, Z.; LIGONZO, T.; LINHART, V.; LITOVCHENKO, P.; LOUKAS, D.; LOZANO, M.; LUCZYNSKI, Z.; LUTZ, G.; MACEVOY, B.; MANOLOPOULOS, S.; MARKOU, A.; MARTINEZ, C.; MESSINEO, A.; MIKUŽ, M.; MOLL, M.; NOSSARZEWSKA, E.; OTTAVIANI, G.; OSHEA, V.; PARRINI, G.; PASSERI, D.; PETRE, D.; PICKFORD, A.; PINTILIE, I.; PINTILIE, L.; POSPISIL, S.; POTENZA, R.; RAINE, C.; RAFI, J. M.; RATOFF, P. N.; RICHTER, R. H.; RIEDLER, P.; ROE, S.; ROY, P.; RUZIN, A.; RYAZANOV, A. I.; SANTOCCHIA, A.; SCHIAVULLI, L.; SICHO, P.; SIOTIS, I.; SLOAN, T.; SLYSZ, W.; SMITH, K.; SOLANKY, M.; SOPKO, B.; STOLZE, K.; SUNDBY-AVSET, B.; SVENSSON, B.; TIVARUS, C.; TONELLI, G.; TRICOMI, A.; TZAMARIAS, S.; VALVO, G.; VASILESCU, A.; VAYAKI, A.; VERBITSKAYA, E.; VERDINI, P.; VRBA, V.; WATTS, S.; WEBER, E. R.; WEGRZECKI, M.;. WEGRZECKA, I.; WEILHAMMER, P.; WHEADON, R.; WILBURN, C.; 
WILHELM, I.; WUNSTORF, R.; WÜSTENFELD, J.; WYSS, J.; ZANKEL, K.; ZABIEROWSKI, P.; ŽONTAR, D. Radiation hard silicon detectors-developments by the RD48 (ROSE) Collaboration. Nucl. Instrum. Methods Phys. Res., v. 466, p. 308-326, 2001. Section A.

[21] XIE, X. B.; CHO H. S.; LIANG, G. W.; HUANG, W.; LI, Z.; CHIEN, C. Y. Electrical characterization of a radiation-hardened silicon pixel design for CMS. Nucl. Instrum. Methods Phys. Res., v. 476, p. 665-669, 2002. Section A.

[22] EGOROV, B.; EREMIN, V.; GOLUBKOV, S.; KONKOV, K.; KOZLOV, Y.; LI, Z.; SIDOROV, A. Operation of guard rings on the ohmic side of $\mathrm{n}^{+}-\mathrm{p}-\mathrm{p}^{+}$diodes. Nucl. Instrum. Methods Phys. Res., v. 426, p. 197-205, 1999. Section A.

[23] VERBITSKAYA, E.; Abreu, M.; Anbinderis, P.; Anbinderis, T.; D'AMBROSIO, N.; Boer, W. de; BORCHI, E.; BORER, K.; BRUZZI, M.; BUONTEMPO, S.; CASAGRANDE, L.; CHEN, W.; CINDRO, V.; DEZILLIE, B.; DIERLAMM, A.; EREMIN, V.; GAUBAS, E.; GORBATENKO, V.; GRANATA, V.; GRIGORIEV, V.; GROHMANN, S.; HAULER, F.; HEIJNE, E.; HEISING, S.; HEMPEL, O.; HERZOG, R.; HÄRKÖNEN, J.; ILYASHENKO, I.; JANOS, S.; JUNGERMANN, L.; KALESINSKAS, V.; KAPTURAUSKAS, J.; LAIHO, R.; LI, Z.; MANDIC, I.; MASI, R. De; MENICHELLI, D.; MIKUZ, M.; MILITARU, O.; NIINIKOSKI, T. O.; O'SHEA, V.; PAGANO, S.; PALMIERI, V. G.; PAUL, S.; SOLANO, B. P.; PIOTRZKOWISKY, K.; PIROLLO, S.; PRETZEL, K.; MENDES, P. R.; RUGGIERO, G., SMITH, K.; SONDEREGGER, P.; SOUSA, P.; TUOMINEN, E.; VAITKUS, J.; VIÁ, C. Da; WOBST, E.; ZAVRTANIK, M. The effect of charge collection recovery in silicon $p-n$ junction detectors irradiated by different particles. Nucl. Instrum. Methods Phys. Res., v. 514, p. 47-61, 2003. Section A.

[24] HÄRKÖNEN, J.; ABREU, M.; ANBINDERIS, P.; ANBINDERIS, T.; D'AMBROSIO, N.; Boer, W. de; BORCHI, E.; BORER, K.; BRUZZI, M.; BUONTEMPO, S.; CHEN, W.; CINDRO, V.; DEZILLIE, B.; DIERLAMM, A.; EREMIN, V.; GAUBAS, E.; GORBATENKO, V.; GRANATA, V.; GRIGORIEV, V.; GROHMANN, S.; HAULER, F.; HEIJNE, E.; HEISING, S.; HEMPEL, O.; HERZOG, R.; ILYASHENKO, I.; JANOS, S.; JUNGERMANN, L.; KALESINSKAS, V.; KAPTURAUSKAS, J.; LAIHO, L.; LI, Z.; LUUKKA, P.; MANDIC, I.; MASI, R. De.; MENICHELLI, D.; MIKUZ, M.; MILITARU, O.; NIINIKOSKI, T. O.; NUESSLE, G.; O'SHEA, V.; PAGANO, S.; PAUL, S.; SOLANO, B. P.; PIOTRZKOWSKI, K.; PIROLLO, S.; PRETZL, K.; RAHMAN, M.; MENDES, P. R.; ROUBY, X.; RUGGIERO, G.; SMITH, K.; SOUSA, P.; TUOMINEN, E.; TUOVINEN, E.; VAITKUS, J.; VERBITSKAYA, E.; VIÁ, C. Da.; VLASENKO, L.; VLASENKO, M.; WOBST, E.; ZAVRTANIK, M. Recent results from the CERN RD39 Collaboration on super-radiation hard-cryogenic silicon detectors for LHC and LHC upgrade. Nucl. Instrum. Methods Phys. Res., v. 535, p. 384-388, 2004. Section A.

[25] BUENO, C. C.; GONÇALVES, J. A. C.; SANTOS, M. D. S. The performance of low-cost commercial photodiodes for charged particle and X-ray spectrometry. Nucl. Instrum. Methods Phys. Res., v. 371, p. 460-464, 1996. Section A.

[26] MAGALHÃES, R. R. de. Espectrometria de raios-X com diodos de Si. Dissertação (Mestrado), São Paulo: Instituto de Pesquisas Energéticas e Nucleares, 2000.

[27] Bueno, C. C.; GONÇAlVES, J. A. C.; MAgAlHÃES, R. R. de; SANTOS, M. D. S. Response of PIN diode as room temperature photon detectors. Appl. Radiat. Isot., v. 61, p. $1343-1347,2004$. 
[28] BUENO, C. C.; CORRÊA, A. A. S.; CAMARgo, F.; GONÇALVES, J. A. C.; MENDES, P. F. P. R. Response of a rad-hard silicon diode for charged particles. Instrum. Methods Phys. Res., v. 533, p. 435-441, 2004. Section A.

[29] CAMARgO, F.; BUENO, C. C.; GONÇALVES, J. A. C.; RATO-MENDES, P. F. P.; PINTO, J. K. C.; SOUZA, J. P. de; SANTOS, M. D. S. On the origin of the satellite peaks in alpha particle spectra. Braz. J. Phys., v. 34, n. 3A, p. 936-938, 2004.

[30] CORRÊA, A. A. S.; BUENO, C. C.; GONÇALVES, J. A. C.; RATO-MENDES, P. F. P.; PINTO, J. K. C.; SOUZA, J. P. de; SANTOS, M. D. S. Manufactured silicon diode used as an internal conversion electrons detector. Braz. J. Phys., v. 34, n. 3A, p. 973-975, 2004.

[31] CAMARGO, F. Fatores que influenciam a resolução em energia na espectrometria de partículas alfa com diodos de Si. Dissertação (Mestrado), São Paulo - Instituto de Pesquisas Energéticas e Nucleares, 2005.

[32] GONÇAlVES, J. A. C.; CAMARgO, F.; FRAGA, M. M. R.; PINTO, J. K. C.; BUENO, C. C. Rad-hard silicon diode response for photon spectrometry. IEEE Trans. Nucl. Sci., v. 54, n. 1, p. 276-279, 2007.

[33] SLAPA, M.; TRACZYK, M. A New concept of dosimeter with silicon photodiodes. IEEE Trans. Nucl. Sci., v. 43, n. 3, p. 1855-1859, 1996.

[34] MALI, T.; CINDRO, V.; MIKUŽ, M. Silicon microstrip detectors for digital mammography-evaluation and spatial resolution study. Instrum. Methods Phys. Res., v. 460, p. 76-80, 2001. Section A.

[35] PAVEL, N. A. Particle detectors for biomedical applications-demands and trends. Instrum. Methods Phys. Res., v. A 478, p. 1-12, 2002. Section A.

[36] JAKSIC, A.; RISTIC, G.; PEJOVIC, M.; MOHAMMADZADEH, A.; SUDRE, C.; LANE, W. Gamma-ray irradiation and post-irradiation responses of high dose range RADFETs. IEEE Trans. Nucl. Sci., v. 49, n. 3, p. 1356-1363, 2002.

[37] CAMANZI, B.; CRAWLEY, H. B.; HOLMES-SIEDLE, A.; MCKAY, R. L.; MCKEMEY, A.; MEYER, W. T.; ROSENBERG, E. I.; STELZER, J.; TINSLAY, J. The babar radFET monitoring board. IEEE Trans. Nucl. Sci., v. 49, n. 3, p. 1275-1280, 2002.

[38] BUTSON, M. J.; CHEUNG, T.; YU, P. K. N. Peripheral dose measurement with a MOSFET detector. Appl. Radiat. Isot., v. 62, p. 631-634, 2005.

[39] BAINBRIDGE, N.; MASON, J. A.; PEERLESS, S. J. Measurements and model predictions for improved microcalorimeter design. In: Reactor Dosimetry: Methods, Applications and Standardization. ASTM STP 1001, p. 742-750. FARRAR, H.; LINPINCOTT, E. H., Eds. American Society for Testing and Materials. Philadelphia, 1989.

[40] NIEUWENHOVE, R. V.; VERMEEREN, L. Online gamma dose-rate measurements by means of self-powered gamma detector. IEEE Trans. Nucl. Sci., v. 49, n. 4, p. 19141918, 2002.

[41] INTERNATIONAL COMMISSION ON RADIATION UNITS AND MEASUREMENTS. Radiation dosimetry: $X$ rays and gamma rays with maximum photon energies between 0.6 and 50 MeV. Report 14, Washington, D.C, 1969. 
[42] CALVO, W. A. P. Desenvolvimento do sistema de irradiação em um irradiador multipropósito de cobalto-60 tipo compacto. Tese (Doutorado), São Paulo Instituto de Pesquisas Energéticas e Nucleares, 2005.

[43] INTERnAtional ATOMIC ENERgy AgENCY. Technical Report Series $n^{\circ}$ 205. HighDose Measurements in Industrial Radiation Processing. STI/DOC/10/205, Viena, 1981.

[44] INTERNATIONAL ATOMIC ENERGY AGENCY. Gamma irradiators for radiation processing. IAEA Brochure. Viena, jul. 2005.

Disponível em: <http://www-naweb.iaea.org/napc/iachem/Brochgammairradd.pdf> Acessado em: 10 março 2009.

[45] MCLAUGHLIN, W. L.; BOYD, A. W.; CHADWICK, K. H.; MCDONALD, J.C.; MILLER, A. Dosimetry for Radiation Processing. London, UK: Taylor \& Francis Ltd, 1989.

[46] INTERNATIONAL COMMISSION ON RADIATION UNITS AND MEASUREMENTS. Report 80. Dosimetry Systems for Use in Radiation Processing. Journal of the ICRU, v. 8, n. 2, 2008.

[47] GALANTE, A. M. S. Pesquisa, desenvolvimento e caracterização de materiais dosimétricos para monitoramento em processos de irradiação com doses altas. Tese (Doutorado), São Paulo - Instituto de Pesquisas Energéticas e Nucleares, 2003.

[48] INTERNATIONAL ATOMIC ENERGY AGENCY. The IAEA/WHO SSDL Network.

Disponível em: <http://www-naweb.iaea.org/nahu/dmrp/ssdl.asp>

Acessado em: 24 março 2009.

[49] EISENLOHR, H. H. Network of Secondary Standard Dosimetry Laboratories. IAEA Bulletin, v. 19, n. 2, p. 1-6, Viena, 1977.

[50] NATIONAL PHYSICAL LABORATORY (NPL).

Disponível em: <http://www.npl.co.uk>.

Acesso em: 24 março 2009.

[51] National Institute of Standards and Technology (NIST).

Disponível em: <http://www.nist.gov/index.html>.

Acessado em: 25 março 2009.

[52] TAUHATA, L.; SALATI, I. P. A.; DI PRINZIO, R.; DI PRINZIO, A. R. Radioproteção e Dosimetria: Fundamentos. 5a rev. Rio de Janeiro: IRD/CNEN, 2003.

[53] ATTIX, F. H. Introduction to Radiological Physics and Radiation Dosimetry. 1a ed. New York: John Wiley \& Sons, Inc., 1986.

[54] EVANS, R. D. The Atomic Nucleus. Malabar, Florida: Robert E. Krieger Publishing Company, Inc., Reprint Edition, 1985.

[55] BERGER, M. J.; HUBBELL, J. H.; SELTZER, S. M.; CHANG J.; COURSEY, J. S.; SUKUMAR, R.; ZUCKER, D. S. XCOM: Photon Cross Sections Database. NIST Standard Reference Database 8 (XGAM). Last Update: February 2009 
Disponível em: < http://physics.nist.gov/PhysRefData/Xcom/Text/XCOM.html>. Acesso em: 2 abril 2009.

[56] GALANTE, A. M. S.; CAMPOS, L. L. The radiation effect of ${ }^{60}$ Co gamma rays on polycarbonate detector. Radiat. Phys. Chem., v. 71, p. 391-394, 2004.

[57] MCLAUGHLIN, W. L.; DESROSIERS, M. F. Dosimetry systems for radiation processing. Radiat. Phys. Chem., v. 46, n. 4-6, p. 1163-1174, 1995.

[58] PESEK, M. Rapid determination of optimal irradiation conditions on large radionuclide sources. In: Proceedings of an International Symposium on High-Dose Dosimetry Organized by the International Atomic Energy Agency and Held in Vienna, 8-12 October 1984, p. 263-275. Proceedings... Viena: IAEA, 1984.

[59] RAGEH, M. S. I.; EL-BEHAY, A. Z.; SOLIMAN, F. A. S. Application of commercial silicon diodes for dose rate measurements. In: Proceedings of an International Symposium on High-Dose Dosimetry Organized by the International Atomic Energy Agency and Held in Vienna, 8-12 October 1984, p. 263-275. Proceedings... Viena: IAEA, 1984.

[60] SUEVA, D.; GEORGIEV, S.; CHIKOV, N.; SPASSOV, V. Measurement of strong gamma fields by silicon detectors working in a current-generation mode. Nucl. Instrum. Methods Phys. Res., v. 588, p. 375-379, 2008. Section A.

[61] LINDSTRÖM, G. Radiation damage in silicon detectors. Nucl. Instrum. Methods Phys. Res., v. 512, p. 30-43, 2003. Section A.

[62] RD39 Status Report 2008. CERN-LHCC-2008-019/LHCC-SR-001.

Disponível em: <http://cdsweb.cern.ch/record/1140477>.

Acessado em: 04 de maio de 2009.

[63] CASSE, G. Prediction of the performances of finely segmented Si detector for tracking applications in future super-colliders after severe radiation damage. Nucl. Instrum. Methods Phys. Res., v. 566, p. 26-34, 2006. Section A.

[64] DIXON, R. L.; EKSTRAND, K. E. Silicon Diode Dosimetry. Appl. Radiat. Isot., v. 33, p. 1171-1176, 1982.

[65] BARTHE, J. Eletronic Dosimeters based on Solid State Detectors. Nucl. Instrum. Methods Phys. Res., v. 184, p. 158-189, 2001. Section B.

[66] CATTANEO, P. W. Calibration procedure for irradiation tests on silicon devices. IEEE Trans. Nucl. Sci., v. 38, n. 3, p. 894-900, 1991.

[67] SCHARF, K.; SPARROW, J. H. Steady-State Response of Silicon Radiation Detectors of Diffused $p$-n Junctuion Type to X Rays. I: Photovoltaic Mode of Operation. Journal of Research of the National Bureau of Standards. Journal of Research of the National Bureau of Standards-A. Physics and Chemistry, v. 68A, n. 6, p. 683-701, 1964.

[68] DIXON, R. L.; EKSTRAND, K. E. Linear accelerator calibration monitor with a memory. Med. Phys., v. 6, n. 5, p. 436-440, 1979.

[69] LUTZ, G. Semiconductor Radiation Detector. $1^{\underline{a}}$ ed. New York: Springer-Verlag, 1999. 
[70] SPIELER, H. Semiconductor Detector Systems. New York: Oxford University Press, Inc., 2006.

[71] KRANER, H. W. Radiation damage in semiconductor detectors. IEEE Trans. Nucl. Sci., v. 29, n. 3, p. 1088-1100, 1982.

[72] BURKE, E.A. Energy dependence of proton-induced displacement damage in silicon. IEEE Trans. Nucl. Sci., v. NS-33, n. 6, p. 1276-1281, 1986.

[73] VASILESC, A.; LINDSTRÖM, G. Displacement damage in silicon, on-line compilation. Disponível em: <http://sesam.desy.de/members/gunnar/Si-dfuncs.html>. Acesso em: 30 maio 2009.

[74] GRIFFIN, P. J. et al. SNLRML Recommended dosimetry cross section compendium, Report SAND92-0094. Sandia National Laboratories, Albuquerque, NM, 1993.

[75] KONOBEYEV, A. Y.; KOROVIN, Y. A.; SOSNIN, V. N. Neutron displacement crosssection for structural materials below $800 \mathrm{MeV}$. J. Nucl. Mater., v. 186, n. 2, p. 117130, 1992.

[76] HUHTINEN, M.; AARNIO, P.A. Pion induced displacement damage in silicon devices. Nucl. Instrum. Methods Phys. Res., v. 335, p. 580-582, 1993. Section A.

[77] SUMMERS, G.P. et al. Damage correlations in semiconductors exposed to gamma, electron and proton radiations. IEEE Trans. Nucl. Sci., v. NS-40, p. 1372-1379, 1993.

[78] SROUR, J. R.; CHEN, S. C.; OTHMER, S.; HARTMANN, R. A. Radiation damage coefficients for silicon depletion regions. IEEE Trans. Nucl. Sci., v. 26, n. 6, p. 47844791, 1979.

[79] HUHTINEN, M. Simulation of non-ionising energy loss and defect formation in silicon. Nucl. Instrum. Methods Phys. Res., v. 491, p. 194-215, 2002. Section A.

[80] PINTILLIE, I. Radiation induced defects with strong impact on damage properties of silicon diodes. Palestra ministrada em: 23 abr. 2009. São Paulo: Instituto de Pesquisas Energéticas e Nucleares.

[81] PINTILIE, I.; FRETWURST, E.; LINDSTRÖM, G.; STAHL, J. Second-order generation of point defects in gamma-irradiated float-zone silicon, an explanation for "type inversion". Appl. Phys. Lett., v. 82, n. 13, p. 2169-2171, 2003.

[82] HÄRKÖNEN, J.; TUOMINEN, E.; TUOVINEN, E.; MEHTÄLÄ, P.; LASSILA-PERINI, K.; OVCHINNIKOV, V.; HEIKKILÄ, P.; YLI-KOSKI, M.; PALMU, L.; KALLIJÄRVI, S.; NIKKILÄ, H.; ANTTILA, O.; NIINIKOSKI, T.; EREMIN, E.; IVANOV, A.; VERBITSKAYA, E. Processing of microstrip detectors on Czochralski grown high resistivity silicon substrates. Nucl. Instrum. Methods Phys. Res., v. 514, p. 173-179, 2003. Section A.

[83] HÄRKÖNEN, J.; TUOVINEN, E.; LUUKKA, P.; NORDLUND, H. K.; TUOMINEN, E. Magnetic Czochralski silicon as detector material. Nucl. Instrum. Methods Phys. Res., v. 579, p. 648-652, 2007. Section A.

[84] LI, Z.; HÄRKÖNEN, J.; CHEN, W.; KIERSTEAD, J.; LUUKKA, P.; TUOMINEN, E.; TUOVINEN, E.; VERBITSKAYA, E.; EREMIN, V. Radiation Hardness of High Resistivity Magnetic Czochralski Silicon Detectors After Gamma, Neutron, and Proton Radiations. IEEE Trans. Nucl. Sci., v. 51, n. 4, p. 1901-1908, 2004. 
[85] EREMIN, V.; STROKAN, N.; VERBITSKAYA, E.; LI, Z. Development of transient current and charge techniques for the measurement of effective net concentration of ionized charges $\left(N_{\text {eff }}\right)$ in the space charge region of $p-n$ junction detectors. Nucl. Instrum. Methods Phys. Res., v. 372, p. 388-398, 1996. Section A.

[86] NASCIMENTO, J. S. Development of a semiconductor parameter analyser. Private Communication, 2007.

[87] Datasheet of Operational Amplifier OPA656U. Wideband, Unity-Gain Stable, FETInput operational amplifier. Texas Instrument - SBOS196G. Dec. 2001. Revised: Nov. 2008.

Disponível em: <http://www.ti.com/>.

Acessado em: 08 jun. 2009.

[88] CHILINGAROV, A. RD50 Technical Note RD50-2003-03. Recommendations towards a standardization of the macroscopic parameter measurements. Part I: IV and CV measurements in Si diodes. Lancaster University.

Disponível em: <http://rd50.web.cern.ch/rd50/default.htm>.

Acessado em: 09 jun. 2009.

[89] ASSOCIAÇÃO BRASILEIRA DE NORMAS TÉCNICAS e INSTITUTO NACIONAL DE METROLOGIA, NORMALIZAÇÃO E QUALIDADE INDUSTRIAL. Guia para a expressão da incerteza de medição. 3. ed. Brasileira. Rio de Janeiro: ABNT, INMETRO, 2003.

[90] BATES, A. G.; MOLL, M. A comparison between irradiated magnetic Czochralski and float zone silicon detectors using the transient current technique. Nucl. Instrum. Methods Phys. Res., v. 555, p. 113-124, 2005. Section A.

[91] LEO, W. R. Techniques for Nuclear and Particle Physics Experiments, A How-to Approach. 2.ed. Berlin: Springer-Verlag, 1994.

[92] LEMEILleUR, F.; GLASER, M.; HEIJNE, E. H. M.; JARRON, P.; SOAVE, C.; LEROY, C.; RIOUX, J.; TRIGGER, I. Neutron, Proton, and Gamma Irradiations of Silicon Detectors. IEEE Trans. Nucl. Sci., v. 41, n. 3, p. 425-431, 1994.

[93] LI, Z.; BRUZZI, M.; EREMIN, V.; HÄRKÖNEN, J.; KIERSTEAD, J.; LUUKKA, P.; MENICHELLI, D.; TUOMINEN, E.; TUOVINEN, E.; VERBITSKAYA, E. Gamma radiation induced space charge sign inversion and re-inversion in p-type MCZ Si detectors and in proton-irradiated n-type MCZ Si detectors. Nucl. Instrum. Methods Phys. Res., v. 552, p. 34-42, 2005. Section A.

[94] RD50 - Status Report 2006. CERN-LHCC-2007-005/LHCC-RD-013.

Disponível em: <http://rd50.web.cern.ch/rd50/default.htm $>$.

Acessado em: 10 jun. 2009. 